\title{
Análise e avaliação de técnicas de interação humano-computador para sistemas de recuperação de imagens por conteúdo baseadas em um estudo de caso
}

\author{
Ana Lúcia Filardi
}

Orientadora: Profa. Dra. Agma Juci Machado Traina

Dissertação apresentada ao Instituto de Ciências Matemáticas e de Computação - ICMC-USP, como parte dos requisitos para obtenção do título de Mestre em Ciências - Ciências de Computação e Matemática Computacional.

\section{"VERSÃO REVISADA APÓS A DEFESA"}

Data da Defesa:

$30 / 08 / 2007$

Visto do Orientador:

USP - São Carlos

Se te mbro/ 2007 

Aos meus pais com amor e carinho. 

"O valor das coisas não está no tempo que elas duram, mas na intensidade com que acontecem. Por isso existem momentos inesqueciveis, coisas inexplicáveis e pessoas incomparáveis".

Fernando Sabino 



\section{Agradecimentos}

À Prof ${ }^{a}$. Dr ${ }^{\mathrm{a}}$. Agma. Juci Machado Traina, pela orientação, confiança e incentivo na realização desta pesquisa.

Aos meus pais, meu irmão Arnaldo, minha irmã Isabel, ao Roberto e meus queridos sobrinhos Henrique e Filipe, pelo amor, carinho, apoio e compreensão em todos os momentos.

À Embrapa Monitoramento por Satélite, pela oportunidade e apoio proporcionado pelo programa de aperfeiçoamento de pós-graduação.

Ao Dr. Ivo Pierozzi Júnior, pelo estímulo e apoio como Conselheiro Acadêmico da Embrapa.

À Rosangela do Nascimento Pereira, pela amizade e acompanhamento das atividades atribuídas ao programa de pós-graduação.

Ao André Guilherme Ribeiro Balan, pelo desenvolvimento e concessão do sistema, contribuindo efetivamente para a realização deste trabalho.

À Luciana Alvim Santos Romani, pela amizade, força, sugestões e revisão deste trabalho.

Aos colegas do Grupo de Bases de Dados e Imagens (GBdI), especialmente ao Prof. Dr. Caetano Traina Junior, pelos valiosos ensinamentos, e a Marcela Xavier Ribeiro, Ives Renê Venturini Póla e Mônica Ribeiro Porto Ferreira, pela participação nesta pesquisa.

Ao Dr. Paulo Mazzoncini de Azevedo Marques e aos radiologistas do Centro de Ciências de Imagens e Física Médica do Hospital das Clínicas da USP de Ribeirão Preto, pela colaboração nos testes de avaliação.

Ao Renato Pena Jardim, por estar sempre ao meu lado, e a todos os amigos e colegas que estiveram presentes nessa caminhada.

À Empresa Brasileira de Pesquisa Agropecuária - Embrapa, pelo auxílio financeiro. 

FILARDI, A. L. Análise e avaliação de técnicas de interação humano-computador para sistemas de recuperação de imagens por conteúdo baseadas em um estudo de caso. São Carlos, 2007. 149f. Dissertação (Mestrado em Ciências de Computação e Matemática Computacional) - Instituto de Ciências Matemáticas e de Computação, Universidade de São Paulo.

A recuperação de imagens baseada em conteúdo, amplamente conhecida como CBIR (do inglês Content-Based Image Retrieval), é um ramo da área da computação que vem crescendo muito nos últimos anos e vem contribuindo com novos desafios. Sistemas que utilizam tais técnicas propiciam o armazenamento e manipulação de grandes volumes de dados e imagens e processam operações de consultas de imagens a partir de características visuais extraídas automaticamente por meio de métodos computacionais. Esses sistemas devem prover uma interface de usuário visando uma interação fácil, natural e atraente entre o usuário e o sistema, permitindo que o usuário possa realizar suas tarefas com segurança, de modo eficiente, eficaz e com satisfação. Desse modo, o design da interface firma-se como um elemento fundamental para o sucesso de sistemas CBIR. Contudo, dentro desse contexto, a interface do usuário ainda é um elemento constituído de pouca pesquisa e desenvolvimento. Um dos obstáculos para eficácia de design desses sistemas consiste da necessidade em prover aos usuários uma interface de alta qualidade para permitir que o usuário possa consultar imagens similares a uma dada imagem de referência e visualizar os resultados. Para atingir esse objetivo, este trabalho visa analisar a interação do usuário em sistemas de recuperação de imagens por conteúdo e avaliar sua funcionalidade e usabilidade, aplicando técnicas de interação humano-computador que apresentam bons resultados em relação à performance de sistemas com grande complexidade, baseado em um estudo de caso aplicado à medicina. 



\section{Abstract}

The content-based image retrieval (CBIR) is a challenging area of the computer science that has been growing in a very fast pace in the last years. CBIR systems employ techniques for extracting features from the images, composing the features vectores, and store them together with the images in data bases management system, allowing indexing and querying. CBIR systems deal with large volumes of images. Therefore, the feature vectors are extracted by automatic methods. These systems allow to query the images by content, processing similarity queries, which inherently demands user interaction. Consequently, CBIR systems must pay attention to the user interface, aiming at providing friendly, intuitive and attractive interaction, leading the user to do the tasks efficiently, getting the desired results, feeling safe and fulfilled. From the points highlighted beforehand, we can state that the human-computer interaction (HCI) is a key element of a CBIR system. However, there is still little research on HCI for CBIR systems. One of the requirements of HCI for CBIR is to provide a high quality interface to allow the user to search for similar images to a given query image, and to display the results properly, allowing further interaction. The present dissertation aims at analyzing the user interaction in CBIR systems specially suited to medical applications, evaluating their usability by applying HCI techniques. To do so, a case study was employed, and the results presented. 



\section{Sumário}

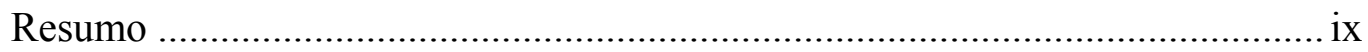

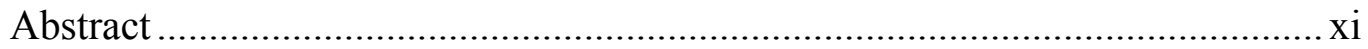

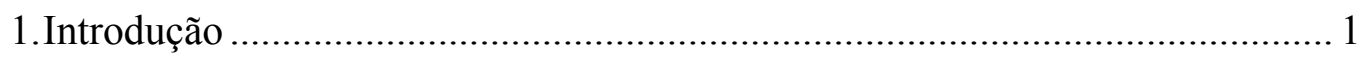

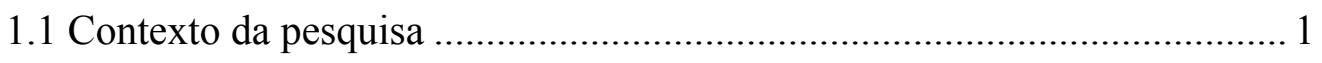

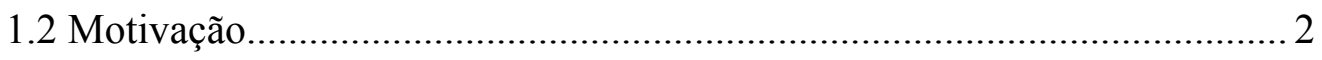

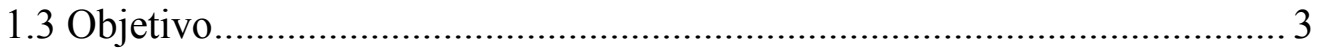

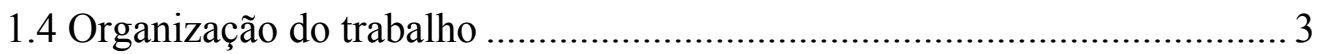

2.Recuperação de imagens baseada em conteúdo ................................................ 5

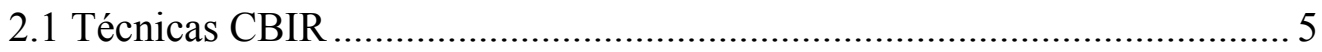

2.2 Caracterização das imagens ............................................................... 7

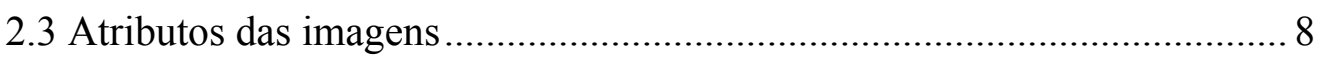

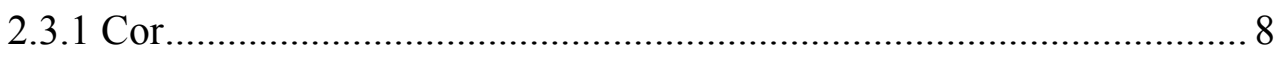

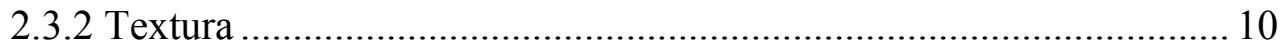

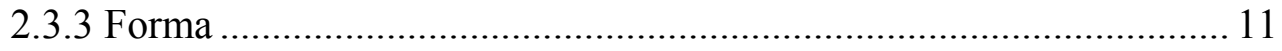

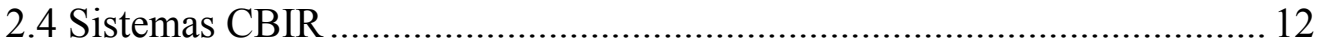

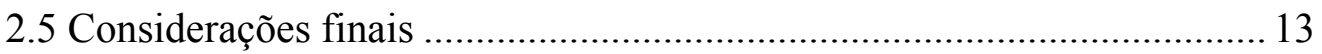

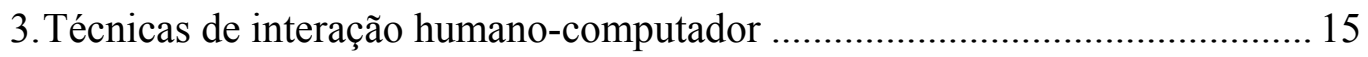

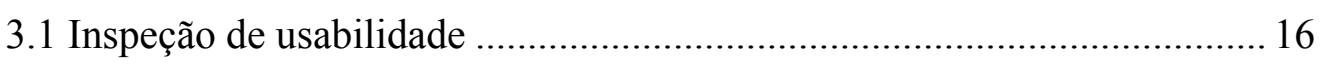

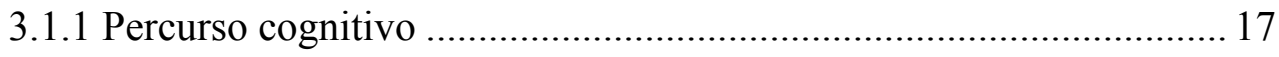

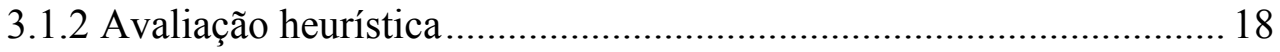

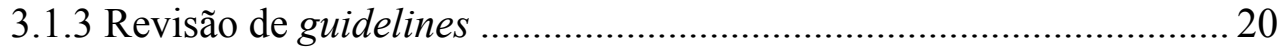

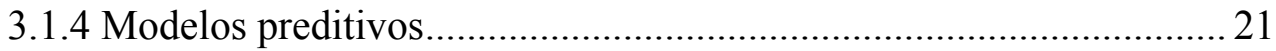

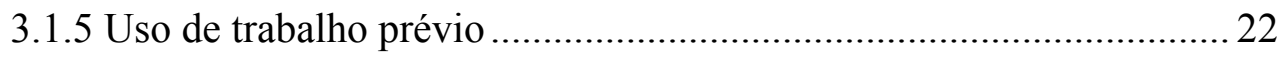

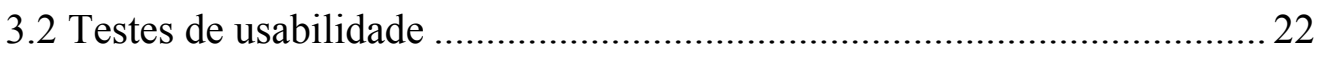

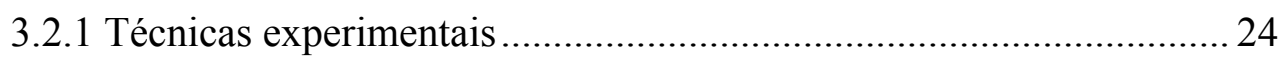

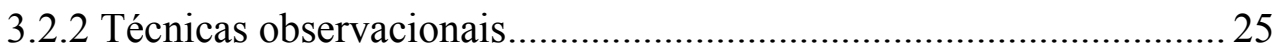

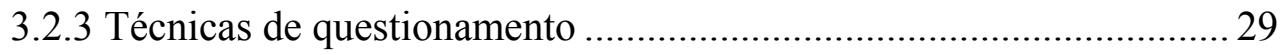

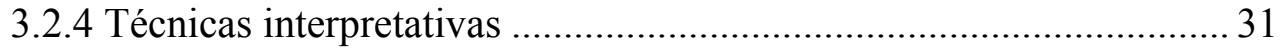

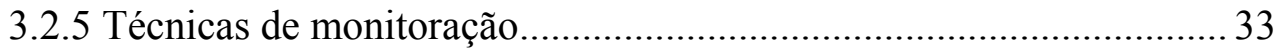

3.3 Comparação dos métodos ................................................................ 35

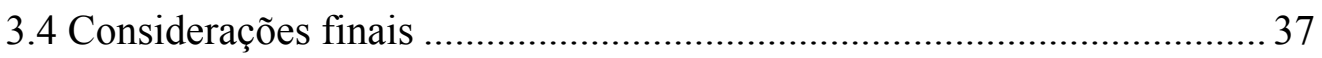




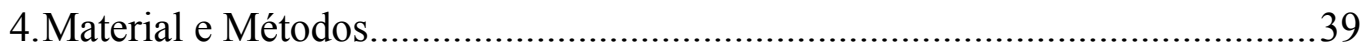

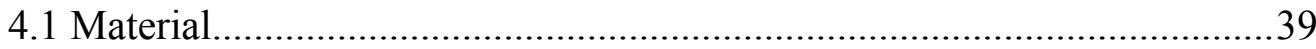

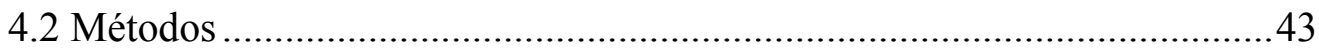

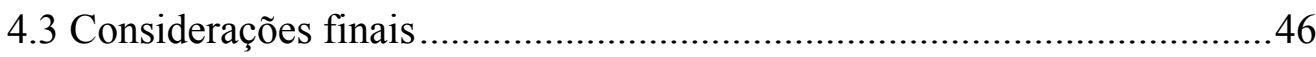

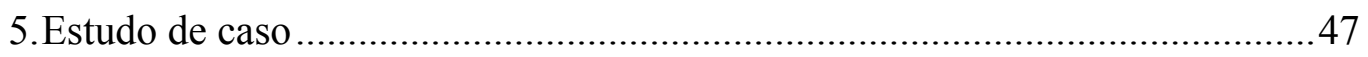

5.1 Sistema CBIR aplicado à medicina ............................................................4

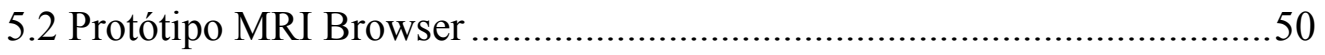

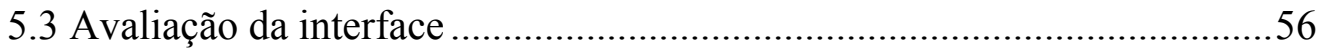

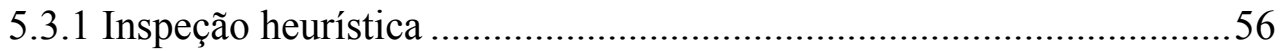

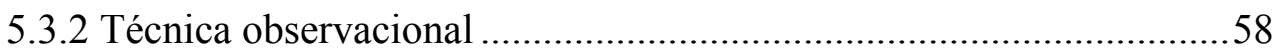

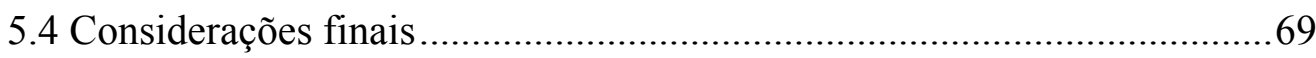

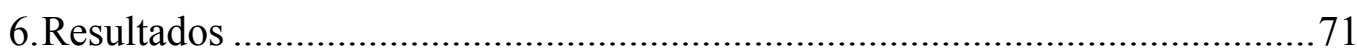

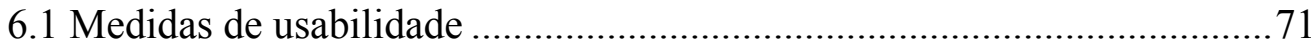

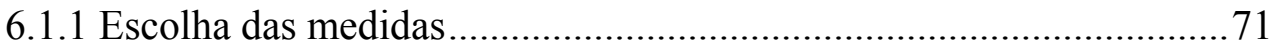

6.1.2 Critérios de medidas....................................................................... 73

6.2 Análise e interpretação dos dados .............................................................. 74

6.2.1 Observação dos usuários ................................................................... 74

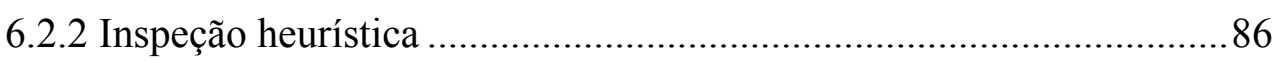

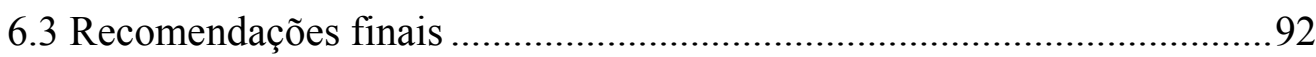

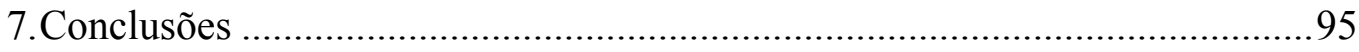

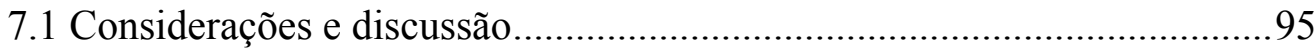

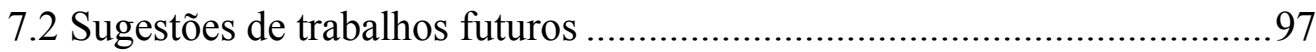

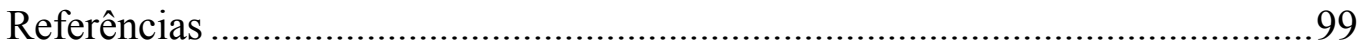

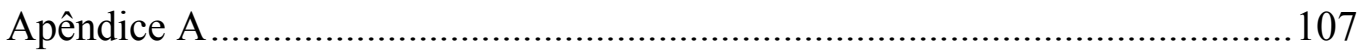

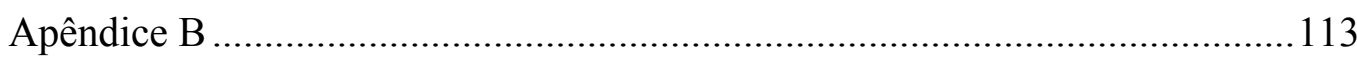

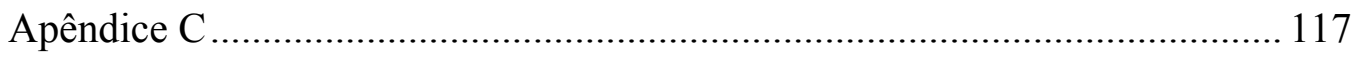

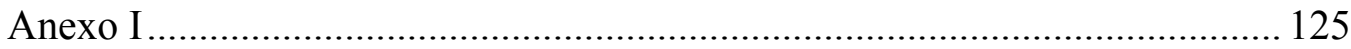




\section{Índice de Figuras}

Figura 2.1: Visão geral de um sistema CBIR.

Figura 2.2: Exemplo de uma imagem e seu histograma de cor associado [Bueno-2002a, p.43].

Figura 2.3: Mesmo histograma de cores em 2 níveis de cinza, associado a quatro imagens diferentes [Bueno-2002a, p.44]. 10

Figura 2.4: Exemplos de imagens de texturas [Castañón-2003a, p.11] 10

Figura 2.5: Exemplo de um contorno de peixe, adaptado de Alferez et al. (2005, p.148).

Figura 3.1: Técnicas de inspeção de usabilidade.

Figura 3.2: Testes de usabilidade

Figura 5.1: Exemplos de imagens de Ressonância Magnética (RM), adaptado de Castañon (2003a, p.55).

Figura 5.2: Resultado de uma consulta com as imagens mais similares [Castañón2003a, p.93].

Figura 5.3: Exemplo de subgrupos de imagens de diversas partes do corpo humano... 51

Figura 5.4: Janela de consulta Query by Text do sistema MRI Browser...................... 52

Figura 5.5: Interface do protótipo MRI Browser....................................................... 53

Figura 5.6: Resultado da consulta de exames de um paciente.................................... 53

Figura 5.7: Resultado da consulta por similaridade a partir de uma dada imagem de referência. 54

Figura 5.8: Resultado de busca por imagens relevantes........................................... 55

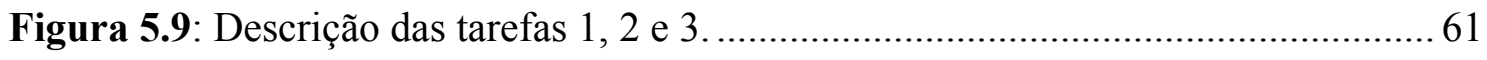

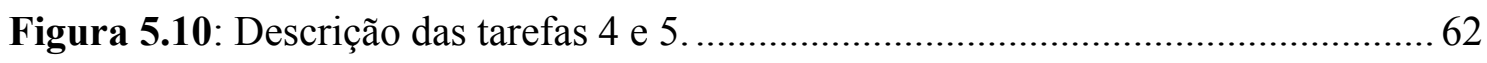

Figura 6.1: Participação dos usuários por área de especialidade médica. ...................... 75

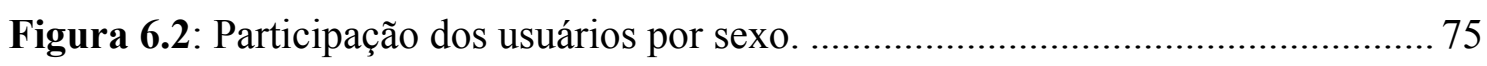

Figura 6.3: Participação dos usuários por faixa etária................................................ 76

Figura 6.4: Experiência dos participantes em informática. ........................................ 77

Figura 6.5: Participantes por níveis de experiência em informática............................ 77

Figura 6.6: Conhecimento dos participantes na língua inglesa. .................................. 78

Figura 6.7: Tempo de atuação profissional dos participantes...................................... 79 


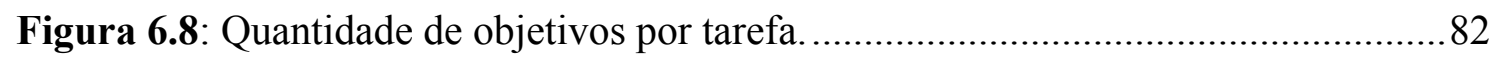

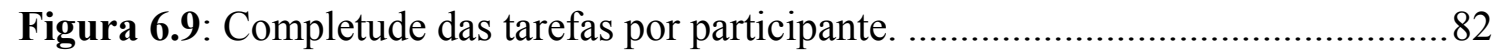

Figura 6.10: Resultado das medidas de satisfação do QUIS........................................... 84

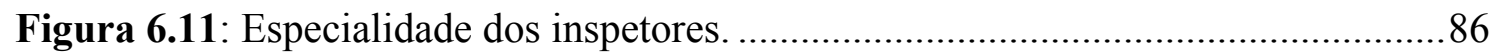

Figura 6.12: Quantidade de defeitos de usabilidade pelos graus de severidade. ...........88

Figura 6.13: Defeitos encontrados por grau de severidade........................................ 89

Figura 6.14: Defeitos encontrados por heurística. ....................................................... 91

Figura 6.15: Defeitos de usabilidade encontrados. .....................................................91

Figura 6.16: Quantidade de defeitos encontrados por cada inspetor. ............................92

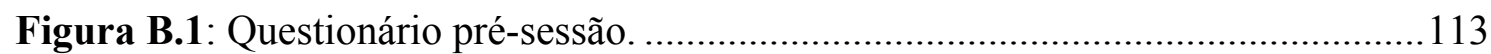

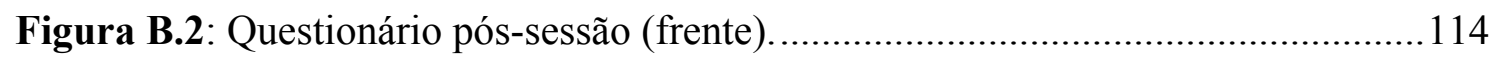

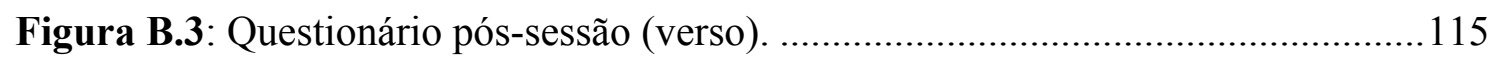

Figura I.1: Infraestrutura de um PACS em um ambiente hospitalar [Campo-2003, p.2]. 


\section{Índice de Tabelas}

Tabela 3.1: Comparação dos métodos de inspeção de usabilidade e testes de usabilidade.

Tabela 4.1: Requisitos da avaliação traduzidos para o contexto de uso.

Tabela 4.2: Categorização de algumas técnicas de avaliação, adaptado de Dix et al. (2004)......

Tabela 5.1: Graus de severidade. 57

Tabela 6.1: Medidas de usabilidade. 73

Tabela 6.2: Tempo de execução de tarefas por participante. 80

Tabela 6.3: Tempo de aprendizagem de uso do sistema. 81

Tabela 6.4: Quantidade de erros cometidos e o tempo gasto para corrigi-los. .83

Tabela 6.5: Quantidade de defeitos de usabilidade encontrados em cada heurística e distribuídos pelos graus de severidade. 87

Tabela 6.6: Recomendações para abordagens de design. 93 



\section{Introdução}

\subsection{Contexto da pesquisa}

A área da computação vem contribuindo e integrando diversas áreas da pesquisa científica, lançando novos desafios, aprimorando o desenvolvimento da ciência e impulsionando o seu próprio crescimento. A medicina é uma das áreas beneficiadas com o estudo e interação da ciência da computação, visando tornar o diagnóstico médico e a evolução dos tratamentos cada vez mais precisos e eficientes. Para dar suporte a diagnósticos, imagens de exames gerados por meio de equipamentos médicos (tomografia, mamografia, ultrassonografia, radiografia etc.) têm sido incorporadas nos Sistemas de Informações Hospitalares (SIH), para consolidar em um só sistema as informações dos pacientes.

$\mathrm{O}$ interesse em utilizar imagens nos diagnósticos vem aperfeiçoando o desenvolvimento de novas técnicas que se preocupam com a recuperação desses tipos de dados. Para recuperar tais dados, geralmente, as consultas são realizadas por meio de critérios de similaridades baseados nas características intrínsecas extraídas das imagens, ou seja, em seu conteúdo. Tratando-se de imagens, é virtualmente impossível obter duas imagens exatamente iguais, porém podem ser bastante semelhantes. Nesse sentido, as consultas por similaridade tornam-se muito interessantes, pois, ao analisar uma imagem, o usuário pode desejar recuperar as imagens mais semelhantes a ela com o objetivo de efetuar cruzamentos entre diagnósticos e tratamentos já realizados e auxiliar o profissional da área médica na elaboração de laudos e novos diagnósticos. Para isso, o sistema deve prover uma interface interativa e intuitiva para facilitar a recuperação e exibição desses dados.

Um dos desafios decorrentes desses sistemas é o processo de validação das imagens em relação à sua semelhança. Contudo, as técnicas adotadas ainda permanecem sob o senso de análise automática de recuperação de informações. Uma das possíveis 
razões para isso pode ser que muitos estudos têm focado, principalmente, sobre os processos de extração de características e consultas por similaridade, sem levar em consideração o usuário final e os fatores humanos que influenciam a indexação, navegação e recuperação da imagem.

Dentro desse contexto, o estudo envolvendo o usuário caracteriza-se pela sua interação com a interface do sistema, permitindo que o usuário possa consultar imagens similares a uma dada imagem de referência e visualizar os resultados.

Um dos obstáculos para realizar tais estudos é encontrar usuários reais, visto que os sistemas CBIR, de certo modo, ainda não são utilizados no domínio clínico como um instrumento efetivo de trabalho e, conseqüentemente, os usuários reais ainda não têm conhecimento de como essas técnicas podem beneficiar seus trabalhos cotidianos. Por outro lado, o processo de avaliação por meio da interação humano-computador também envolve encontrar bons avaliadores com experiência tanto em usabilidade, como também sobre o domínio em questão.

Apesar dos avanços no desenvolvimento de novas tecnologias para recuperação de imagens baseada em seu conteúdo e diante dessas dificuldades, constata-se uma certa ausência de referencial técnico para avaliar o uso desses sistemas por meio da interação humano-computador e esse é o principal desafio desse trabalho.

\subsection{Motivação}

O Grupo de Base de Dados e Imagens (GBdI) do Instituto de Ciências Matemáticas e de Computação (ICMC) da Universidade de São Paulo (USP), vem contribuindo em pesquisas e desenvolvimentos de algoritmos automáticos de extração de características e consultas por similaridade aplicados em sistemas que utilizam imagens médicas.

As técnicas utilizadas para efetuar as consultas por similaridade têm sido constantemente avaliadas em relação a performance da resposta provida pela recuperação de informações [Lecce-1999, Bueno-2002a, Zhang-2003, Zhou-2003] e aferidas por vários tipos de métricas, das quais destaca-se a avaliação quantitativa por meio de cálculos de precisão e revocação (precision and recall) [Baeza-Yates-1999].

O crescimento, aprimoramento e a excelência da pesquisa em técnicas CBIR, avaliados pela sua performance na recuperação de informações, contradizem-se com a ausência de procedimentos específicos de avaliação por meio da percepção visual do 
usuário. A interação humano-computador pode contribuir efetivamente para avaliar o desempenho de sistemas CBIR em relação à eficiência e eficácia, bem como a satisfação do usuário.

Além disso, a introdução de sistemas CBIR dentro do domínio clínico pode beneficiar o desenvolvimento de pesquisas com o envolvimento sempre presente do usuário final.

\subsection{Objetivo}

O objetivo principal deste trabalho é analisar e avaliar as técnicas de interação humano-computador para sistemas CBIR. Tal avaliação é baseada em um estudo de caso aplicado à medicina para auxiliar o médico no processo de diagnóstico. Esta iniciativa visa melhorar a interação humano-computador, facilitando o trabalho com grandes volumes de dados e imagens e viabilizando a recuperação de informações com eficiência e eficácia.

\subsection{Organização do trabalho}

O trabalho proposto está organizado em capítulos, da seguinte maneira:

- Neste primeiro capítulo é apresentada uma introdução geral sobre o contexto da pesquisa, bem como a motivação para o seu desenvolvimento e os objetivos a serem alcançados.

- Capítulo 2: introduz as técnicas de recuperação de imagens por conteúdo, abrangendo os conceitos e o estado da arte referentes aos sistemas CBIR, as características e atributos das imagens e, também, descreve alguns sistemas desenvolvidos para recuperar imagens similares através das suas características intrínsecas, utilizados em diferentes aplicações que se beneficiam dessa abordagem.

- Capítulo 3: descreve as principais técnicas de interação humano-computador utilizadas nos processos de avaliação de interfaces, salientando as técnicas de inspeção de usabilidade, baseadas no julgamento de especialistas e os testes de usabilidade, com a participação efetiva de usuários. 
- Capítulo 4: especifica o material necessário para o processo de avaliação e os métodos selecionados a partir da categorização dos fatores que mais se adaptam ao contexto de uso em questão.

- Capítulo 5: aborda um estudo de caso aplicado à medicina para auxiliar o processo de diagnóstico médico, descrevendo o domínio da aplicação, o protótipo utilizado no processo de avaliação e a condução da avaliação.

- Capítulo 6: apresenta os resultados do processo da avaliação, obtidos pela combinação das técnicas de inspeção heurística e observação de usuário.

- Capítulo 7: apresenta a conclusão final, as principais contribuições deste trabalho e as sugestões para futuros trabalhos.

- Apêndice A: apresenta a relação de alguns sistemas CBIR disponíveis on-line.

- Apêndice B: apresenta os questionários aplicados na avaliação.

- Apêndice C: incorpora as recomendações sugeridas para as mudanças no protótipo.

- Anexo I: descreve alguns sistemas de armazenamento e comunicação de imagens utilizados nas aplicações médicas. 


\section{Capítulo}

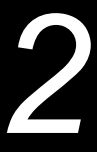

\section{Recuperação de imagens baseada em conteúdo}

\subsection{Técnicas CBIR}

As técnicas CBIR propiciam a recuperação de imagens baseada em seu conteúdo por meio de suas características visuais. Essas técnicas são bastante utilizadas nas áreas de processamento de imagens e base de dados.

Sistemas que utilizam as técnicas CBIR têm emergido nas últimas décadas devido à necessidade de manipular grandes volumes de dados e imagens armazenadas e ao interesse de recuperar informações visuais de maneira eficiente e precisa.

As principais ferramentas conceituais utilizadas nos sistemas CBIR são denominadas consultas por similaridade e são realizadas a partir do significado do conteúdo do objeto ao invés das informações descritivas associadas às imagens.

As consultas tradicionais sobre informações armazenadas em bases de dados são efetuadas utilizando-se chaves de busca que permitem recuperar o registro associado e encontram-se, normalmente, no formato numérico ou textual. Entretanto, nos sistemas de recuperação de imagens, a chave de busca utilizada é a própria imagem. O propósito desse processo nem sempre é buscar a imagem exata, o que poderia ser realizado por meio de uma comparação pixel a pixel, e sim, buscar a imagem mais parecida ou similar. A consulta por similaridade recupera objetos dentro de um certo grau de similaridade e um número fixo de objetos mais similares. A comparação de imagens por similaridade é essencial para tratar dados complexos e capturar o que há de mais representativo a fim de extrair informação que as represente de modo mais fiel.

Um sistema CBIR depende de três fases de procedimentos, que incluem: processamento de imagens, extração de vetores de características e indexação [Traina Jr.-2004]. 
A primeira fase de processamento de imagens tem como objetivo melhorar a qualidade da imagem. Consiste na execução de algoritmos e filtros para eliminar ruídos, restaurar e ressaltar a informação presente na imagem, a fim de unificar suas características para permitir uma comparação consistente entre as imagens no processo de recuperação.

A segunda fase extrai uma série de características que melhor representam a imagem, executando-se algoritmos denominados extratores de características, segundo um critério determinado que descreve aspectos particulares da imagem. Um ou mais extratores podem ser aplicados e por meio da concatenação dos resultados obtidos são construídos os vetores de características, que permitem identificar o conteúdo da imagem com mais precisão. O processo de extração de características mais comum é baseado nos algoritmos que analisam as características de baixo nível, constituídas pela cor, textura e forma das imagens.

A terceira e última fase utiliza as estruturas de indexação para organizar as características das imagens armazenadas, visando acelerar o processamento das consultas por similaridade realizadas diretamente na base de dados. Uma abordagem que vem sendo bastante usada é empregar estruturas métricas para indexar as características das imagens, pois tais estruturas são talhadas para responder consultas por similaridade [Chávez-2001].

Normalmente, os sistemas CBIR são configurados para conceber as três fases em uma única aplicação, principalmente, porque os algoritmos de processamento e recuperação de imagens propostos têm sempre que se ajustar a um contexto específico. Os algoritmos devem ser pré-definidos e adequados para executar uma operação sobre uma base de dados de imagens determinada e, uma vez configurados, todas as imagens relacionadas são processadas da mesma maneira. A uniformidade do processo de cada imagem é requerida para permitir a execução de operações de consultas que buscam imagens específicas nesse repositório dentro do seu contexto.

Esses aspectos estabelecem o conceito de domínio da imagem e são muito importantes para sistemas CBIR devido à influência direta da aplicação de algoritmos coerentes e precisos para cada imagem. Os algoritmos específicos validam automaticamente algumas características relevantes da imagem, fundamentando o domínio correto ao qual a imagem pertence.

Porém, o fator determinante que estabelece se as imagens são similares dentro do seu contexto é obtido por meio da percepção visual humana. O processo de validação 
das imagens em relação a sua semelhança é uma operação usualmente executada com a interação humana, sendo difícil fazê-lo de modo automático. Operações de validação asseguram que as imagens possuem as propriedades requeridas e podem ser processadas adequadamente por um extrator de características ou analisador de imagens determinado. A Figura 2.1 apresenta uma visão geral de um sistema CBIR.

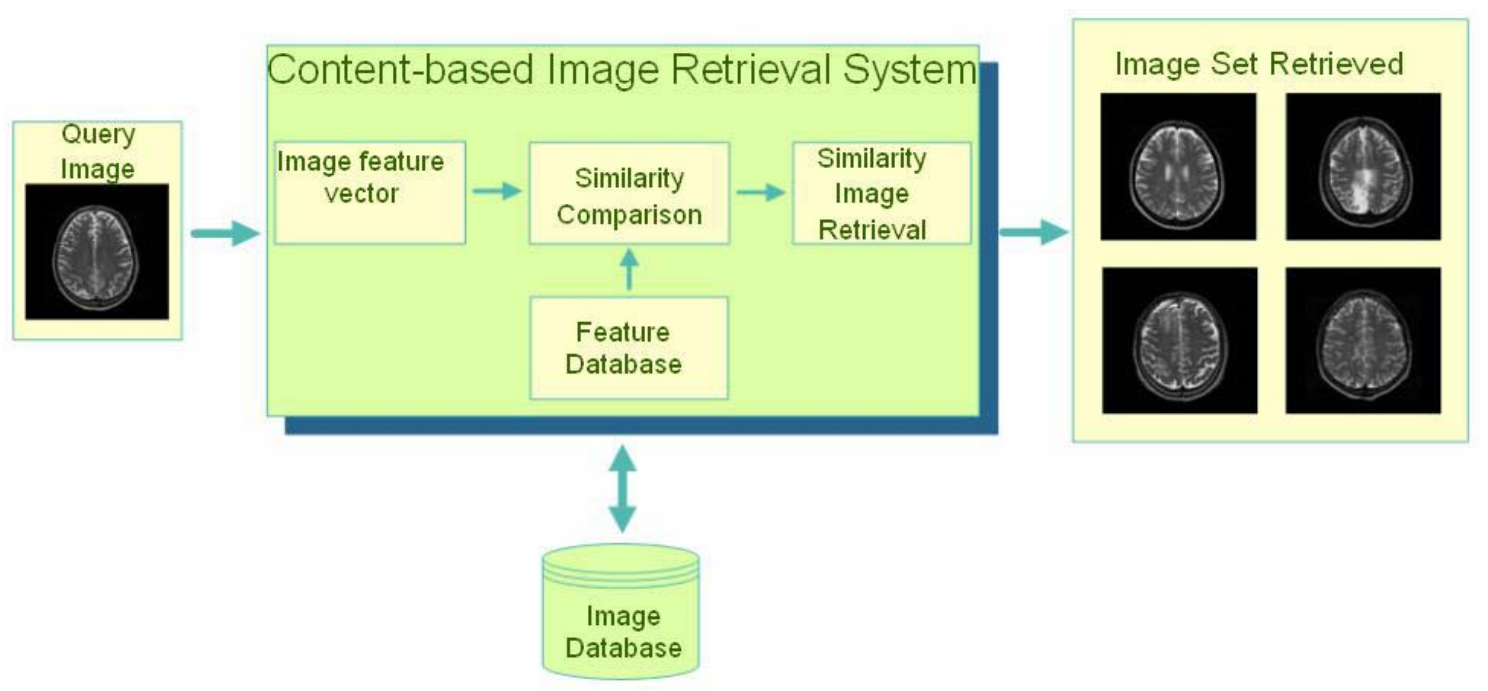

Figura 2.1: Visão geral de um sistema CBIR.

\subsection{Caracterização das imagens}

As imagens são consideradas como dados complexos, pois suas características são representadas por um número usualmente elevado de atributos. Para tratar esse tipo de dado é necessário extrair informações que melhor o represente. Esse processo, denominado extração de características, permite identificar as propriedades inerentes da imagem que serão utilizadas para recuperar imagens de maneira eficiente.

As características da imagem podem ser consideradas como globais e locais. Em um processo de busca por imagens similares são retornadas as imagens mais semelhantes globalmente, obtidas por meio de um descritor que codifica as informações globais da imagem. As técnicas de extração de características globais não se preocupam com detalhes de regiões individuais da imagem, podendo ocasionar o aparecimento de informações irrelevantes no resultado de uma consulta. Contudo, não é possível detectar quando duas imagens contêm objetos similares em locais diferentes, seja em segundo plano, em diferentes pontos de vista ou diferentes variações de iluminação. Por não conseguir capturar aspectos de semântica mais local da imagem, pode propiciar, assim, 
uma descontinuidade semântica. Para resolver esse problema, técnicas de processamento de imagens têm focado no reconhecimento de objetos, tipicamente para extrair informações locais contidas em pequenas regiões das imagens. Nas técnicas de extração de características locais, as imagens são segmentadas em regiões menores que podem ser utilizadas para identificar objetos com um alto nível semântico, podendo obter um reconhecimento robusto em relação à rotação e translação da imagem, variação de iluminação e oclusões parciais [Amsaleg-2004].

Algumas características da imagem podem ser detectadas automaticamente, porém sua precisão depende da complexidade da imagem. As características extraídas automaticamente da imagem são categorizadas como baixo nível (raw features) e são baseadas, principalmente, nos atributos de cor, textura e forma.

\subsection{Atributos das imagens}

A comparação de imagens efetuada em sistemas CBIR busca simular a percepção humana comparando as características visuais de cor, textura e forma [Kosara-2002].

Apesar da cor ser um atributo bastante utilizado e eficaz na recuperação de imagens, dependendo da aplicação e do domínio específico, essa característica pode não ser a mais adequada, sendo requerido, o uso dos atributos de textura e forma para a recuperação de imagens. Além disso, muitas vezes é necessário o uso de múltiplos atributos para alcançar uma resposta desejada [Mirmehdi-2002, Castañón-2003a, Castañón-2003b].

\subsubsection{Cor}

As cores presentes em uma imagem representam uma característica bastante significativa em relação à sua indexação e recuperação. $O$ atributo cor pode ser representado por diferentes modelos, que incluem desde o mais simples e mais utilizado, como o RGB (Red, Green, Blue), que mapeia diretamente as características físicas do dispositivo de exibição, até mesmo os modelos mais complexos e utilizados freqüentemente para indexação e consulta, como HSI (Hue, Saturation, Intensity), que reflete com mais precisão o modelo de cores em relação à percepção humana. Os modelos de cores visam padronizar a representação de cores por meio de um sistema de coordenadas tridimensionais constituídas de subespaços, onde cada cor é representada 
por um único ponto, denominado pixel. Cada pixel consiste de 24 bits no modelo RGB ( 8 bits para cada cor), que representa aproximadamente 16,7 milhões de cores diferentes. Contudo, muitas vezes, é preciso diminuir o número de cores para aumentar a eficiência no processamento e para isso é necessário re-quantizar as cores.

A distribuição de cores existente em cada pixel da imagem é, geralmente, representada por um histograma de cor, como mostra a Figura 2.2, que calcula o número de pixels correspondente a cada cor da imagem.

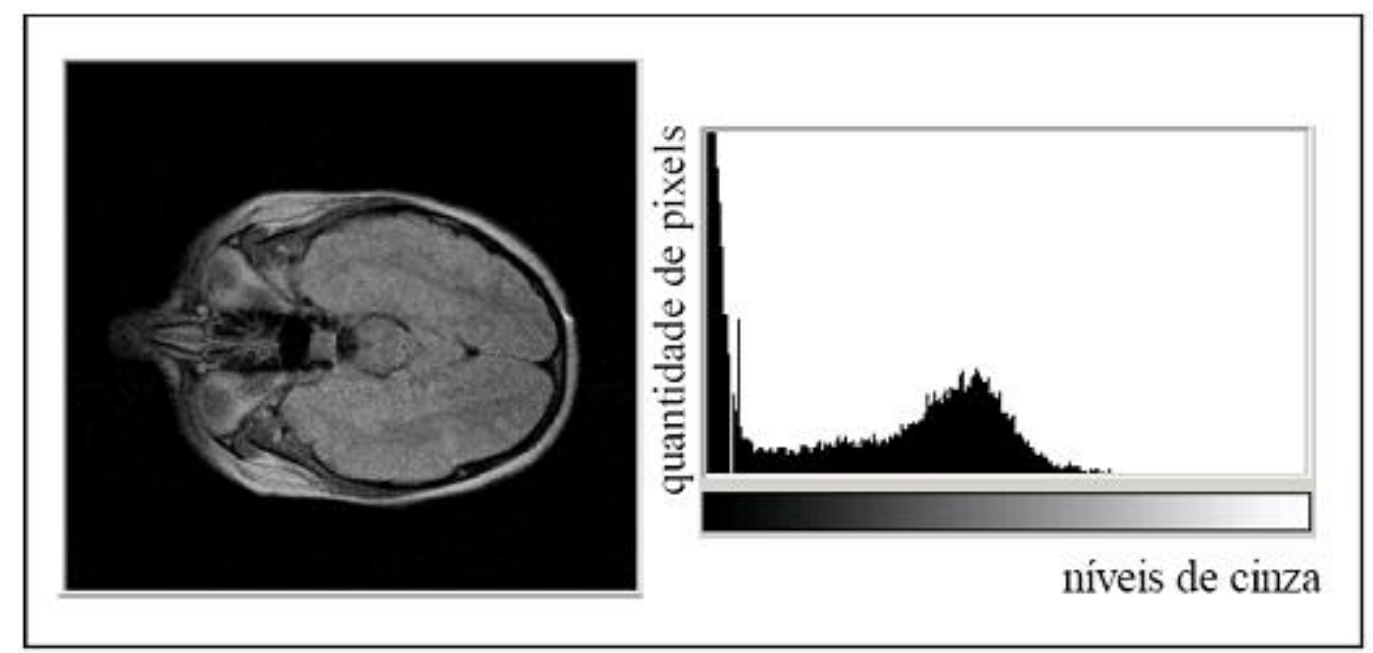

Figura 2.2: Exemplo de uma imagem e seu histograma de cor associado [Bueno-2002a, p.43].

O histograma de cor é empregado para comparar imagens por meio de suas cores. Tem como vantagens ser computacionalmente simples e barato. As pequenas alterações de movimento na imagem praticamente não afetam os histogramas e são capazes de diferenciar objetos distintos apresentando diferentes histogramas. Os histogramas normalizados são invariantes à translação, escala e rotação das imagens, o que os tornam uma característica bastante interessante.

Porém, por não dispor da localização espacial dos pixels nas imagens, alguns problemas devem ser considerados no uso de histogramas. O principal é o seu caráter ambíguo, em que imagens diferentes podem possuir histogramas de cores iguais. $\mathrm{O}$ problema de ambigüidade é exemplificado na Figura 2.3, que apresenta quatro imagens diferentes (a), (b), (c) e (d) possuindo o mesmo histograma associado (e). Para buscar uma solução a esse problema, outros métodos devem ser empregados em conjunto [Mirmehdi-2002]. 


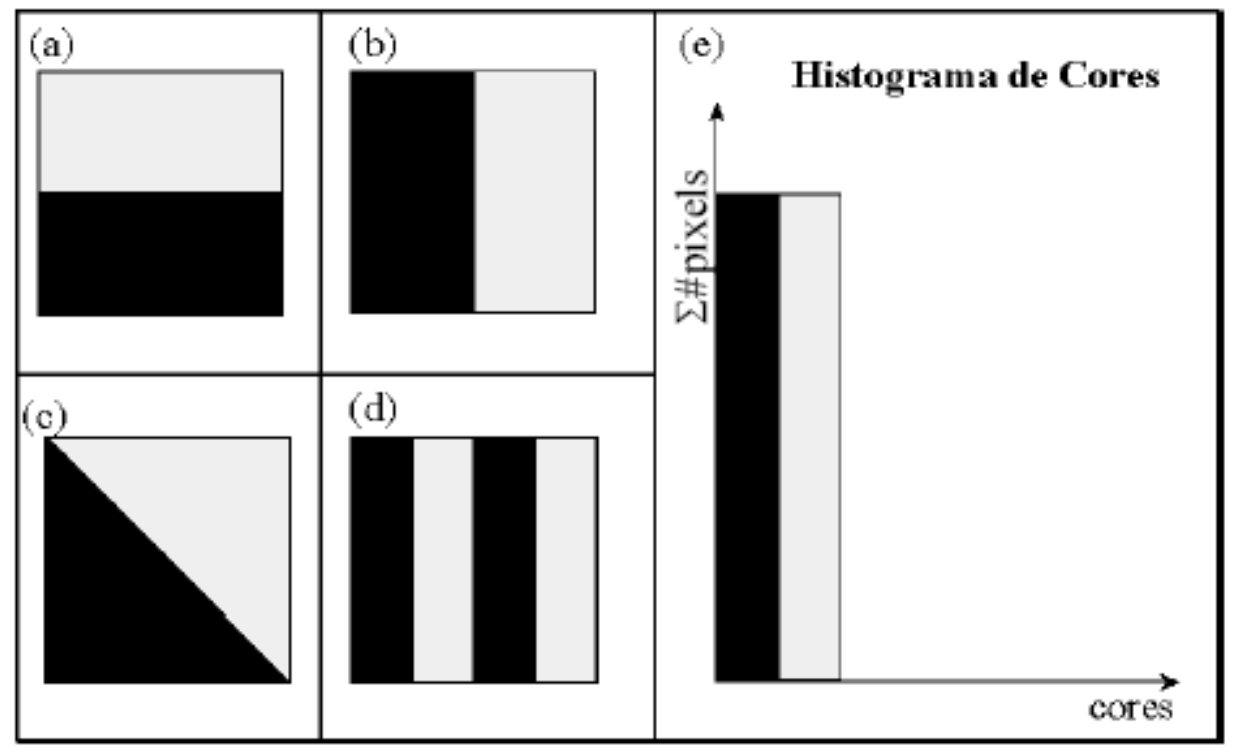

Figura 2.3: Mesmo histograma de cores em 2 níveis de cinza, associado a quatro imagens diferentes [Bueno-2002a, p.44].

Outro problema é a indexação de vetores que possuem um grande número de cores (ou níveis de cinza). A indexação de histogramas de alta dimensão (da ordem de dezenas) causa um colapso na maioria das estruturas de indexação ou métodos de acesso, apresentando um desempenho pior do que uma simples busca seqüencial.

\subsubsection{Textura}

A textura é um padrão visual composto por um grande número de elementos com densidades variadas e dispostos uniformemente. Ao contrário da cor, que é definida por pixels, a textura é tratada por janelas ou regiões que formam padrões repetitivos dentro de um intervalo, conforme mostra a Figura 2.4.
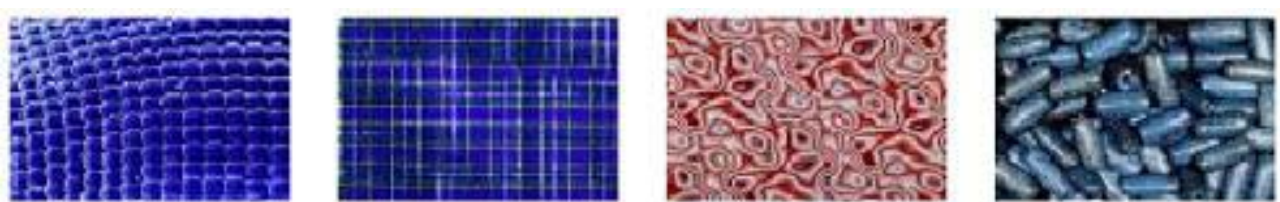

Figura 2.4: Exemplos de imagens de texturas [Castañón-2003a, p.11].

A textura pode ser analisada de modo estatístico, estrutural e espectral. A análise estatística permite caracterizar a variação da intensidade de contraste (contraste alto e baixo, por exemplo, referentes respectivamente a pele de zebra e a pele de elefante), da 
granulação (tamanho dos elementos) e da direção (direcionamento da estampa, como o xadrez e o liso) [Felipe-2002, Çarkacioglu-2003, Lin-2003].

A análise estrutural captura elementos da imagem, determinando seu formato e posição em relação a outros elementos da imagem. Permite estimar o número de elementos vizinhos (conectividade), o número de elementos em uma região (densidade) e a sua regularidade (homogeneidade) [Baeg-2000].

Já a análise espectral é baseada na análise da freqüência da imagem, usando o domínio espacial, filtros de Fourier e Gabor [Wolf-2000, Ginneken-2001, Park-2002, Glatard-2004] e modelos que extraem características geradas por meio da decomposição de Wavelet [Huang-2003].

Embora as informações baseadas em texturas sejam amplamente usadas como primitiva visual em muitas aplicações de processamento de imagens em áreas diversas, também apresentam alguns problemas na sua representação devido à mudança de orientação, escala e outras aparências visuais como brilho e contraste.

\subsubsection{Forma}

A forma é um atributo visual mais difícil de ser tratado pelos sistemas CBIR devido, principalmente, à dificuldade de segmentar automaticamente objetos de interesse presentes na imagem.

Para a recuperação de imagens baseada na forma é necessário, primeiramente, um pré-processamento para selecionar os objetos que estão presentes na imagem, aplicando algoritmos de processamento específicos para o tipo de objeto nela contido. Os algoritmos permitem identificar formas pré-definidas e formas geométricas, bem como eliminar ruídos em imagens mais complexas. Uma vez identificados os objetos, é necessário determinar suas bordas, sendo esse um processo bastante difícil devido à presença de ruídos, a oclusão parcial de objetos e as sombras sobre as regiões das imagens [Stehling-2002, Cheng-2003, Torres-2003, Xu-2003, Huang-2004].

Para auxiliar a busca por conteúdo, a imagem pode ser segmentada restringindo-se para uma determinada região de interesse (Region Of Interest - ROI) [Li-2000, Moghaddam-2000, Moghaddam-2001, Vu-2003]. O atributo forma também pode ser representado pela construção de vetores de características gerados pelos processos de segmentação de imagens [Gagaudakis-2001, Traina-2004] e também com a utilização de técnicas de triangulação e de aproximação por retângulos de contorno (bounding boxes) para representar formas irregulares. 
A Figura 2.5 apresenta um exemplo de contorno de uma base de dados de peixes.
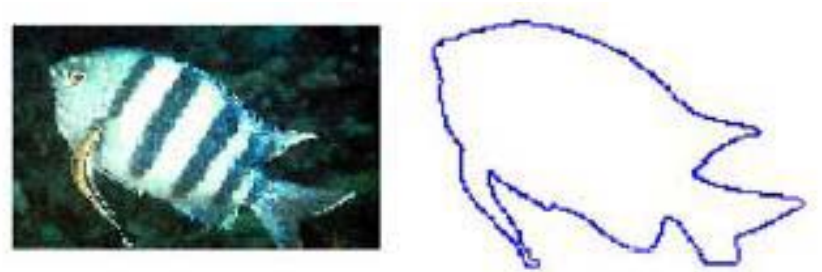

Figura 2.5: Exemplo de um contorno de peixe, adaptado de Alferez et al. (2005, p.148).

\subsection{Sistemas CBIR}

A maioria dos sistemas CBIR possui uma arquitetura muito similar, constituindo de uma interface gráfica que inclui ferramentas de compressão de imagem para navegação, arquivamento, indexação e extração de características visuais, permitindo a execução de operações eficientes para armazenagem e recuperação dessas características. Por isso, os sistemas CBIR podem ser aplicados a diversas áreas diferentes.

Os sistemas comerciais de recuperação de imagens baseados em conteúdo mais conhecidos são o $\mathrm{QBIC}^{1}$ (Query By Image Content) da IBM, que foi o pioneiro na área, e o Virage ${ }^{2}$, idealizado para recuperação de imagens e vídeos. Posteriormente, outros sistemas foram sendo desenvolvidos como o $\mathrm{Netra}^{3}$, o Photobook ${ }^{4}$ e o Candid ${ }^{5}$ (Comparison Algorithm for Navigating Digital Image Database), agregando novos recursos que incluíram características de cor e textura para descrever o seu conteúdo. $\mathrm{O}$ Blobworld ${ }^{6}$ introduziu o uso de segmentação de imagens e o PicHunter ${ }^{7}$ implementou um mecanismo de realimentação de relevância. $\mathrm{O} \mathrm{MARS}^{8}$ (Multimedia Analysis and Retrieval System) também propôs uma solução de realimentação de relevância e distingue-se dos outros sistemas pelo esforço do envolvimento de múltiplas pesquisas,

\footnotetext{
${ }^{1} \mathrm{http}: / /$ wwwqbic.almaden.ibm.com

${ }^{2} \mathrm{http}: / / \mathrm{www}$.virage.com

${ }^{3} \mathrm{http}: / /$ vision.ece.ucsb.edu/NETRA/

${ }^{4} \mathrm{http}: / /$ vismod.media.mit.edu/vismod/demos/photobook/

${ }^{5} \mathrm{http}$ ://public.lanl.gov/Kelly/CANDID/index.shtml

${ }^{6} \mathrm{http}: / /$ elib.cs.berkeley.edu/blobworld/

${ }^{7}$ NEC Research Institute, Princeton, NJ, USA

${ }^{8} \mathrm{http}: / / \mathrm{www}-\mathrm{db}$.ics.uci.edu/ pages/research/mars.shtml
} 
incluindo a visualização computacional, sistemas de gerenciamento de base de dados e recuperação de informação.

Atualmente, encontram-se disponíveis via Web sistemas de domínio público como o GIFT $^{9}$ (GNU Image-Finding Tool) e várias versões de demonstração disponíveis on-line como o Viper ${ }^{10}$ e o Compass $^{11}$ (Computer Aided Search System) [Rui-1999, Müller-2004], entre outras que são apresentadas no Apêndice A.

O GBdI também tem contribuído fortemente nas pesquisas e desenvolvimento de sistemas destinados à área médica, que dentre outros, destacam-se: o SRI (Sistema de Recuperação de Imagens) que possui uma arquitetura aberta para oferecer suporte a imagens de resultados de exame médico [Araujo-2001]; o CIRCE (Content-based Image Retrieval Core Engine) que consiste de um sistema para dar suporte a base de dados relacionais estendidas [Araujo-2002]; o MultiWaveMed que representa um sistema para recuperação de imagens médicas utilizando as transformadas Wavelets [Traina-2003a]; o iRIS (Internet-based Retrieval of Images by Similarity) que propõe a disponibilização de acesso ao sistema PACS pela Internet, de modo a aumentar sua acessibilidade [Lopes-2005]; e o SIREN (SImilarity Retrieval Engine) que descreve um interpretador de comandos da linguagem SQL e inclui consulta por similaridade via Web [Traina Jr.-2005].

\subsection{Considerações finais}

Neste capítulo são introduzidos conceitos básicos relacionados às técnicas de recuperação de imagens por conteúdo e às características das imagens utilizadas no processo de indexação e recuperação, baseadas nos atributos de cor, textura e forma. Por fim, são introduzidos alguns sistemas CBIR desenvolvidos para recuperar imagens similares por meio das suas características intrínsecas, utilizados em diferentes aplicações que se beneficiam dessa abordagem.

\footnotetext{
${ }^{9} \mathrm{http}: / /$ www.gnu.org/software/gift/

${ }^{10} \mathrm{http} / / /$ viper.unige.ch

${ }^{11} \mathrm{http}: / /$ compass.itc.it
} 



\section{Capítulo}

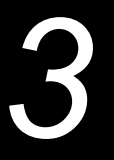

\section{Técnicas de interação humano-computador}

A Interação Humano-Computador, do inglês Human-Computer Interaction (HCI), visa o estudo de como as pessoas interagem com os sistemas computacionais a fim de estabelecer técnicas e guias mestras para projetar e desenvolver interfaces com o usuário que alcancem alta usabilidade. Um bom design de interface de usuário deve prover uma interação fácil, natural e atraente entre o usuário e o sistema, permitindo que o usuário possa realizar suas tarefas com segurança, de maneira eficiente, eficaz e com satisfação. Esses aspectos são conhecidos como usabilidade e são aplicados para medir o desempenho (eficácia e eficiência) e a satisfação do usuário, a fim de determinar quanto um produto é usável dentro de um contexto particular [ISO-9241-11-1998].

O grande desafio em projetar sistemas para pessoas usarem é saber como fazer a transição do que pode ser feito (funcionalidade) para como deve ser feito (usabilidade), buscando alcançar as necessidades e os objetivos dos usuários. Desse modo, avaliações da interação humano-computador são necessárias para verificar se as idéias do projetista são realmente o que os usuários necessitam ou desejam.

É essencial que os projetistas de interface saibam porque é importante avaliar, o que avaliar e quando avaliar [Preece-2005]. Resumidamente, pode-se dizer que a avaliação possui três objetivos principais, que são [Rocha-2003]:

- avaliar a funcionalidade do sistema;

- avaliar o efeito da interface junto ao usuário; e

- identificar problemas específicos do sistema.

O primeiro objetivo visa avaliar a funcionalidade do sistema, ou seja, avaliar a eficiência do sistema na execução das tarefas pelo usuário. $\mathrm{O}$ design da interface deve permitir que o usuário efetue a tarefa pretendida de modo fácil e eficiente. Esse tipo de avaliação envolve medir a performance do usuário em relação ao sistema. O segundo objetivo da avaliação é medir o impacto do design junto ao usuário, levando em 
consideração os aspectos da facilidade de aprendizado do sistema (learnability), sua flexibilidade (flexibility), bem como sua robustez (robustness). O último objetivo da avaliação requer identificar problemas específicos do design, verificando os aspectos usados no contexto do design que ocasionam resultados inesperados ou confusos para os usuários.

Qualquer tipo de avaliação é guiado por um conjunto de crenças e práticas que podem ser firmadas pela teoria. Essas crenças e práticas possuem métodos e técnicas a elas associadas. Porém, a terminologia nesse campo tende a ser um pouco vaga e, em geral, confusa, portanto é difícil fazer uma distinção entre os termos métodos e técnicas [Preece-2005]. Assim, pode-se estabelecer que tanto um método como uma técnica de avaliação em HCI é um procedimento de coleta de dados relevante no que diz respeito ao design da interface e a postura do usuário voltado para ele [Preece-1995].

Existem vários métodos destinados à avaliação da interface que podem ser classificados em inspeção de usabilidade (predictive evaluation) e testes de usabilidade [Preece-1995, Rocha-2003, Tory-2004]. Selecionar uma técnica de avaliação adequada envolve escolher, compor e adaptar técnicas a partir de um conjunto disponível.

\subsection{Inspeção de usabilidade}

Vários métodos e técnicas têm sido propostos para avaliar a interatividade de sistemas por meio da análise de especialistas em HCI. Esses métodos podem ser usados em qualquer ciclo de desenvolvimento do sistema, esteja este implementado ou não e, geralmente, são usados para detectar problemas em vez de se preocupar em melhorar a interface. Muitas dessas técnicas de avaliação são analíticas e envolvem o julgamento de especialistas para estimar o impacto do design em relação a um usuário típico. Baseiam-se nos processos cognitivos e nos princípios de usabilidade. Por não requerer o envolvimento de usuários, esses métodos são considerados relativamente baratos. No entanto, não estimam o uso real do sistema, somente preservam os aspectos relacionados à usabilidade da interface e, por isso, são conhecidos como inspeção de usabilidade [Dix-2004]. A Figura 3.1 ilustra algumas técnicas de inspeção de usabilidade encontradas na literatura. 


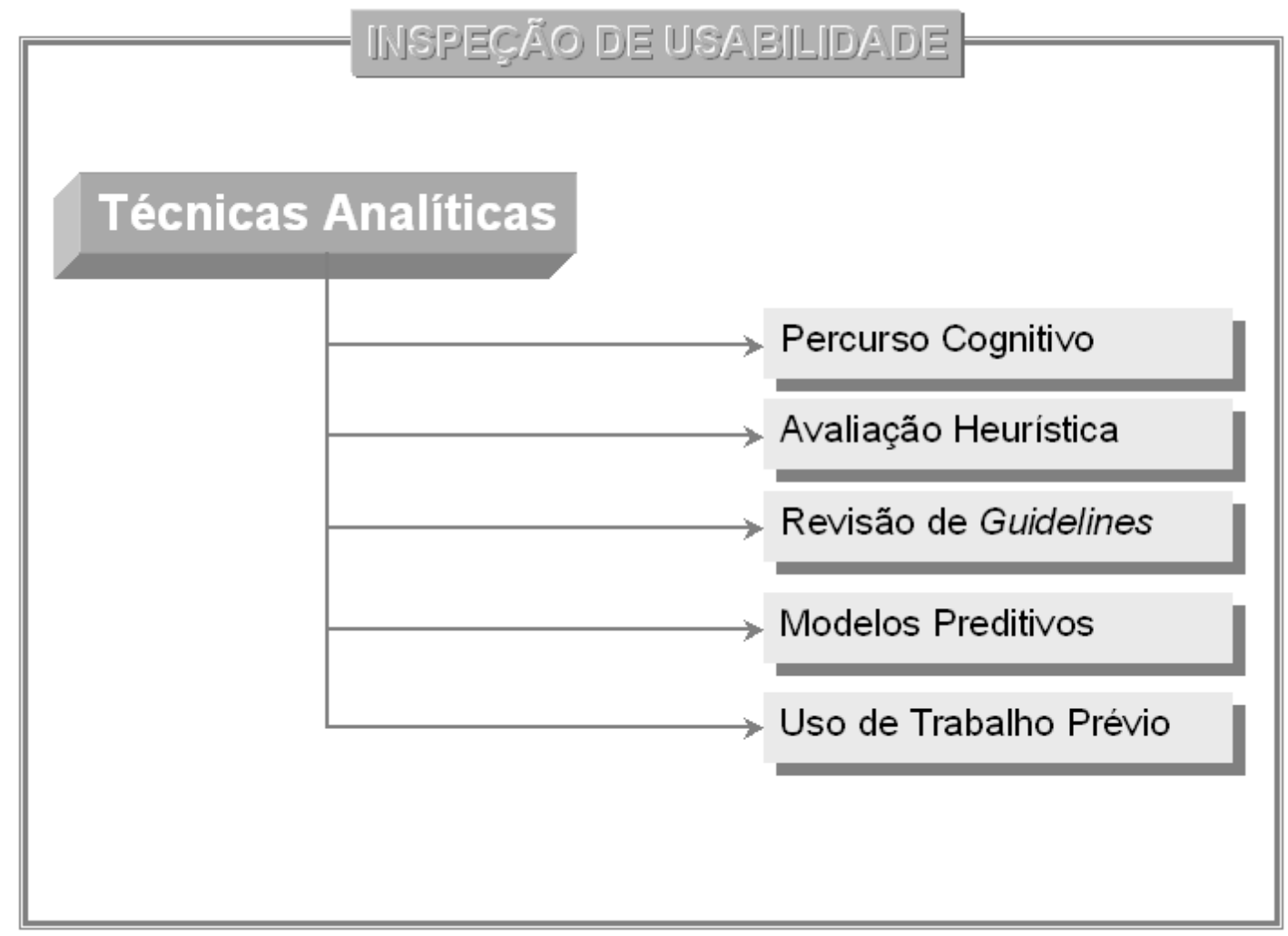

Figura 3.1: Técnicas de inspeção de usabilidade.

\subsubsection{Percurso cognitivo}

O percurso cognitivo (cognitive walkthrough) tem como foco principal avaliar o design em relação a sua facilidade de aprendizagem por exploração [Lewis-1990, Polson-1992]. Assim como na engenharia de software, o objetivo do percurso cognitivo em HCI é detectar problemas potenciais de usabilidade e descobrir erros que possam dificultar a aprendizagem por exploração [Preece-1994].

É uma abordagem que inclui uma teoria psicológica para ajudar a esclarecer como a interface satisfaz às necessidades cognitivas da intenção dos usuários. Dessa maneira, o método tem se concentrado no processo de percepção do usuário e tem sido considerado como um método rápido e barato de avaliação de design de interface, podendo ser aplicado nos primeiros estágios de desenvolvimento do sistema [Ereback1994].

Para realizar o percurso cognitivo, alguns critérios de avaliação devem ser estabelecidos. É necessário descrever quem são os usuários, especificar cada tarefa a ser executada e listar uma série de ações para completar cada uma dessas tarefas. Desse 
modo, é requerida uma inspeção detalhada do comportamento do usuário. Os avaliadores devem percorrer uma seqüência de tarefas e ações, passo a passo, e tentar descobrir a escolha do usuário ao efetuar uma determinada ação.

O percurso cognitivo também pode identificar conflitos entre o projetista e o usuário em relação à concepção das tarefas, às escolhas ruins e inconsistentes de terminologias e às respostas inadequadas das ações. Resultados obtidos de experimentos apresentaram que o método cognitivo pode detectar até quase $50 \%$ dos problemas que foram avaliados [Lewis-1990]. O método é considerado muito útil para observar pequenos detalhes relacionados à execução da tarefa, mas pode falhar ao identificar problemas gerais.

Outro aspecto do método que vem sendo examinado ultimamente é o uso do percurso cognitivo na avaliação de aplicações relacionadas com o trabalho colaborativo apoiado por computador (CSCW - Computer Supported Cooperative Work). Esse tipo de avaliação considera as atividades de comunicação e resolução de problemas executados por grupos de colaboradores ao invés de um único usuário [Jones-2005].

Nesse contexto, novas técnicas de inspeção de usabilidade estão sendo estudadas, como o groupware walkthrough que é uma modificação do percurso cognitivo que considera as informações sobre usuários e o contexto do seu trabalho, incluindo as complexidades de colaboração do trabalho em equipe. O groupware walkthrough utiliza um modelo de tarefas para identificar e analisar tarefas colaborativas do mundo real e um processo de percurso para dar apoio a essas tarefas. É uma técnica de baixo custo que pode identificar problemas de usabilidade específicos de colaboração e pode encontrar problemas que seriam difíceis de serem revelados em outros métodos de inspeção [Pinelle-2002]. Outra técnica é o percurso cognitivo para a Web (CWW - Cognitive Walkthrough for the Web), que se refere a um método de avaliação de usabilidade parcialmente automático para identificar e reparar problemas de navegação de Websites [Blackmon-2003, Blackmon-2005].

\subsubsection{Avaliação heurística}

A avaliação heurística é um método para encontrar problemas de usabilidade em design de interface de usuários, em que os sistemas são avaliados por meio da reflexão crítica a respeito de alguns pontos da interface. A inspeção da interface é feita por um conjunto de avaliadores que examinam a interface e julgam se cada elemento do diálogo 
segue os reconhecidos princípios de usabilidade, denominados heurísticas de usabilidade [Preece-1994].

As heurísticas de usabilidade para design de interface foram originalmente propostas em 1990 por Nielsen em colaboração com Rolf Molich [Nielsen-1990]. Foram planejadas em resposta à necessidade de se obter um método barato e efetivo para ser usado por pequenas companhias que não dispusessem de tempo ou especialista em engenharia de usabilidade [Preece-1994].

Esse método é parte integrante da proposta de engenharia econômica de usabilidade (Discount Usability Engineering) também desenvolvida por Nielsen, que tem como objetivo capacitar desenvolvedores com poucos recursos, em termos de tempo, dinheiro ou experiência, para se beneficiar com os testes de usabilidade e minimizar os problemas decorrentes.

$\mathrm{Na}$ avaliação heurística, a inspeção da interface é orientada por uma série de heurísticas de alto nível que focam os problemas de usabilidade. Inicialmente foram baseadas em um fator de análise de 249 problemas de usabilidade, sendo que, posteriormente, essas heurísticas foram refinadas resultando em uma série constituída de um poder máximo de exploração, conhecida como as "10 heurísticas de usabilidade de Nielsen" [Nielsen-2005]. Além de detectar problemas de usabilidade, a avaliação heurística pode ser usada para estimar a gravidade de cada problema.

As heurísticas de Nielsen têm sido a base para diferentes avaliações, porém algumas modificações têm sido propostas para aplicações específicas, obtendo bons resultados e conseguindo identificar até $60 \%$ de problemas de usabilidade [Mankoff2003]. Outras variações integram a avaliação de interfaces para, além de categorizar e priorizar os problemas mais significativos de acordo com os graus de severidade, incluir recomendações de como resolvê-los, fornecendo, assim, uma documentação para obter um melhor planejamento e alcançar melhorias [McQuaid-2001].

A avaliação heurística é considerada como o melhor método a ser utilizado, por ser um método intuitivo, fácil e rápido de ser ensinado e barato de se aplicar [Nielsen1993]. 


\subsubsection{Revisão de guidelines}

A revisão de guidelines é uma técnica de inspeção que envolve avaliar ou inspecionar uma interface do usuário para checar se está em conformidade com uma série de princípios de guidelines ou padrões de usabilidade como a ISO 9241.

Tem como proposta analisar a interface utilizando uma lista de guidelines de usabilidade que contém cerca de 1.000 itens, o que torna o uso desse método um pouco inviável, pois exige um conhecimento avançado do avaliador [Rocha-2003].

O processo de revisão de guidelines consiste em selecionar as guidelines relevantes para uma determinada aplicação e traduzi-las em regras específicas de design antes que possam ser realmente aplicadas. Um problema a ser considerado é que as guidelines podem ter diferentes interpretações.

Da maneira como foi proposto, o design de guidelines usa termos gerais para serem aplicados em uma variedade de sistemas diferentes. No entanto, nem todas as guidelines propostas podem ser aplicadas em um sistema específico. Para cada aplicação particular algumas guidelines podem ser relevantes e outras não. Estudos recentes têm apresentado uma ligação entre esses extremos para que os testes de usabilidade de guidelines possam ocorrer em vários níveis, desde testes gerais até testes em produtos mais específicos. Uma das vantagens é que as lições aprendidas nos experimentos podem servir como exemplo em outras pesquisas [Beier-2003].

Para alcançar o máximo de eficiência, as guidelines devem ser aplicadas nos primeiros processos de design, antes da construção de qualquer design de interface de usuário. Projetistas devem ter uma compreensão cuidadosa dos requisitos das tarefas e das características dos usuários. Dessa maneira, a análise das tarefas deve ser considerada como um pré-requisito necessário.

Considerando todo o processo de desenvolvimento do sistema, a aplicação de guidelines não necessariamente evita o trabalho de design de interface do usuário e, de fato, pode acarretar um trabalho extra, pelo menos no estágio inicial em que as regras de design são estabelecidas.

A aplicação de guidelines deve ajudar a produzir uma interface de usuário melhor, resultando em um design mais consistente e pode incorporar muitas recomendações boas e úteis. No entanto, o mais cuidadoso design requer testes com usuários reais para confirmar o valor dos aspectos bons e descobrir quais aspectos ruins devem ser inspecionados [Smith-1986]. 


\subsubsection{Modelos preditivos}

Uma outra abordagem é o uso de modelos preditivos, que utiliza um mesmo framework para especificar e avaliar o design. Os modelos mais conhecidos são o modelo GOMS (Goals, Operators, Methods and Selection), que inspeciona o desempenho do usuário com a interface e pode ser usado para filtrar itens particulares do design, e o modelo KLM (Keystroke Level Model), que provê uma inspeção do tempo que os usuários levam para executar uma tarefa. Metodologias de design, como design rationale, também têm um papel na avaliação do design. Design rationale provê um framework para que as opções de design possam ser avaliadas [Dix-2004].

\section{Modelo GOMS}

O modelo GOMS foi desenvolvido no início da década de 80 por Stu Card, Tom Moran e Alan Newell [Card-1983] e foi baseado na premissa de modelar o conhecimento e os processos cognitivos envolvidos na interação dos usuários com o sistema. O termo GOMS é um acrônimo para Goals (objetivos), Operators (operadores), Methods (métodos) e Selection rules (regras de seleção). O modelo tem sido usado, principalmente, para prever o desempenho do usuário quando comparado com diferentes aplicações. Pode produzir previsões como, por exemplo, o tempo levado para se realizar uma tarefa e quais as estratégias mais eficazes a serem utilizadas. É capaz de realizar análises comparativas para diferentes sistemas de maneira relativamente fácil [Preece-2005].

\section{Modelo KLM}

O modelo KLM difere do modelo GOMS por fornecer previsões numéricas reais do desempenho do usuário. As tarefas podem ser comparadas de modo quantitativo, utilizando diferentes estratégias como a medição do tempo gasto para realizá-las.

Card et al. (1983) desenvolveu o modelo KLM na tentativa de analisar vários estudos empíricos acerca do desempenho real de usuários, a fim de derivar um conjunto-padrão baseado em tempos aproximados para os principais tipos de operadores utilizados durante uma tarefa. Esse conjunto-padrão inclui o tempo médio para realizar algumas ações físicas, como pressionar uma tecla ou o botão do mouse e, também, outros aspectos da interação humano-computador, como o tempo gasto para decidir o 
que fazer ou o tempo de resposta do sistema [Preece-2005]. Assim, é possível determinar qual sistema é mais eficaz na realização de cada tarefa específica.

\subsubsection{Uso de trabalho prévio}

A psicologia experimental em HCI possui uma riqueza de resultados experimentais e evidências empíricas. Geralmente, experimentos são custosos para serem repetidos continuamente, enquanto que uma relevante revisão da literatura pode evitar esse esforço, podendo atribuir resultados de experimentos já realizados em outros experimentos. Essa abordagem explora essa herança, usando resultados de trabalhos prévios como evidência para apoiar aspectos do design. Nem sempre os resultados experimentais podem ser esperados dentro do contexto requerido. Alguns resultados são específicos de um domínio particular, porém tentam direcionar para resultados mais genéricos que podem ser adaptados em várias situações diferentes. O revisor deve selecionar as evidências cuidadosamente. Por exemplo, um teste de usabilidade experimental de um sistema de ajuda, usando participantes principiantes pode não prover uma avaliação precisa de um sistema de ajuda projetado para usuários experientes. A revisão deve levar em conta as similaridades e diferenças entre o contexto experimental e as considerações sobre o design. Por isso, a revisão requer avaliadores experientes para assegurar que as suposições sejam feitas corretamente [Dix-2004].

\subsection{Testes de usabilidade}

As técnicas apresentadas até o momento concentraram nas avaliações de design por meio da análise de um especialista ao invés da participação efetiva de usuários reais. Essas técnicas são úteis para filtrar e refinar o design, porém não substituem os testes com pessoas para as quais os sistemas foram projetados, que são os usuários. As avaliações de design centrado no usuário tem como premissa básica que as necessidades dos usuários devem ser levadas em conta durante todo o ciclo de desenvolvimento do projeto [Preece-2005]. No entanto, a participação do usuário na avaliação, geralmente, tende a ocorrer nos últimos estágios de desenvolvimento, onde há pelo menos um protótipo do sistema para simular sua capacidade interativa do sistema. As abordagens de avaliação com a participação do usuário são conhecidas como testes de usabilidade. 
Os testes de usabilidade são métodos de avaliação centrados no usuário e tem o objetivo de auxiliar como o design pode ser melhorado durante o seu desenvolvimento e avaliar a qualidade global da interface utilizando-se medidas de performance. Os testes de usabilidade determinam medidas quantitativas de desempenho que são importantes para avaliar se os objetivos de usabilidade foram atendidos, para comparar produtos competitivos e para realizar pesquisas em fatores humanos.

Em geral, os testes de usabilidade são considerados como os métodos mais eficazes em detectar problemas mais graves, porém são também os mais caros. Existem diversas técnicas disponíveis para avaliação que contam com a participação do usuário, dentre as quais se destacam [Dix-2004]:

- Técnicas experimentais;

- Técnicas observacionais;

- Técnicas de questionamento;

- Técnicas interpretativas; e

- Técnicas de monitoração.

A Figura 3.2 ilustra as principais técnicas de testes de usabilidade.

\section{TIESTESE DE USSA BUILIDADE}
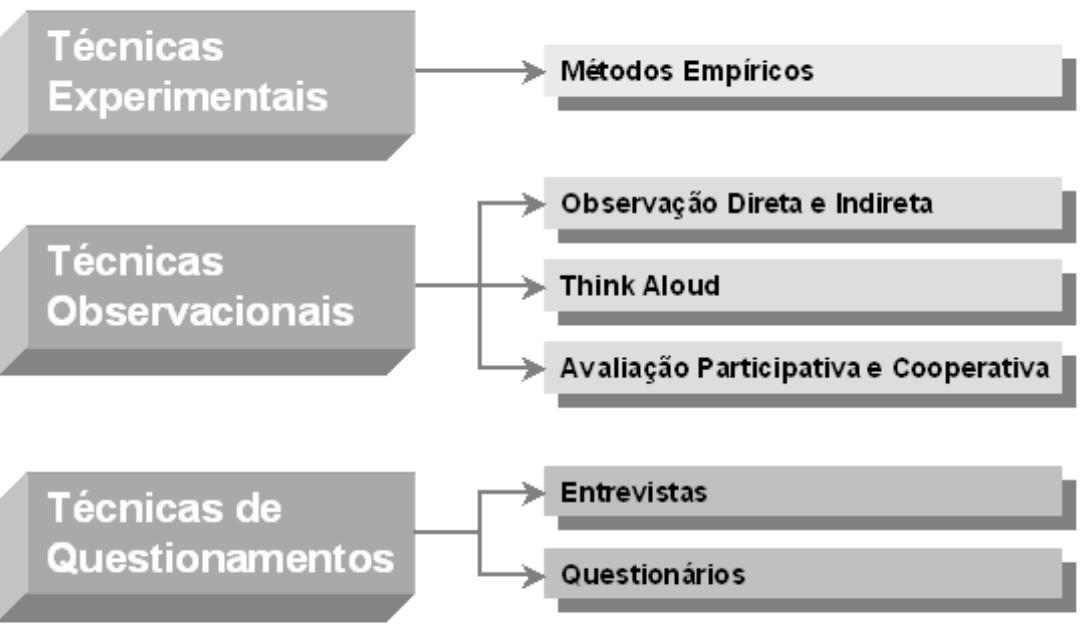

Técnicas

Interpretativas

Avaliação Etnográfica

Investigação Contextual

Técnicas de

Monitoração

Eye Tracking

Medidas Fisiológicas

Figura 3.2: Testes de usabilidade. 


\subsubsection{Técnicas experimentais}

Um dos métodos mais poderosos de avaliação de design é o uso de experimentos controlados que provê uma evidência empírica para uma hipótese em particular e é conhecido como método empírico ou experimental. Geralmente, no método empírico ou experimental, os experimentos têm a mesma forma básica, onde o avaliador escolhe uma hipótese para teste que pode ser determinada pela medição de alguns atributos do comportamento do participante [Dix-2004].

Os experimentos tradicionais usados em HCI focam alguns aspectos específicos do design da interface. O método experimental tem como regra básica especificar uma série de tarefas para os usuários executarem em um ambiente controlado, onde é possível controlar as variáveis de interesse. Uma característica importante é que o investigador pode manipular alguns fatores associados aos aspectos de desempenho do usuário. Estudos experimentais bem elaborados, geralmente, têm uma hipótese clara, que provê o efeito do desempenho esperado associado com os experimentos e conclui uma análise estatística dos dados coletados.

Ao planejar um experimento deve-se considerar três aspectos [Preece-1994]:

- o propósito do experimento, ou seja, quais as mudanças que estão sendo planejadas e o que está sendo medido;

- uma hipótese, que precisa ser afirmada da maneira a ser testada; e

- quais testes estatísticos serão aplicados para os dados coletados e por quê.

Alguns fatores devem ser considerados cuidadosamente no design para a garantia do experimento, como a escolha dos participantes, das variáveis a serem testadas e manipuladas e da hipótese a ser testada.

Essa abordagem segue um paradigma científico, em que os experimentadores testam uma hipótese e tentam controlar variáveis de interesse específicas. Laboratórios de usabilidade são criados especialmente para esse tipo de trabalho experimental. Freqüentemente, os usuários trabalham nos laboratórios de experimentos e, por meio de um controle efetivo nas variáveis das interações, dados são coletados e analisados quantitativamente para produzir métricas com o objetivo de orientar o re-design. Também é necessário algum conhecimento estatístico para validar os resultados.

Não é fácil projetar bons laboratórios de experimentos. Uma hipótese testada precisa ser relatada e o controle das variáveis nas interações complexas envolvem humanos. Conseqüentemente, a área de HCI tem desenvolvido uma abordagem na 
engenharia para testar dados em condições semi-científicas, denominados testes de Benchmark.

\section{Testes de Benchmark}

Testes de Benchmark têm como ênfase monitorar o desempenho dos usuários. Esses testes são executados em laboratórios de usabilidade ou em algum outro cenário similar. São utilizados equipamentos para registrar aspectos das atividades dos usuários. Câmeras de vídeo são posicionadas simultaneamente na tela do computador, no teclado ou em outro dispositivo de entrada. Deve-se planejar antecipadamente como os dados serão analisados e quais as técnicas a serem usadas na análise. Tipicamente, os dados são convertidos em métricas para obter informação sobre quanto tempo o usuário leva para executar uma tarefa, quais os tipos de erros, o uso de manual e assim por diante. Em geral, testes de Benchmark são freqüentemente usados em experimentos científicos, mas muito pouco se aplica nas tarefas da vida real [Preece-1994].

\subsubsection{Técnicas observacionais}

Um modo simples para obter informação sobre o uso real de um sistema é observar a interação dos usuários com ele. Na técnica observacional, os usuários são solicitados a completar uma série de tarefas pré-determinadas, que podem ser aplicadas no seu próprio local de trabalho, enquanto são observados cumprindo por completo as suas obrigações rotineiras. A função do avaliador é observar os usuários, prestando atenção em suas ações e registrando-as. Apesar da idéia de observar eventos parecer muito fácil, nem sempre o que o observador pensa que parece estar acontecendo é o que realmente está ocorrendo. Uma simples observação pode não ser suficiente para determinar se o sistema corresponde às necessidades dos usuários, pois nem sempre é possível perceber suas atitudes e perspicácia no processo de decisão [Dix-2004].

Por várias razões fisiológicas e psicológicas, o olho produz uma imagem visual muito precária de como o cérebro é interpretado, sendo que as pessoas vêem o que querem ver. $\mathrm{O}$ observador deve saber exatamente o que pedir para o usuário fazer e especificar como será o processo de monitoração durante a realização da tarefa. Deve-se, primeiramente, definir quais as principais razões para observá-los. Esse é o fator determinante para a escolha do tipo de registro que será usado durante a observação. Várias ferramentas podem ser usadas na coleta e análise dos dados. O modo 
como os dados serão analisados depende das questões que os avaliadores precisam descobrir e quais tipos de dados são requeridos [Preece-1994].

Existem dois modos de observar o usuário, a observação direta e a observação indireta. Observação direta é o modo mais barato de registrar as ações dos usuários, no entanto, a observação indireta tem a vantagem de poder usar outras maneiras de registro automático, como uma gravação em vídeo, que provê um registro permanente.

\section{Observação direta}

Essa técnica inclui observar os usuários individualmente fazendo tarefas especificamente planejadas ou fazendo seu trabalho normal, estando um observador tomando nota sobre o seu comportamento e ações. No entanto, o usuário pode estar ciente de que seu desempenho está sendo monitorado constantemente e, como conseqüência, isso pode alterar seu comportamento e os níveis de desempenho. O desempenho do usuário pode ser registrado de várias maneiras como, por exemplo, pelo tempo de seqüência das ações. A observação direta pode ser muito útil no início do projeto para obter um feedback informal sobre o que os usuários fazem e o que eles gostam ou não de fazer. Embora o observador possa tomar notas, o registro da observação torna-se, geralmente, incompleto se o observador não souber exatamente o que está procurando.

\section{Observação indireta}

Para obter registros permanentes é necessária a utilização de alguns equipamentos para esse fim, que incluam vídeo e áudio. A gravação em vídeo é bastante útil por oferecer um registro permanente que permite, posteriormente, retroceder a gravação e rever quantas vezes for necessário. Os usuários devem estar cientes que estão sendo filmados, por isso essa técnica é considerada, por muitos, um tanto quanto constrangedora. Porém, uma maneira de reduzir o impacto que os usuários possam ter sobre seu comportamento diante de uma câmera é deixar o equipamento no local por vários dias antes de começar a gravação efetiva para que eles possam se acostumar e agir de maneira natural. Em alguns testes, vários aspectos das atividades dos usuários são monitorados usando diferentes câmeras de vídeo de uma só vez. Por exemplo, uma câmera pode focar o teclado e a tela do computador, gravando onde o usuário está olhando e o que está fazendo, enquanto que uma outra câmera pode estar direcionada 
diretamente para o usuário, capturando a linguagem corporal do usuário que pode prover dicas úteis sobre o modo como eles se sentem em relação ao uso do sistema. Existem vários tipos diferentes de equipamentos e técnicas disponíveis para coletar dados, que podem ser sincronizados e gerenciados. Porém, isso pode prover muitos dados para analisar e, conseqüentemente, pode consumir muito tempo.

As técnicas observacionais podem ser aplicadas em outros tipos diferentes de avaliação para monitorar o modo que os usuários interagem com o produto ou protótipo. Informalmente, observações podem ser usadas como parte de testes de usabilidade em estudos de campo ou laboratórios e também podem ser usadas sob uma perspectiva participativa ou etnográfica com o objetivo de tentar entender como os usuários interagem com a tecnologia de uma maneira natural [Preece-1994].

As técnicas mais conhecidas e usadas para observar o comportamento do usuário são as denominadas think aloud e a avaliação participativa e cooperativa.

\section{Think aloud}

Think aloud é o termo dado para um tipo especial de protocolo verbal usado na observação, em que os usuários dizem em voz alta o que pensam enquanto estão realizando uma tarefa ou resolvendo algum problema [Preece-1994, Dix-2004]. Protocolos verbais aumentam o esforço dos usuários, que são requisitados para fazer duas coisas de uma só vez, a tarefa propriamente dita e falar sobre o que estão pensando ao executar suas ações. O usuário deve descrever o que ele acha que está acontecendo, o que o levou a escolher algumas ações e o que ele está tentando fazer. Isso pode ser empregado para observar como o sistema está realmente sendo usado.

O protocolo think aloud é uma técnica muito simples, requer pouca experiência para realizar e pode prover soluções úteis acerca dos problemas com a interface. No entanto, a informação provida é freqüentemente subjetiva, pois depende especificamente das tarefas selecionadas.

\section{Avaliação participativa e cooperativa}

A avaliação participativa e cooperativa é uma variação do think aloud, em que o usuário é encorajado a ser um colaborador da avaliação e não apenas um simples participante do experimento. Assim, o avaliador pode questionar ao usuário caso seu comportamento não esteja claro, e o usuário também pode pedir ao avaliador para 
esclarecer alguns pontos para poder cumprir a tarefa em questão. Essa versão do protocolo think aloud tem as seguintes vantagens [Dix-2004]:

- o processo é menos constrangedor e por esse motivo mais fácil de aprender a ser usado pelo avaliador;

- o usuário é encorajado a criticar o sistema; e

- o avaliador pode esclarecer pontos de conflitos assim que ocorrem e então maximizar a eficiência da abordagem para identificar problemas.

$\mathrm{Na}$ avaliação participativa o usuário sai do seu local de trabalho e compartilha as tarefas de design com designer profissional, assim, pode-se considerar que o usuário também desempenha o papel de designer. $O$ design participativo incorpora as experiências subjetivas do local de trabalho, diferente da etnografia e outras abordagens interpretativas que levam o analista ao local de trabalho e retém um nível de objetividade. A vantagem da avaliação participativa é que o analista avalia não somente o envolvimento individual, como também toda a perspectiva do grupo. O envolvimento dos usuários no processo de design aumenta sua motivação e aceitação do sistema, qualquer que seja o resultado do design, seja ele bom ou não [Dix-2004].

Por outro lado, a avaliação cooperativa foi projetada para ser uma técnica de baixo custo e para ser usada por designers e usuários sem contar com especialistas com conhecimento de HCI. É necessário pouco treinamento para fazer uma avaliação cooperativa. Inicialmente, os designers identificam as tarefas da avaliação e os usuários são encorajados a comentar, questionar e sugerir alternativas. O propósito é fazer com que a interação seja a mais natural possível. Durante a avaliação pode ser utilizado o protocolo think aloud para coleta de dados e pode adotar os seguintes procedimentos para realizar a avaliação [Preece-1994]:

- recrutar um ou mais usuários e certificar que eles fazem parte do domínio real de usuário que será usado no produto final;

- selecionar tarefas representativas intuindo o que os usuários poderiam desejar fazer quando interagem com o sistema;

- o avaliador deve tomar notas dos problemas relatados e observados pelo usuário ao usar o sistema;

- deve ser feito um resumo no final da sessão para esclarecer qualquer mal entendido que possa ter ocorrido e chegar a um entendimento comum; e 
- o designer deve sumarizar as notas e relatar os problemas para a equipe de design.

A avaliação participativa difere da avaliação cooperativa por ser mais aberta e subjetiva, obtendo um controle maior dos usuários. Contudo, a avaliação participativa e a cooperativa compartilham a mesma filosofia e as mesmas técnicas e, na prática, são consideradas basicamente a mesma coisa.

Em geral, a vantagem do protocolo think aloud e da avaliação participativa e cooperativa é dependente da eficiência do método de registro e das análises subseqüentes.

\subsubsection{Técnicas de questionamento}

Outra série de técnicas de avaliação é perguntar diretamente ao usuário sobre a interface com o objetivo de descobrir se o sistema está de acordo com as suas necessidades. Essas técnicas são conhecidas como técnicas de questionamento e podem ser úteis para extrair detalhes do ponto de vista do usuário em relação ao sistema. Normalmente, são usadas para coletar informações sobre as necessidades dos usuários e podem revelar resultados que não teriam sido considerados pelo designer. Além disso, é um método relativamente simples, barato de administrar e provê materiais suplementares úteis para serem usados por outros métodos. As principais técnicas de questionamento são entrevistas e questionários [Dix-2004].

Entrevistas e questionários provêm dados sobre a preferência dos usuários, porém diferem no tipo de preparação requerida, no estilo de apresentação e na flexibilidade das respostas. Os dados coletados nas entrevistas tendem a ser qualitativos enquanto que os questionários são geralmente quantitativos. Questionários também oferecem a vantagem de atingir um grande número de pessoas, podendo obter resultados estatísticos significantes [Preece-1994].

\section{Entrevistas}

Entrevistas provêm uma maneira direta e estruturada de obter informação sobre as experiências dos usuários em sistemas interativos. Tem como vantagem a flexibilidade de conduzir o questionamento condizendo com os assuntos que podem surgir ao investigar mais profundamente os interesses dos usuários. Usualmente, uma entrevista segue uma abordagem top-down, começando com questões gerais e seguindo 
com questões mais específicas direcionadas sobre os aspectos da sensibilidade do usuário [Dix-2004].

É necessário planejar e estruturar cuidadosamente as entrevistas, determinando as linhas de questionamento a seguir de acordo com os tipos de resultados obtidos. O avaliador pode adaptar a estrutura da entrevista para cada tipo de usuário para obter um maior benefício. Isso ajuda a focar o propósito da entrevista, investigando aspectos particulares da interação e garantir uma base de consistência no caso de existir vários entrevistadores para usuários diferentes. As entrevistas podem ser classificadas como: estruturadas e não-estruturadas ou flexíveis. A entrevista estruturada possui questões pré-determinadas e não há como explorar as atitudes individuais de cada usuário, enquanto que a não-estruturada ou flexível possui geralmente uma série de tópicos sem uma seqüência pré-estabelecida e o entrevistador é livre para conduzir a entrevista e explorar as atitudes individuais [Preece-1994].

\section{Questionários}

A aplicação de questionários é um método alternativo de interrogar o usuário. É menos flexível que a técnica de entrevista, visto que as questões são elaboradas com antecedência e provavelmente são menos investigadas. No entanto, questionários podem ser usados para atingir um grande número de participantes, levam menos tempo para serem projetados e podem ser analisados mais rigorosamente. Podem ser aplicados em várias fases do processo de design, incluindo o levantamento de requisitos, análise e avaliação das tarefas. Todavia, os questionários devem ser bem elaborados. Deve-se estabelecer qual o propósito do questionário, como as respostas serão analisadas e especificar quais as variáveis a serem mensuradas. É prudente realizar um estudo piloto antes de aplicar efetivamente o questionário para checar se as questões são compreensíveis e os resultados são os esperados. Isso permite corrigir qualquer problema com a estruturação do questionário antes de ser distribuído para centenas de pessoas [Dix-2004].

A distribuição de questionários deve contar com um número representativo e deve assegurar que é capaz de alcançar um total significativo de pessoas. Normalmente, a taxa de retorno de questionários é muito baixa, entre 25 a 30\%, assim devem ser enviados muitos questionários para obter um retorno razoável. Os questionários devem ser distribuídos para um conjunto representativo do domínio real de usuários. Atualmente, os questionários são freqüentemente distribuídos via Internet: ou por 
e-mail, onde as pessoas podem ser selecionadas randomicamente, ou pelo Website, sendo limitado àqueles que visitam o site e corre-se o risco de não serem representativos. $\mathrm{Na}$ prática, os voluntários para responder aos questionários são auto-declarados e somente aqueles que optaram por responder são incluídos no estudo [Dix-2004].

As respostas obtidas nos questionários são convertidas em valores numéricos e são realizadas análises estatísticas. Geralmente, média e desvio padrão são as principais medidas estatísticas usadas nas análises da maioria dos dados da pesquisa. Se houver a necessidade de utilizar técnicas mais avançadas deve-se ter o auxilio de um estatístico durante a fase de planejamento e elaboração dos questionários.

Outro uso bem conhecido dos questionários é o estudo "antes e depois" do desempenho do usuário. Alguns temas são elaborados em forma de questionário para extrair as expectativas do usuário ou testar seu desempenho antes de ser realizada uma experiência em particular. Então, depois da experiência, o mesmo questionário é novamente aplicado. Esses tipos de questionários, conhecidos como pré e pós-questionários, são capazes de identificar como a atitude e o desempenho dos usuários mudam de perspectiva [Preece-1994].

\subsubsection{Técnicas interpretativas}

As técnicas interpretativas têm como propósito capacitar o designer a compreender melhor como os usuários usam o sistema em seus ambientes naturais e como interagem com outras atividades. Essa técnica é apropriada para entender interações complexas e é bastante usada com sucesso em sistemas de trabalho cooperativo suportado por computador (CSCW). A avaliação interpretativa pode ser valiosa em várias fases do desenvolvimento. Os dados coletados são considerados fáceis de analisar e interpretar, pois são obtidos de maneira informal e natural [Preece-1994]. Os tipos de métodos que pertencem a essa categoria incluem a etnografia e a investigação contextual.

\section{Avaliação etnográfica}

A etnografia não é um método novo e sim uma prática padrão que tem sido usada na antropologia por vários anos [Preece-1994]. Porém, ultimamente, a etnografia vem ganhando credibilidade no design de integração. Recentemente, pesquisadores têm 
reconhecido a importância de aprender mais sobre o modo com que a tecnologia é usada in situ [Preece-2005]. O foco deve ser direcionado em estudar especificamente o trabalho no seu local real e deve ser entendido dentro do seu próprio contexto. A etnografia é baseada em registros detalhados de interações entre pessoas e seus ambientes. Tem como premissa que a natureza das ações do usuário muda completamente se ele estiver fora do seu ambiente de trabalho. As ações reais são consideradas como aquelas que ocorrem na interação das novas tecnologias com as pessoas dentro do contexto do seu local de trabalho, considerando sua situação social e cultural.

Estudos apresentam que o uso de práticas etnográficas durante o ciclo de design pode auxiliar o designer a avaliar antecipadamente o uso do sistema proposto, visando orientar o re-design do sistema por meio da identificação de problemas e sugestões das necessidades do usuário na realização de tarefas [Oeiras-2001].

Em particular, a etnografia tem se tornado muito influente nos grupos de estudo de sistemas. É uma das principais abordagens para coletar informação para o design de tecnologias colaborativas. O resultado de tais estudos pode mostrar-se bastante esclarecedor, revelando como as pessoas gerenciam o trabalho em seu próprio ambiente de trabalho e pode fornecer uma base para considerar como os ambientes podem ser melhorados ou aprimorados, mediante o uso de novas tecnologias. Também pode expor os problemas sobre como as tecnologias colaborativas deveriam ser utilizadas em um determinado ambiente [Preece-2005].

\section{Investigação contextual}

O modelo de investigação contextual (contextual inquiry) tem muito em comum com a abordagem etnográfica. Este modelo estuda o usuário no contexto tentando capturar a realidade de seu trabalho cultural e prático, porém difere na intenção de compreender e interpretar os dados adquiridos [Dix-2004].

$\mathrm{Na}$ investigação contextual o designer faz o papel de aprendiz, ou seja, seu papel é aprender sobre o trabalho. O designer deve apenas observar o usuário e questionar sobre seu comportamento, sem participar. Essa abordagem caracteriza-se em uma entrevista contextual do investigador com o usuário em seu local de trabalho. O objetivo é obter um entendimento compartilhado de como o trabalho acontece e saber interpretar as observações a fim de entender como o trabalho funciona. A entrevista deve ser mais intensa e focada do que em um estudo etnográfico, porém não deve ser muito longa, 
cerca de duas a três horas já é o suficiente. Dessa maneira, a investigação contextual baseia-se nos princípios fundamentais do contexto, parceria, interpretação e foco [Preece-2005].

\subsubsection{Técnicas de monitoração}

Um dos problemas apresentados em algumas técnicas de avaliação é a confiança depositada nos usuários em descrever o que estão fazendo e sentindo. Recentemente, o interesse em medir esses pontos vem crescendo. Testes objetivos de usabilidade têm sido efetivos em monitorar aspectos fisiológicos no uso do computador, permitindo observar mais claramente o que os usuários estão fazendo quando interagem com os computadores, bem como medir o que estão sentindo. Há duas técnicas que registram esse tipo de comportamento: o eye tracking e as medidas fisiológicas, que serão discutidas a seguir.

\section{Eye tracking}

Por mais que se observe onde o usuário está olhando, sempre pode haver uma suspeita de perder algum movimento do olho ou, até mesmo, uma falta de compreensão do que isso significa. O sistema de eye tracking foi desenvolvido com o propósito de registrar exatamente onde o usuário está olhando, sendo possível identificar se um olhar é de relance ou fixação.

O sistema eye tracking monitora o movimento do olho através de um display que reflete o processamento cognitivo, permitindo medir não somente onde as pessoas olham, mas também os padrões de movimento do olho, identificando as áreas da tela que são fáceis e difíceis de entender. As medidas dos movimentos do olho são baseadas em fixações, onde os olhos retêm uma posição estável por um período de tempo e, também, nos reflexos rápidos do movimento de um ponto de interesse para outro. Algumas medidas que se pode extrair em relação à avaliação de usabilidade são o número de fixações e a duração da fixação [Dix-2004].

$\mathrm{O}$ equipamento eye tracker original é considerado inapropriado para testes de usabilidade, pois possui um procedimento invasivo, onde um tampão de olho é associado à córnea sobre a ação de um anestésico. Já os sistemas modernos têm pouco ou nenhum contato entre o equipamento e o participante, alguns usam uma câmera 
montada na cabeça para monitorar o olho e outros, mais sofisticados, possuem a câmera e outros recursos auxiliares apoiados sobre algum móvel.

A técnica eye tracking para testes de usabilidade ainda é muito recente e o equipamento muito caro para uso diário. No entanto, é uma técnica promissora para prover percepções no que realmente atrai o olho e identificar onde estão as áreas problemáticas no uso do sistema. Com os avanços tecnológicos de hardware e software, o equipamento de eye tracking vem se tornando cada vez mais eficaz para mensurar a usabilidade, pois possui um controle mais rápido e preciso, permitindo produzir um grande volume de dados. Mas ainda é preciso saber interpretar com mais precisão o significado das várias medidas do movimento do olho, bem como desenvolver equipamentos mais acessíveis e robustos. Porém, dado o potencial em obter dados mensuráveis, provavelmente, em poucos anos, o eye tracking se tornará parte integrante do equipamento padrão para uso em laboratórios de usabilidade.

\section{Medidas fisiológicas}

A resposta emocional do usuário é estritamente relacionada com as mudanças fisiológicas durante a sua interação com o sistema. Essas mudanças incluem o ritmo do coração, a respiração e a secreção da pele. Medir a resposta fisiológica pode ser útil para determinar a resposta emocional do usuário com a interface. Conseqüentemente, é possível determinar quais eventos da interação realmente causam um estresse no usuário e quais são relaxantes. As medidas fisiológicas envolvem investigar as seguintes atividades do usuário [Dix-2004]:

- Atividades do coração: indicada pela pressão, volume e pulso do sangue. Podem responder pelo estresse ou irritação;

- Atividades das glândulas sudoríferas: indicada pela resistência da pele ou pela resposta galvânica da pele (GSR-Galvanic Skin Response). Determinam os níveis de agitação e do esforço mental;

- Atividades elétricas nos músculos: medida obtida por meio do exame de eletromiografia (EMG - Electromyogram). Refletem o envolvimento em uma tarefa; e 
- Atividades elétricas no cérebro: medida obtida utilizando-se exame de eletroencefalograma (EEG - Electroencephalogram). Estão associadas com a decisão a tomar, atenção e motivação.

As medidas obtidas não são suficientemente claras para determinar a relação existente entre os eventos. Por exemplo, um aumento na taxa de pulsação durante uma tarefa interativa pode indicar uma frustração com a interface, bem como um estresse pela incapacidade de completar a tarefa. As mudanças fisiológicas diferem na resposta de eventos distintos, sendo difícil mapear os padrões de medidas fisiológicas para especificar um estado emocional. Assim sendo, essas questões ainda precisam ser mais investigadas, mas a abordagem é bastante interessante, oferece um significado potencial de capturar informação objetiva sobre o estado emocional do usuário e o impacto causado na usabilidade para solucionar problemas ao executar tarefas.

\subsection{Comparação dos métodos}

Cada método apresentado para avaliar sistemas interativos possui seus pontos fortes e fracos. Para cada aplicação é necessária uma comparação minuciosa para identificar qual método mais se aproxima do contexto de uso e os requisitos necessários em questão. Na Tabela 3.1 é apresentada uma comparação dos métodos de inspeção de usabilidade baseados no julgamento de especialistas e nos testes de usabilidade por meio da participação do usuário, salientando suas potencialidades e limitações. 
Tabela 3.1: Comparação dos métodos de inspeção de usabilidade e testes de usabilidade.

\begin{tabular}{|c|c|c|}
\hline & Potencialidades & Limitações \\
\hline $\begin{array}{l}\text { Inspeção de } \\
\text { usabilidade }\end{array}$ & $\begin{array}{l}\text { - Pode ser aplicada em qualquer fase do } \\
\text { desenvolvimento do sistema, esteja } \\
\text { implementado ou não. } \\
\text { - Eficiente em detectar erros e } \\
\text { problemas potenciais de usabilidade. } \\
\text { - Fornece resultados rápidos e } \\
\text { evidências concretas de quais } \\
\text { aspectos da interface apresentam } \\
\text { problemas. } \\
\text { Considerado relativamente barato, } \\
\text { pois não requer a participação de } \\
\text { usuários e nem a criação de } \\
\text { laboratório de usabilidade } \\
\text { especializado. } \\
\text { Geralmente apresenta recomendações } \\
\text { para mudanças ou orientações para o } \\
\text { re-design. }\end{array}$ & $\begin{array}{l}\text { - Geralmente usado para detectar } \\
\text { problemas, em vez de se preocupar } \\
\text { em melhorar a interface. } \\
\text { - Baseada no julgamento de } \\
\text { especialistas, não envolvendo a } \\
\text { presença de usuários reais. } \\
\text { - Geralmente os processos de } \\
\text { aprendizagem são custosos, pois } \\
\text { exigem um conhecimento avançado } \\
\text { do avaliador. } \\
\text { Tende a ter uma subjetividade na } \\
\text { avaliação, pois os resultados } \\
\text { dependem da opinião dos avaliadores. }\end{array}$ \\
\hline $\begin{array}{l}\text { Testes de } \\
\text { usabilidade }\end{array}$ & $\begin{array}{l}\text { - Podem ser úteis para extrair detalhes } \\
\text { do ponto de vista do usuário em } \\
\text { relação ao sistema. } \\
\text { - Avaliam a qualidade global da } \\
\text { interface por meio de medidas de } \\
\text { desempenho. } \\
\text { - Podem obter medidas qualitativas e } \\
\text { quantitativas. } \\
\text { - Podem ser eficientes para extrair } \\
\text { informações sobre as preferências do } \\
\text { usuário, suas impressões e atitudes. } \\
\text { - Não contém um grau de subjetividade } \\
\text { devido à opinião dos avaliadores, uma } \\
\text { vez que, o que é analisado } \\
\text { corresponde em exemplos práticos e } \\
\text { não simulações ou suposições. }\end{array}$ & $\begin{array}{l}\text { - É necessária a existência de uma } \\
\text { implementação real do sistema. } \\
\text { - São considerados caros, pois } \\
\text { requerem a participação de usuários } \\
\text { e são empreendidos em laboratórios } \\
\text { especializados ou no próprio } \\
\text { ambiente de trabalho. } \\
\text { - Podem prover muitos dados para } \\
\text { analisar e, conseqüentemente, podem } \\
\text { consumir muito tempo. } \\
\text { - Nem sempre é possível interpretar } \\
\text { com precisão o significado dos vários } \\
\text { tipos de medidas. } \\
\text { - Uso de equipamentos caros, como } \\
\text { câmera de vídeo e áudio ou } \\
\text { eye tracking. } \\
\text { alocados em um determinado período } \\
\text { de tempo para a aplicação do teste. }\end{array}$ \\
\hline
\end{tabular}




\subsection{Considerações finais}

Este capítulo descreve as principais técnicas de interação humano-computador que podem ser aplicadas para avaliar a funcionalidade e a usabilidade de sistemas. São apresentados métodos tradicionais de inspeção de usabilidade baseados no julgamento de especialistas e também testes de usabilidade por meio da participação do usuário real.

Dentre os métodos mais utilizados inclui-se a avaliação heurística e o percurso cognitivo, pois são eficientes em detectar erros e problemas potenciais de usabilidade. No entanto, os métodos mais representativos para avaliar a interface e que apresentam melhores resultados práticos são os testes com o usuário. Os métodos de inspeção de usabilidade provêm informações de usabilidade de maneira mais rápida e barata comparada aos testes de usabilidade. Na prática, deve-se também considerar o fator econômico e analisar cuidadosamente a relação custo-benefício na escolha do método a ser empregado. Experimentos controlados dependem da criação de laboratórios de usabilidade para testes e, geralmente, são muito caros e por esse motivo são pouco utilizados.

Cada projeto requer um modo diferente de avaliação para ser empregada dentro do seu próprio contexto, conseqüentemente, a escolha do método mais apropriado implica em um estudo detalhado de cada design. Em geral, uma ou mais técnicas são adotadas para atender às necessidades específicas da interface a ser avaliada. 



\section{Capítulo}

4

\section{Material e Métodos}

\subsection{Material}

Para organizar e planejar uma avaliação é necessário reunir o material a ser utilizado, que consiste em estabelecer o que, quem, quando e onde avaliar [Stone-2005]. Para isso, o material deve ser especificado de acordo com os seguintes requisitos:

- Domínio: representa a área de conhecimento dos especialistas em relação à aplicação desenvolvida. Pode ser descrito usando conceitos particulares que realçam os aspectos relevantes do ambiente de trabalho, considerando o conhecimento das necessidades dos usuários para executar suas tarefas e alcançar seus objetivos.

- Propósito: refere-se ao objetivo para empreender uma avaliação. Cada projeto de interface possui um objetivo diferente e cada qual requer um modo diferente de avaliação.

- Artefato físico: refere-se ao produto, sistema ou protótipo que será testado. Usualmente, as avaliações são empreendidas em protótipos, que são considerados como parte essencial do projeto e seu desenvolvimento. Os protótipos podem ser classificados em dois tipos: de baixa-fidelidade, baseados em papel, que provêm uma avaliação limitada e não demonstram a funcionalidade do sistema, ou de alta-fidelidade, como um software interativo, que provêm uma avaliação mais detalhada por envolver uma interação dos usuários.

- Usuários: são as pessoas que usam a aplicação como base para seu trabalho. É importante conhecer para quem a aplicação está sendo desenvolvida e o 
que os usuários desejam da aplicação. Primeiramente, deve-se identificar quem são os usuários reais do sistema, saber o que eles fazem, como trabalham e onde trabalham. Depois deve-se descobrir o que eles querem que o sistema faça a fim de identificar suas necessidades.

- Dados: são resultados coletados na avaliação que podem ser usados de maneiras diferentes para auxiliar a tomada de decisões sobre o re-design da interface do usuário. Os dados podem ser numéricos e não-numéricos. Dados numéricos provêm medidas referentes ao desempenho e atitudes dos usuários para avaliar a eficiência e produtividade de um sistema e para comparar alternativas de design. Dados sem um conteúdo numérico podem ser obtidos por meio de uma lista de problemas e opiniões dos usuários em relação ao uso da interface, que resultam em sugestões para modificações, com intuito de melhorar a interação do design.

- Tarefas: referem-se às atividades relacionadas à natureza do trabalho. Consiste em interagir fisicamente com o dispositivo para executar uma série de ações estruturadas e relacionadas, que são empreendidas em alguma seqüência para alcançar um objetivo. Tem a finalidade de obter um entendimento do que o sistema de computador deve fazer e da funcionalidade provida para apoiar os usuários nos seus objetivos.

- Considerações ambientais: são fatores relacionados ao ambiente em que a aplicação será empreendida. Deve ser observado o que os usuários reais fazem, como eles desempenham seu trabalho e quais as condições em que eles trabalham. É importante conhecer onde o trabalho é realizado e observar o ambiente como um todo, considerando o aspecto físico, que relaciona o tipo de ambiente que será usado o sistema; o aspecto social, como as pessoas interagem ou compartilham as tarefas; o aspecto organizacional referente à hierarquia e às diferentes maneiras de trabalhar; e o ambiente de apoio ao usuário, que consiste na disponibilidade de materiais e pessoas para auxiliar o usuário.

- Restrições: consiste nas limitações em relação ao custo, tempo, tecnologia e recursos humanos que devem ser consideradas para realizar uma avaliação. 
Esse é um fator importante que afeta diretamente o processo de avaliação e também ajuda a priorizar os requisitos de usabilidade que são mais importantes para a avaliação.

Todos esses requisitos a respeito da elaboração de uma estratégia de avaliação devem ser traduzidos para refletir o contexto de uso do estudo de caso. A Tabela 4.1 apresenta uma visão dos principais requisitos e a informação obtida a fim de especificar o domínio da aplicação do estudo em questão, os usuários, suas tarefas e o ambiente dentro do contexto em que o sistema será usado.

Tabela 4.1: Requisitos da avaliação traduzidos para o contexto de uso.

\begin{tabular}{|c|c|}
\hline Requisitos & Informação obtida \\
\hline Domínio & $\begin{array}{l}\text { - Um sistema CBIR aplicado à medicina, visando auxiliar o processo de } \\
\text { diagnóstico médico. }\end{array}$ \\
\hline Propósito & $\begin{array}{l}\text { - Tem o objetivo de determinar se as tarefas dos usuários são suportadas e quais } \\
\text { os problemas de usabilidade podem ser encontrados no design. }\end{array}$ \\
\hline Artefato físico & $\begin{array}{l}\text { - Protótipo de alta-fidelidade: utilização do protótipo MRI Browser, desenvolvido } \\
\text { pelo GBdl da USP, que consiste de um navegador para consulta e recuperação } \\
\text { de imagens médicas. }\end{array}$ \\
\hline Usuários & - Usuários reais: médicos radiologistas e residentes. \\
\hline $\begin{array}{l}\text { Características } \\
\text { dos usuários }\end{array}$ & $\begin{array}{l}\text { - } \text { Idade: jovens, adultos e idosos. } \\
\text { - Limitação física: pode ser totalmente sadio, isto é, fisicamente apto ou pode } \\
\text { ter algumas limitações físicas como audição ou visão e mobilidade no uso das } \\
\text { mãos. Pode ter altura variada. } \\
\text { - Formação educacional: qualificação na área médica. } \\
\text { - Experiência em informática: pode ter pouca ou nenhuma experiência prévia } \\
\text { em informática. } \\
\text { - Motivação: pode ter muita motivação para usar o sistema, considerando a } \\
\text { necessidade de aprendizagem e poder realizar suas atividades diárias } \\
\text { rapidamente, ou não ter nenhuma motivação, preferindo fazer tudo manual à } \\
\text { moda antiga. } \\
\text { Atitudes: podem variar, dependendo dos serviços do sistema oferecidos e da } \\
\text { confiança na tecnologia. }\end{array}$ \\
\hline
\end{tabular}


Tabela 4.1: Requisitos da avaliação traduzidos para o contexto de uso (continuação).

\begin{tabular}{|c|c|}
\hline Requisitos & Informação obtida \\
\hline Dados & $\begin{array}{l}\text { - Os dados coletados devem medir o desempenho (eficiência e eficácia) e } \\
\text { satisfação do usuário, portanto devem ser considerados tanto dados } \\
\text { quantitativos como qualitativos. }\end{array}$ \\
\hline Tarefas & $\begin{array}{l}\text { - Consiste em executar atividades relacionadas à busca por imagens similares a } \\
\text { uma dada imagem de referência. }\end{array}$ \\
\hline $\begin{array}{l}\text { Características } \\
\text { das Tarefas }\end{array}$ & $\begin{array}{l}\text { - Aarefas fáceis e inusitadas. } \\
\text { - Areqüente. } \\
\text { - A tarefa tem tempo critico, pois geralmente o uso do sistema é executado } \\
\text { durante uma consulta médica com horários agendados, possuindo um tempo } \\
\text { relativamente curto. A consulta deve permitir tempo para o profissional realizar } \\
\text { exames físicos, conversar com o paciente, checar seu histórico médico, bem } \\
\text { como usar o sistema para auxiliar o diagnóstico. } \\
\text { - Geralmente, o trabalho é executado sozinho, por um único médico durante uma } \\
\text { consulta. Porém, o trabalho pode ser realizado com a atuação de uma equipe } \\
\text { médica para obter um consenso no diagnóstico acerca de alguns casos críticos. } \\
\text { Os usuários normalmente intercalam entre várias tarefas. Usualmente, os } \\
\text { médicos examinam os pacientes, fazem anotações enquanto realizam as } \\
\text { consultas, formulam o prontuário médico, checam históricos médicos, etc. } \\
\text { - A tarefa não varia de uma ocasião para outra. Os mesmos procedimentos são } \\
\text { utilizados para procurar uma imagem independente do formato da imagem, da } \\
\text { - Aua classificação ou do tipo de exame gerado por equipamentos médicos. } \\
\text { - Aão há risco de segurança no uso do sistema CBIR. No entanto, deve ter muita } \\
\text { cautela ao interpretar as imagens para obter um diagnóstico seguro e efetivo. } \\
\text { reconhecer as ações ao invés de lembrá-las. } \\
\text { possuindo interferência de fatores externos como o sol ou chuva incidindo } \\
\text { diretamente na máquina. }\end{array}$ \\
\hline Local & $\begin{array}{l}\text { - A avaliação pode ser empreendida em estudos de laboratório ou estudos de } \\
\text { campo. Os estudos de campo devem ser conduzidos no próprio ambiente em } \\
\text { que os usuários trabalham, enquanto que os estudos de laboratório devem ser } \\
\text { conduzidos em algum outro local que simule o ambiente real de trabalho. }\end{array}$ \\
\hline
\end{tabular}


Tabela 4.1: Requisitos da avaliação traduzidos para o contexto de uso (continuação).

\begin{tabular}{|c|c|}
\hline Requisitos & Informação obtida \\
\hline Ambiente físico & $\begin{array}{l}\text { - Iluminação e temperatura ambiente confortável. } \\
\text { - Ambiente limpo e sem barulho. } \\
\text { - Sala individual com boa acomodação para o usuário e o computador. } \\
\text { - Não há necessidade de roupa especial. } \\
\text { - Não há riscos de saúde e segurança no ambiente de trabalho. }\end{array}$ \\
\hline Ambiente social & - Usuários trabalham sozinhos ou em cooperação com uma equipe médica. \\
\hline $\begin{array}{l}\text { Ambiente } \\
\text { organizacional }\end{array}$ & - Integração do trabalho humano com artefatos tecnológicos. \\
\hline $\begin{array}{l}\text { Ambiente de apoio } \\
\text { ao usuário }\end{array}$ & $\begin{array}{l}\text { - Manuais de referência on-line. } \\
\text { - Auxílio de especialistas para orientar novos usuários. }\end{array}$ \\
\hline Restrições & $\begin{array}{l}\text { - Dinheiro: limitado, com recursos restritos. } \\
\text { - Tempo: limitado. } \\
\text { - Equipamentos de hardware e software: notebook com o protótipo MRI } \\
\text { Browser instalado. } \\
\text { - Equipamentos de usabilidade: equipamento de vídeo (filmadora) para ter um } \\
\text { registro permanente das sessões de avaliação. } \\
\text { - Recursos humanos: inspetores especialistas em usabilidade e sobre o domínio } \\
\text { do sistema, recrutador, facilitador que conduzirá a avaliação e participantes } \\
\text { representantes do usuário real. }\end{array}$ \\
\hline
\end{tabular}

\subsection{Métodos}

No capítulo anterior foi apresentada uma variedade de técnicas e métodos disponíveis para avaliar sistemas interativos. Cada método possui suas potencialidades e limitações e cada qual tem sua utilidade quando aplicado adequadamente.

Para selecionar o método mais apropriado, que atenda às necessidades particulares, é necessário considerar os seguintes fatores para categorizar os diferentes métodos [Dix-2004]:

- Fase: é a etapa do ciclo de desenvolvimento em que a avaliação será realizada. É sempre desejável que o processo de avaliação se estabeleça em todas as fases de desenvolvimento. Porém, a avaliação pode ser empreendida na fase de projeto ou implementação, dependendo da existência ou não de um artefato físico. 
- Estilo: refere-se ao tipo de estudo que será empreendido na avaliação, podem ser estudos de laboratório ou de campo. As medidas obtidas em estudos de campo apresentam a situação real do trabalho como base para a avaliação de usabilidade de um produto, enquanto que as medidas obtidas em laboratório podem avaliar um aspecto particular do produto e oferece um controle maior sobre as variáveis de interesse e podem prover medidas mais precisas.

- Nível de objetividade: baseia-se fortemente na interpretação do avaliador. As técnicas mais subjetivas têm como base o conhecimento e experiência do avaliador, que deve saber identificar os problemas e compreender o comportamento do usuário. No entanto, as técnicas objetivas produzem resultados independentes da persuasão do avaliador, evitam tendência e provêm resultados que podem ser comparados.

- Medidas: podem ser quantitativas e qualitativas. As medidas quantitativas são freqüentemente numéricas e podem ser analisadas facilmente usando técnicas estatísticas. Por outro lado, as medidas qualitativas não possuem resultados numéricos e por esse motivo são consideradas mais difíceis de analisar. Contudo, provêm detalhes importantes que não podem ser determinados numericamente. Os tipos de medidas estão relacionados com as técnicas subjetivas e objetivas. Geralmente, técnicas subjetivas tendem a prover medidas qualitativas e técnicas objetivas provêm medidas quantitativas. Porém, às vezes, também é possível quantificar a informação qualitativa mapeando em uma escala ou usando medidas similares.

- Informação: pode ser de baixo ou alto nível. Uma informação de baixo nível pode requerer, por exemplo, a escolha da fonte de letra a ser usada, enquanto que uma informação de alto nível pode determinar quanto o sistema é usável. Informações de alto nível podem prover uma impressão geral da visão do sistema pelo usuário ou medir um aspecto particular da interface.

- Recursos: são equipamentos de hardware e software, equipamentos de gravação de vídeo e áudio, tempo, dinheiro, tecnologia, participantes, experiência do avaliador, o contexto, entre outros. É a consideração final para selecionar uma técnica de avaliação. Algumas decisões são forçadas 
pela limitação de recursos. Nestas circunstâncias, o avaliador deve decidir qual a tática de avaliação que produzirá informação mais efetiva e útil para o sistema em consideração.

Na Tabela 4.2 é apresentado um exemplo da categorização de algumas técnicas para auxiliar a escolha do método. É mostrado um exemplo de cada tipo de técnica: analítica, experimental, observacional, questionamento, interpretativa e monitoração.

Tabela 4.2: Categorização de algumas técnicas de avaliação, adaptado de Dix et al. (2004).

\begin{tabular}{|c|c|c|c|c|c|c|}
\hline & $\begin{array}{l}\text { Técnica } \\
\text { analítica }\end{array}$ & $\begin{array}{c}\text { Técnica } \\
\text { experimental }\end{array}$ & $\begin{array}{c}\text { Técnica } \\
\text { observacional }\end{array}$ & $\begin{array}{c}\text { Técnica de } \\
\text { questionamento }\end{array}$ & $\begin{array}{c}\text { Técnica } \\
\text { interpretativa }\end{array}$ & $\begin{array}{l}\text { Técnica de } \\
\text { monitoração }\end{array}$ \\
\hline & $\begin{array}{l}\text { Avaliação } \\
\text { heurística }\end{array}$ & $\begin{array}{l}\text { Métodos } \\
\text { empíricos }\end{array}$ & Think aloud & Questionários & Etnografia & Eye tracking \\
\hline Fase & $\begin{array}{l}\text { Todas as } \\
\text { fases }\end{array}$ & $\begin{array}{l}\text { Todas as } \\
\text { fases }\end{array}$ & Implementação & $\begin{array}{l}\text { Todas as } \\
\text { fases }\end{array}$ & $\begin{array}{l}\text { Todas as } \\
\text { fases }\end{array}$ & Implementação \\
\hline Estilo & Laboratório & Laboratório & $\begin{array}{l}\text { Laboratório e } \\
\text { Campo }\end{array}$ & $\begin{array}{l}\text { Laboratório e } \\
\text { Campo }\end{array}$ & Campo & Laboratório \\
\hline $\begin{array}{l}\text { Nível de } \\
\text { objetividade }\end{array}$ & Subjetiva & Objetiva & Subjetiva & $\begin{array}{l}\text { Subjetiva e } \\
\text { Objetiva }\end{array}$ & Objetiva & Objetiva \\
\hline Medidas & Qualitativa & Quantitativa & Qualitativa & $\begin{array}{l}\text { Qualitativa e } \\
\text { Quantitativa }\end{array}$ & Quantitativa & Quantitativa \\
\hline Informação & Alto nível & $\begin{array}{l}\text { Alto e Baixo } \\
\text { nível }\end{array}$ & $\begin{array}{l}\text { Alto e Baixo } \\
\text { nível }\end{array}$ & Alto nível & $\begin{array}{l}\text { Alto e Baixo } \\
\text { nível }\end{array}$ & Baixo nível \\
\hline Recursos & Baixo & Médio & Baixo & Baixo & Alto & Alto \\
\hline
\end{tabular}

Normalmente, é escolhida uma única técnica quando busca-se analisar somente um aspecto do design de interface do usuário. Porém, dependendo do contexto de uso, pode-se usar uma combinação de técnicas complementares, conduzindo-se, assim, duas ou mais avaliações.

Considerando a especificação dos requisitos para a avaliação e os fatores utilizados para categorizar as técnicas de avaliação, foi possível selecionar as que mais se adaptam no contexto e propósito do estudo de caso em questão.

Para atender às necessidades particulares desse estudo, foi adotada uma combinação de técnicas de avaliação, consistindo de uma técnica de inspeção de usabilidade e agregando com testes de usabilidade a fim de determinar se as tarefas dos 
usuários são suportadas e quais os problemas de usabilidade podem ser encontrados no design.

Dentre as técnicas de inspeção de usabilidade, a avaliação heurística foi escolhida por ser uma das técnicas mais populares e eficientes em detectar problemas potenciais de usabilidade, e também por ser uma técnica intuitiva, fácil e rápida de ser ensinada, além de possuir baixo custo.

No entanto, por não envolver usuários reais ou representativos, em geral, é fácil cometer erros em predizer como os usuários reais lidam com a interface. Visando minimizar essa limitação, a avaliação deverá ser complementada pela técnica de observação do usuário que apresenta bons resultados práticos de testes com o usuário real.

As técnicas de inspeção heurística e observação do usuário têm o mesmo objetivo de estabelecer se o sistema é usável, porém têm algumas diferenças na maneira de preparar e conduzir a avaliação. Freqüentemente, a inspeção heurística pode ajudar a tomar cuidado com defeitos de usabilidade mais óbvios, enquanto que a observação do usuário empreendida após a inspeção pode ser efetivamente mais útil em focar problemas da perspectiva do usuário. Conseqüentemente, as duas técnicas devem ser vistas como um complemento para avaliação.

\subsection{Considerações finais}

Neste capítulo é descrito o material a ser utilizado no processo de avaliação e os fatores que influenciaram na escolha do método. A partir da especificação dos requisitos necessários para a avaliação, foram selecionados os métodos mais apropriados para compor o estudo em questão. Esse estudo deverá empreender uma combinação de técnicas de avaliação, iniciando com a inspeção heurística, que é conduzida por meio do julgamento de especialistas, seguida pela técnica de observação de usuário, com a participação efetiva de usuários reais. 


\section{Capítulo}

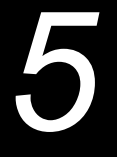

\section{Estudo de caso}

Esse estudo de caso propõe uma análise e avaliação da interação humano-computador em um sistema aplicado à medicina para auxiliar o processo de diagnóstico médico. Para compor o estudo, será apresentado a seguir o domínio da aplicação, o protótipo utilizado no processo de avaliação e a condução da avaliação heurística e a observação do usuário.

\subsection{Sistema CBIR aplicado à medicina}

A medicina tem sido uma das áreas mais beneficiadas com o uso de técnicas de CBIR. Os Sistemas de Informação Hospitalares (SIH) foram elaborados para armazenar informações textuais a respeito dos pacientes, tais como o histórico médico, as doenças e procedimentos adotados, permitindo que os médicos acessem esses dados de modo imediato.

Com a introdução dos sistemas PACS (Picture Archiving and Communication Systems), ampliou-se à possibilidade de se armazenar de modo integrado as imagens médicas dos pacientes, provenientes de exames gerados por equipamentos médicos, tal como Ressonância Magnética (RM), Tomografia Computadorizada (CT), Medicina Nuclear (MN), etc. A Figura 5.1 apresenta alguns exemplos de imagens radiológicas.

Os sistemas PACS lidam com grandes conjuntos de imagens, baseados no formato DICOM (Digital Imaging and COmmunications in Medicine), que são armazenados e classificados por conjuntos individualmente etiquetados para cada imagem, constituindo da identificação de sua aquisição, dados do paciente e outros dados pertinentes. Os sistemas de armazenamento e comunicação de imagens estão descritos mais detalhadamente no Anexo I. 


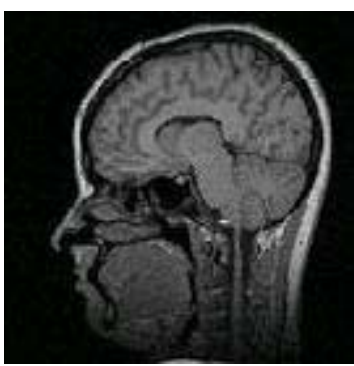

Corte sagital da cabeça

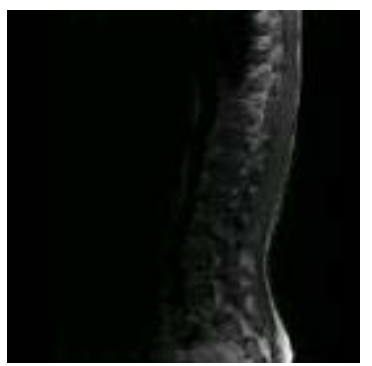

Corte sagital da espinha

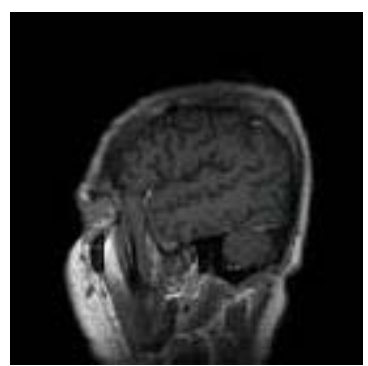

Corte sagital da cabeça

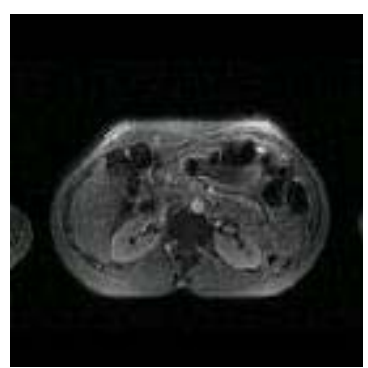

Corte axial da bacia

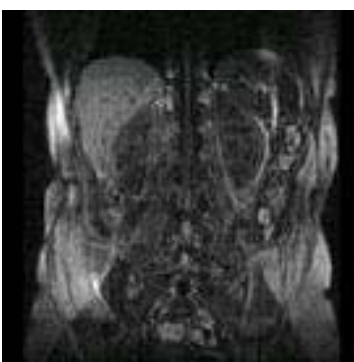

Corte coronal do abdômen

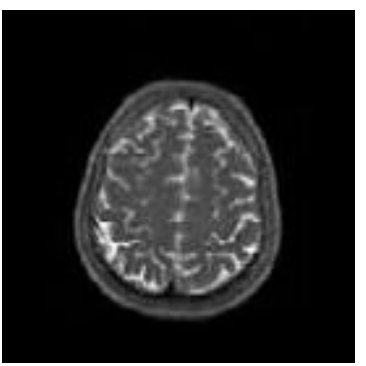

Corte axial da cabeça

Figura 5.1: Exemplos de imagens de Ressonância Magnética (RM), adaptado de Castañon (2003a, p.55).

Os PACS possibilitaram a integração de todas as informações dos pacientes dentro do ambiente hospitalar, sendo possível associar e recuperar rapidamente as imagens disponíveis para consulta logo após a realização dos exames. Desse modo, os diagnósticos são efetuados utilizando as descrições textuais e tendo o apoio visual das imagens dos exames médicos.

Nesses sistemas, as consultas tradicionais são efetuadas considerando algum critério de filtragem, baseado em igualdade e ordem dos dados, constituídos, basicamente, por cadeias de caracteres, valores numéricos e data. O critério de igualdade é caracterizado pela obtenção de dados exatamente coincidentes e a ordem pelo interesse em organizar dados maiores ou menores que um valor fornecido. Um exemplo simples desse tipo de consulta seria "obter a imagem de um exame de raio-X efetuado sobre um determinado paciente". Quando uma consulta solicita uma imagem como resposta, a busca deve ser efetuada baseada nos valores de identificação textual das etiquetas das imagens. Porém, esse enfoque não é adequado para executar operação de recuperação de imagens por conteúdo, pois para cada requisição de um subconjunto de imagens é necessária uma leitura seqüencial de todo o conjunto de imagens.

Para auxiliar o médico nos sistemas de suporte a diagnóstico é importante cruzar diagnósticos previamente realizados e comparar imagens de exames de pacientes 
diferentes, ou mesmo, encontrar imagens semelhantes a partir de uma imagem de referência, como realizar consultas do tipo "obter as dez imagens mais semelhantes à imagem de exame de raio-X de um determinado paciente". A Figura 5.2 ilustra um protótipo de um sistema que apresenta o resultado de uma consulta com as imagens mais similares a uma imagem solicitada, utilizando características extraídas por Wavelets.

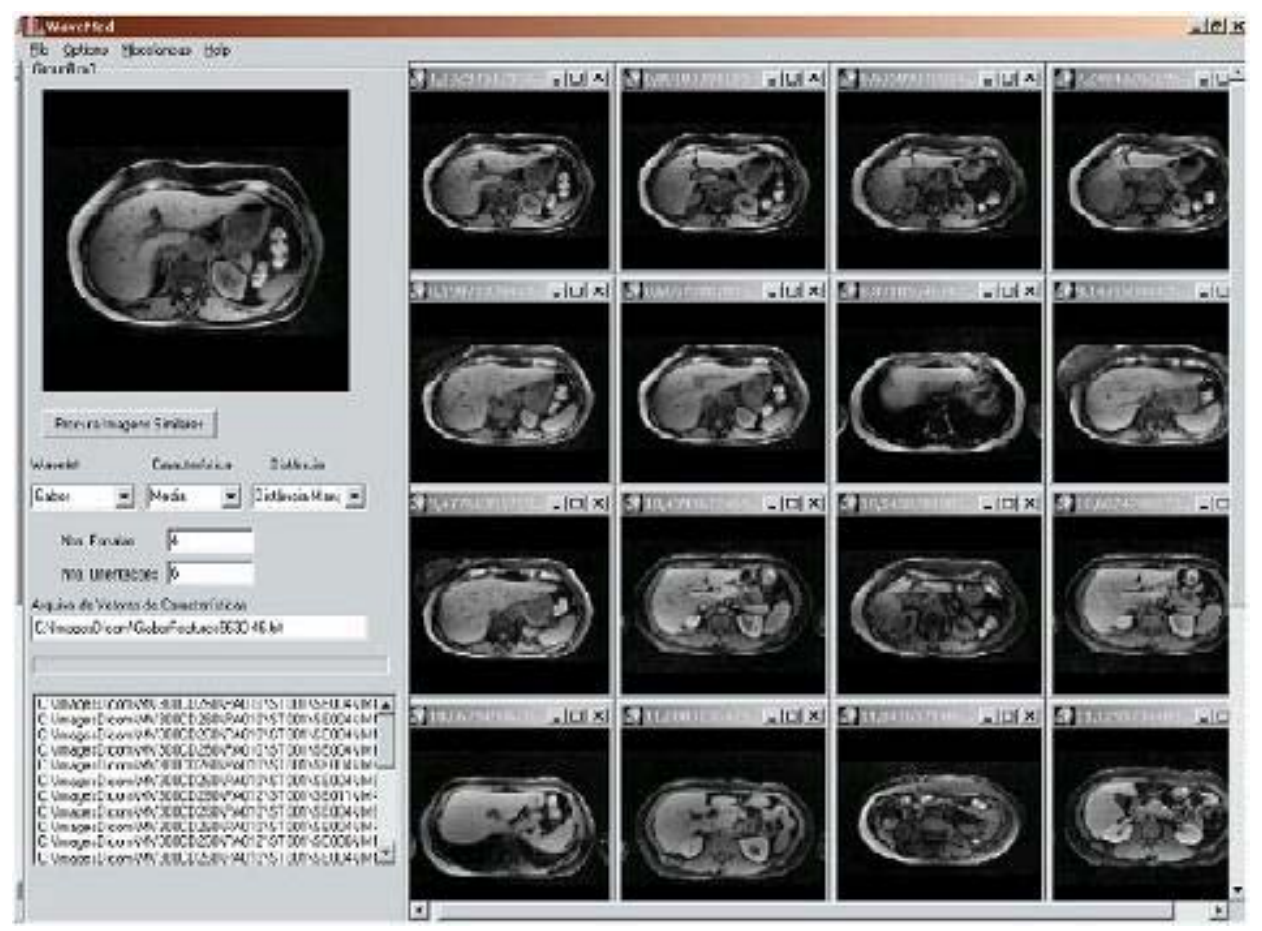

Figura 5.2: Resultado de uma consulta com as imagens mais similares [Castañón-2003a, p.93].

Para análises médicas é interessante recuperar imagens que são similares a uma dada imagem, ou seja, quando um médico necessita comparar casos anteriores ou verificar o diagnóstico efetuado. Não faz sentido realizar consultas como “obter o cadastro dos pacientes com tumor no cérebro cuja tomografia seja igual à do paciente em estudo", pois dificilmente imagens de dois exames médicos serão exatamente iguais, mesmo se as anomalias tiverem a mesma classificação. Assim, é muito mais interessante realizar consultas do tipo "obter o cadastro dos pacientes com tumor no cérebro cuja tomografia seja bastante similar à do paciente em estudo".

Nesses casos, o critério mais adequado para ser usado é o da semelhança, que utiliza como chave de busca a própria imagem. A partir de uma certa imagem, é 
efetuada uma pesquisa na base de imagens para encontrar as que são mais semelhantes ou mais similares por meio de alguns critérios adotados. Uma imagem é considerada um tipo de dado complexo ou não convencional, pois é estruturalmente mais sofisticada e depende de características dela extraídas para ser buscada, indexada e comparada. Desse modo, a comparação da similaridade existente entre esse tipo de dado leva em consideração o significado do conteúdo que as melhor representem. Assim, as imagens devem ser eficientemente armazenadas e recuperadas por técnicas específicas baseadas no conteúdo da imagem.

Porém, esse recurso de busca de imagens baseado no conteúdo e similaridade ainda não é suportado pelos atuais sistemas PACS. Para atingir esse objetivo, o GBdI vem pesquisando as potencialidades das técnicas CBIR, visando o tratamento de dados complexos em Sistemas de Gerenciamento de Bases de Dados (SGBD), incluindo as funcionalidades de armazenagem, recuperação e manipulação de imagens.

Por outro lado, o Centro de Ciências de Imagens e Física Médica (CCIFM) do Hospital das Clínicas da USP de Ribeirão Preto vem buscando o desenvolvimento de um SIH apoiado aos PACS, que atenda às necessidades do hospital.

Desse modo, a parceria entre o GBdI e o CCIFM vem reunindo esforços para o desenvolvimento de um PACS que incorpore características CBIR para propiciar um auxílio efetivo à recuperação de imagens e informações de pacientes de maneira rápida e descentralizada. A construção de um PACS com técnicas de CBIR integrado ao SIH disponibiliza, além da busca baseada em conteúdo para o auxílio a diagnósticos, um sistema completo e centralizado de informações do hospital.

\subsection{Protótipo MRI Browser}

O protótipo "MRI Browser" (Magnetic Resonance Imaging Browser) é um sistema de navegação desenvolvido pelo GBdI, que consiste em uma ferramenta útil e prática para recuperar imagens similares baseadas em seu conteúdo, utilizando-se de uma coleção de imagens de modalidade médica, visando a troca de experimentos entre pesquisadores e colaboradores.

O sistema foi desenvolvido no ambiente de programação Borland $\mathrm{C}++$ Builder, versão 6.0, utilizando a base de dados relacional MySQL como metadados das imagens. As imagens são armazenadas em um repositório, no formato PNG (Portable Network Graphics), constituindo-se de uma coleção composta de 17.239 imagens de exames de 
ressonância magnética efetuadas em 95 pacientes diferentes. Todas as imagens encontram-se no padrão DICOM e são constituídas de 8 bits (256 níveis de cinza), em tamanho de $256 \times 256$ pixels.

As imagens foram classificadas em subgrupos de categorias das diversas partes do corpo, tais como cabeça, abdômen, quadril, coluna, ombro, joelho e coxa, conforme ilustra a Figura 5.3. Os subgrupos constituem de imagens em relação à parte do corpo humano adquiridas nas orientações axial, coronal e sagital, considerando, também, a altura do corte e os parâmetros de ponderação do tempo de relaxação em T1 e T2.

\begin{tabular}{|c|c|c|c|c|c|c|}
\hline $\begin{array}{c}\text { Corte } \\
\text { axial da } \\
\text { cabeça }\end{array}$ & $\begin{array}{c}\text { Corte } \\
\text { coronal } \\
\text { da cabeça }\end{array}$ & $\begin{array}{c}\text { Corte } \\
\text { sagital da } \\
\text { cabeça }\end{array}$ & $\begin{array}{c}\text { Coluna } \\
\text { torácica }\end{array}$ & $\begin{array}{c}\text { Coluna } \\
\text { total }\end{array}$ & Quadril & Joelho \\
\hline & & & & & & \\
\hline & & & & & & \\
\hline
\end{tabular}

Figura 5.3: Exemplo de subgrupos de imagens de diversas partes do corpo humano.

O sistema MRI Browser incorpora todas as funcionalidades de um sistema CBIR e permite realizar tanto consultas textuais como por conteúdo. Primeiramente, por meio de uma janela de consulta denominada Query by Text, são efetuadas as consultas textuais para filtrar os subgrupos de interesse especificados pelo usuário, conforme mostra a Figura 5.4. 


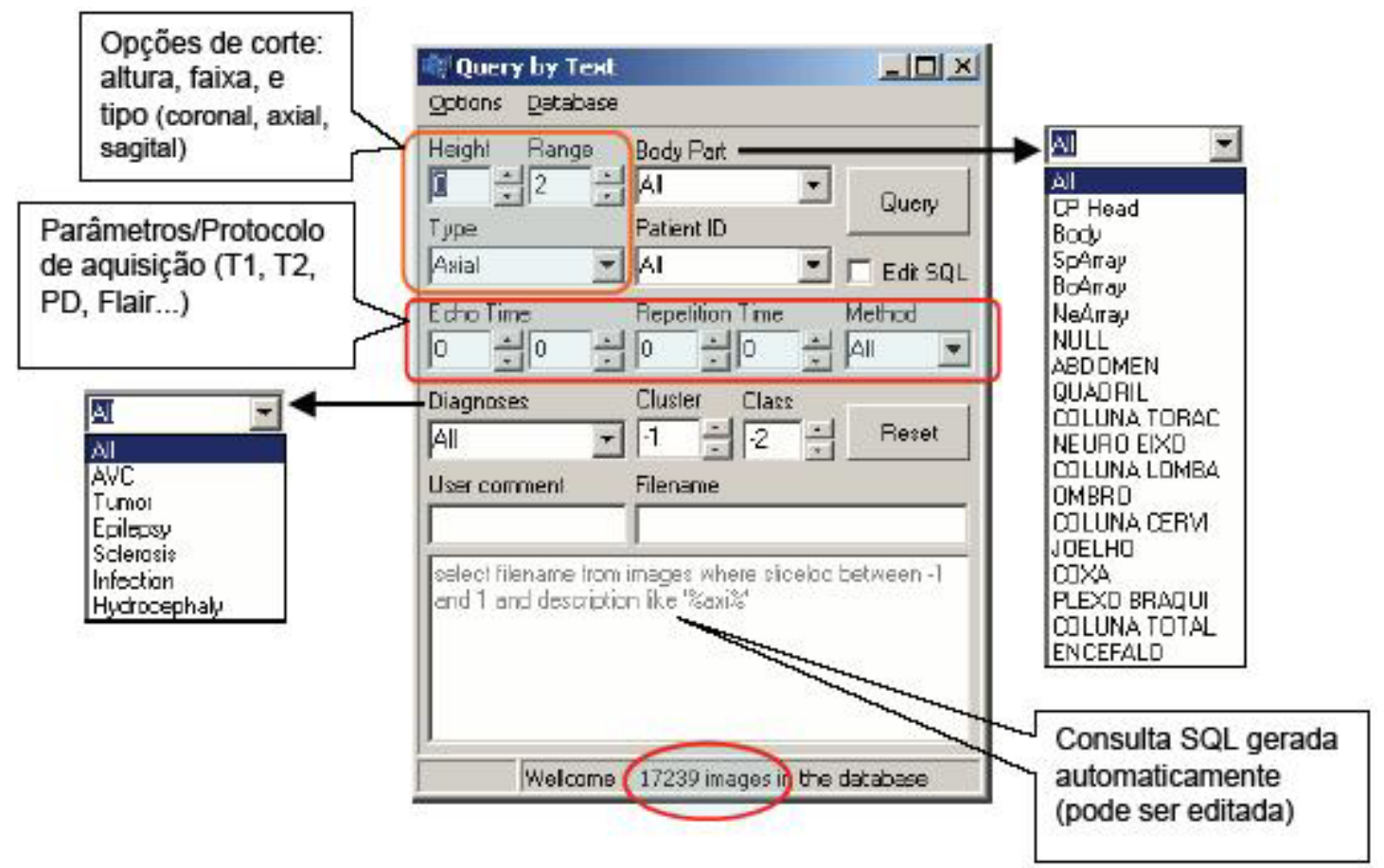

Figura 5.4: Janela de consulta Query by Text do sistema MRI Browser.

O resultado da consulta é exibido em uma janela maior, denominada Result, localizada no centro da tela, onde é apresentado um conjunto de miniaturas (thumbnails) das imagens que satisfazem os critérios da busca textual. A partir desse conjunto de thumbnails é possível selecionar uma imagem de interesse para visualizar seu tamanho original e as informações textuais disponíveis na base de dados correspondentes àquela imagem. Um exemplo de consulta textual é ilustrado na Figura 5.5, que apresenta a interface do sistema, consistindo da janela de opções de consulta Query by Text, da janela Result com os thumbnails retornados pela busca e duas imagens originais selecionadas a partir do thumbnail. 


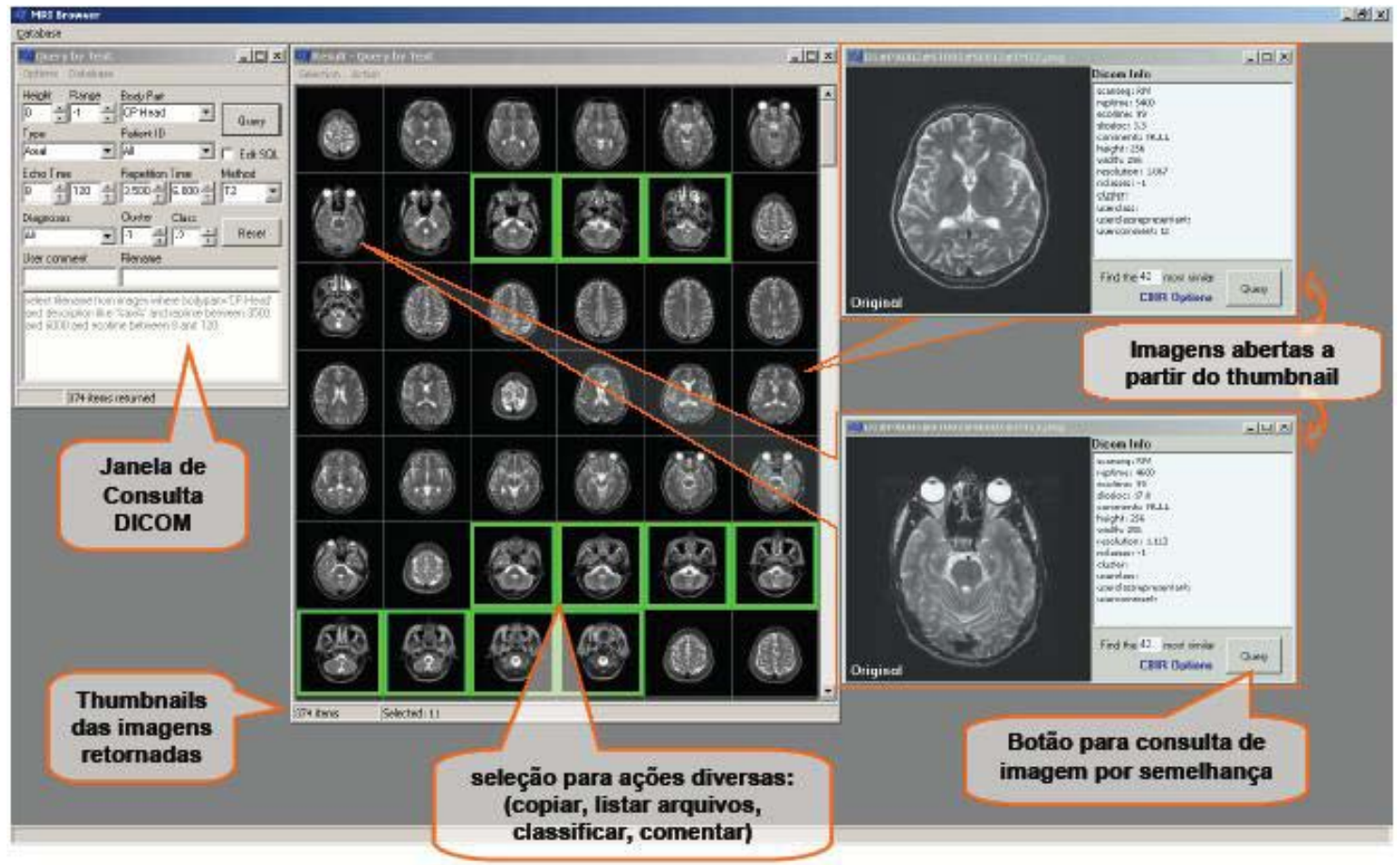

Figura 5.5: Interface do protótipo MRI Browser.

Um outro exemplo é mostrado a seguir, na Figura 5.6, que apresenta os thumbnails do resultado de uma consulta de exames realizados em um determinado paciente, considerando todos os tipos de corte em relação à sua orientação e altura.

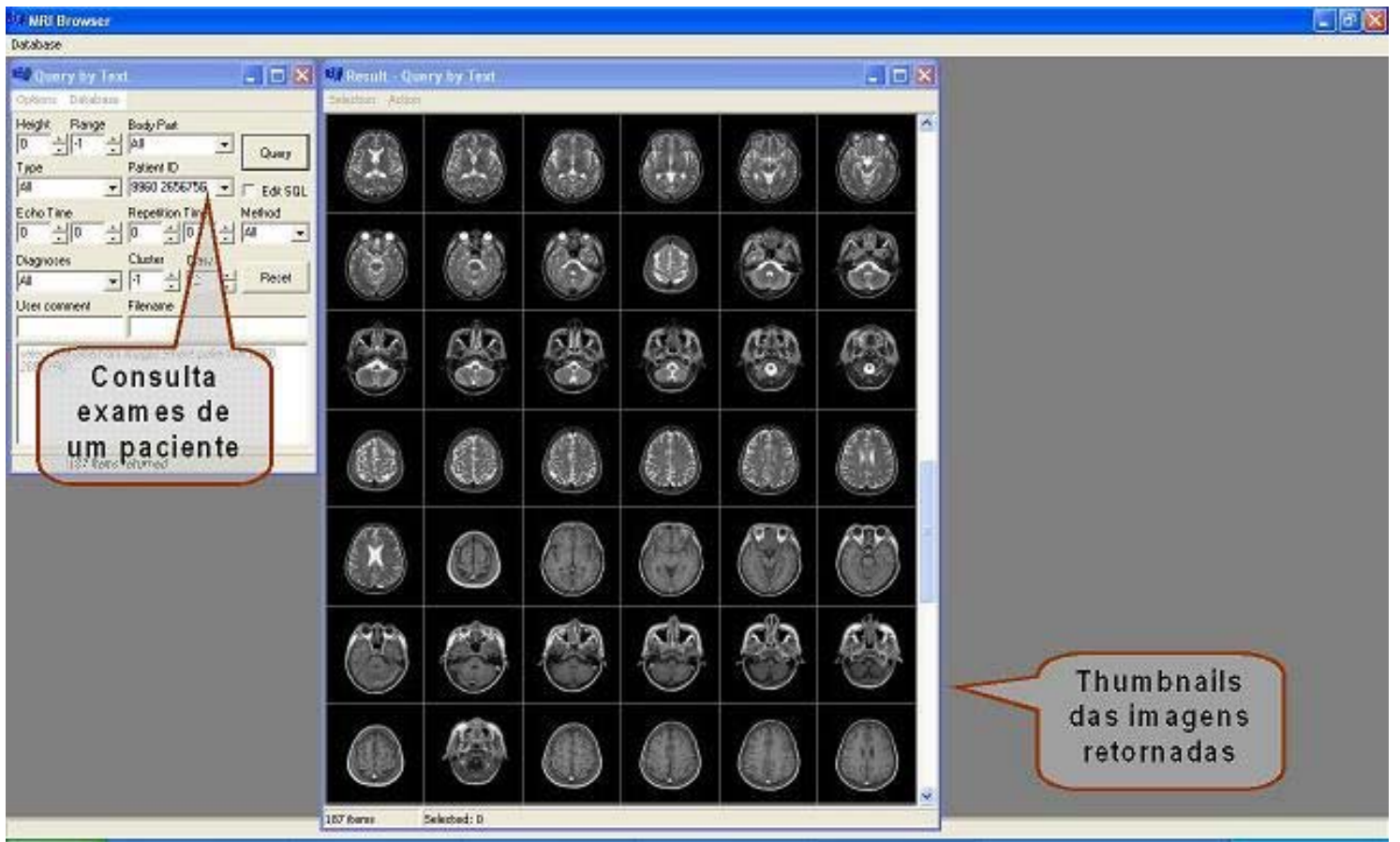

Figura 5.6: Resultado da consulta de exames de um paciente. 
Para efetuar a consulta por imagens similares, o usuário deve selecionar uma imagem de interesse como referência, especificar a quantidade de imagens similares desejadas e pressionar o botão Query para iniciar o processo de busca. O resultado é apresentado na mesma janela Result que é usada para exibir tanto os thumbnails obtidos pelo resultado da busca textual, como para retornar o resultado da consulta de imagens por similaridade. A Figura 5.7 ilustra, na janela à direita, uma imagem em seu tamanho original contendo suas informações textuais, que foi utilizada como referência para uma operação de busca das dez imagens mais semelhantes a ela. Como resultado, os thumbnails que mais satisfizeram o critério da consulta em relação a sua similaridade são apresentados na janela central.

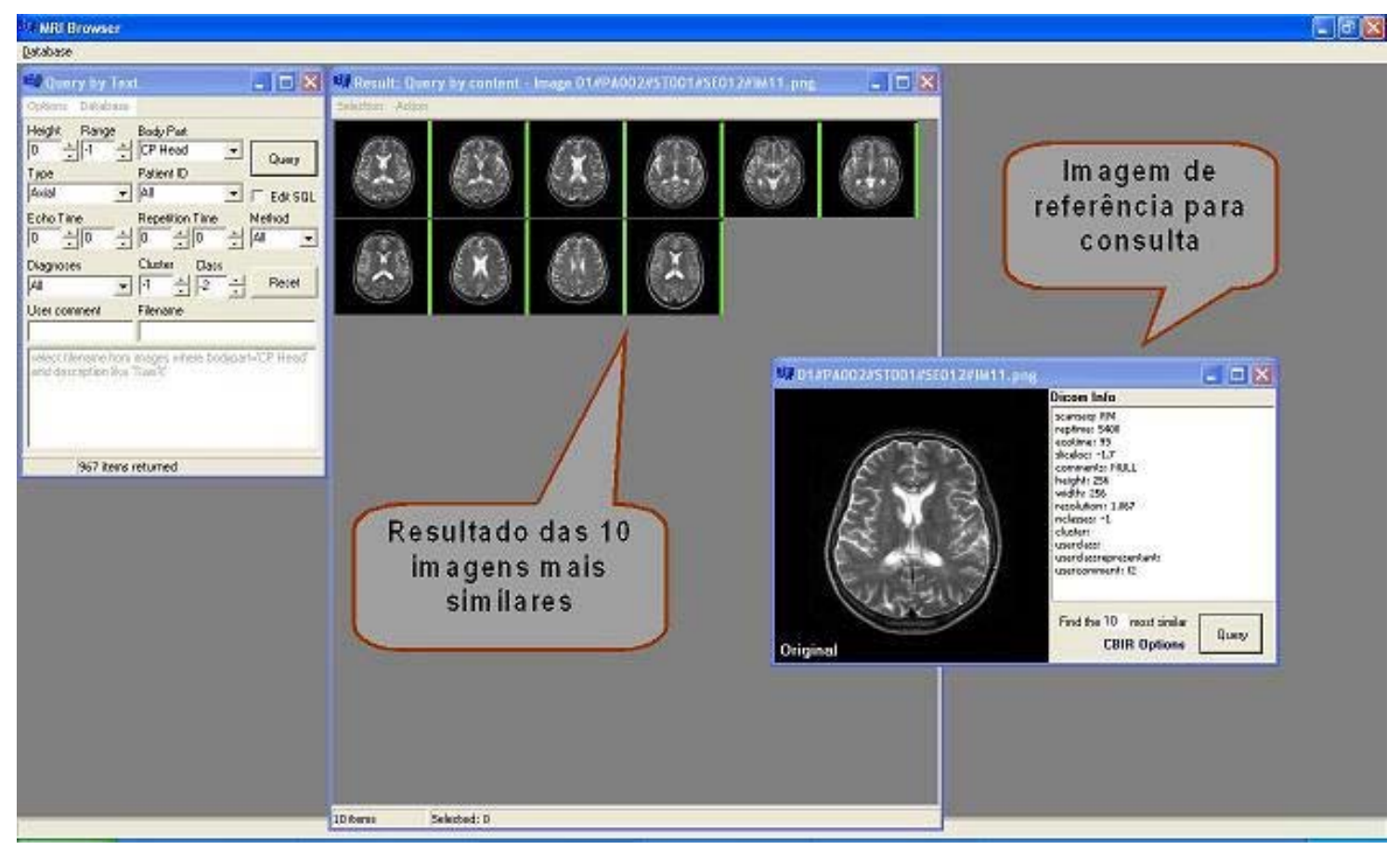

Figura 5.7: Resultado da consulta por similaridade a partir de uma dada imagem de referência.

O conjunto retornado de thumbnails na janela Result também apresenta informações adicionais interessantes a respeito da consulta. Cada miniatura possui ao seu lado direito uma barra vertical colorida que representa o valor da similaridade atribuída a cada imagem retornada em relação à imagem de referência dada. Quando a barra ocupa toda a extensão vertical do thumbnail, significa que a similaridade é total, ou seja, a distância entre as imagens é zero. A cor das barras pode variar de verde (distância mínima) a vermelho (distância máxima), passando por todos os tons intermediários. Quanto mais verde apresentar a barra vertical, mais similar será a 
imagem de referência. A Figura 5.8 mostra um exemplo do resultado de uma consulta por similaridade, apresentando as primeiras imagens mais semelhantes riscadas com uma barra vertical de cor verde e as últimas imagens consideradas não relevantes com uma barra vertical amarela.

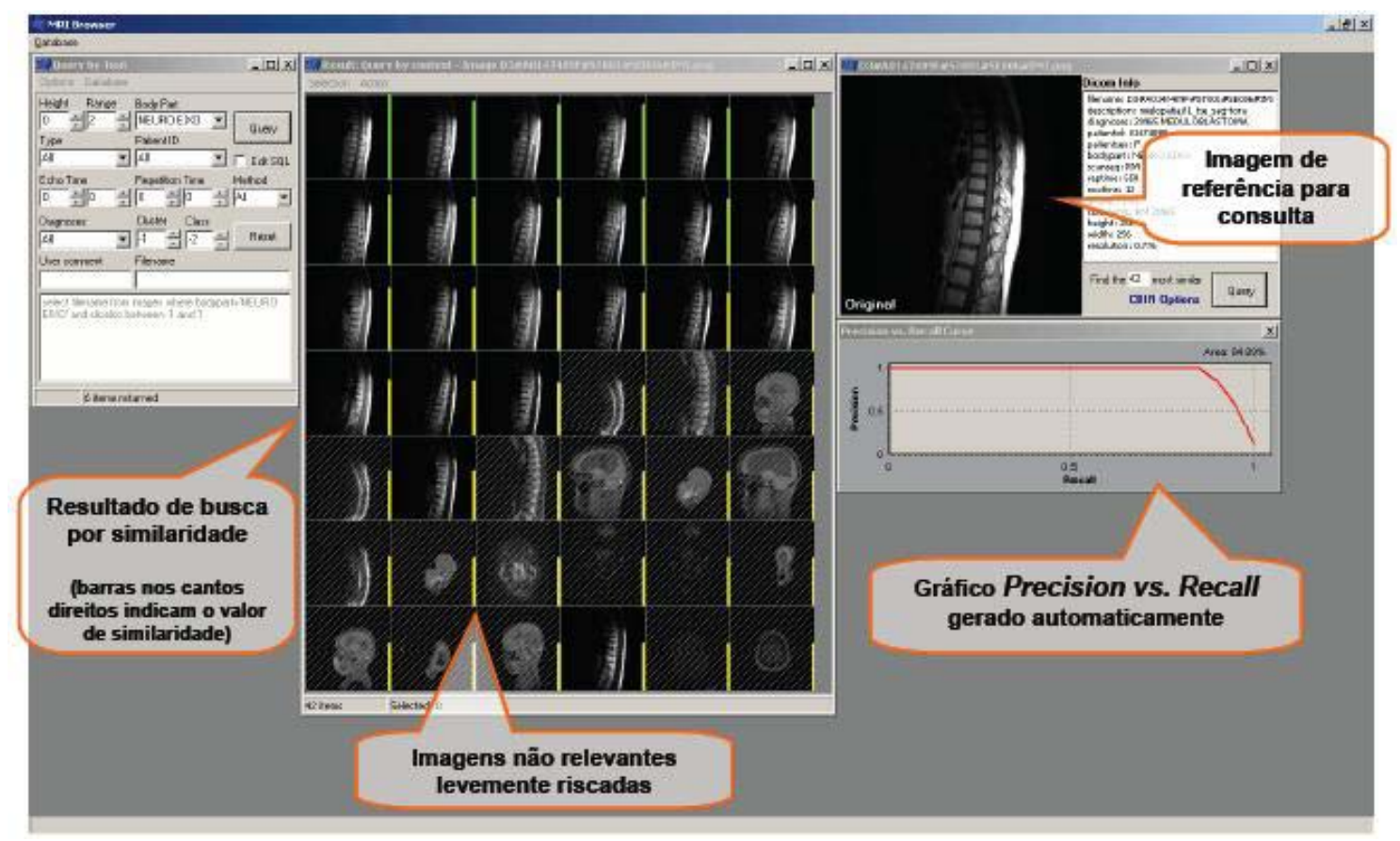

Figura 5.8: Resultado de busca por imagens relevantes.

O sistema também incorpora recursos avançados para avaliar a eficiência dos algoritmos de recuperação de imagens baseada em conteúdo. Os algoritmos necessários para a realização e validação de consultas por similaridade incluem a busca pelos vizinhos mais próximos ( $k$-Nearest Neighbors $-\mathrm{kNN})$, computação automática para geração de curvas de precisão e revocação, geração de histogramas, importação e exportação de vetores de características. Outros recursos permitem classificar um conjunto de thumbnails selecionados a fim de agrupar imagens com características visuais semelhantes.

Esses recursos mais avançados disponíveis no sistema foram desenvolvidos para as pesquisas de âmbito mais abrangente aos objetivos propostos pelo GBdI. Contudo, esse estudo utilizará o protótipo MRI Browser para explorar a interface e avaliar a sua funcionalidade e usabilidade, a fim de resolver algumas questões específicas relacionadas à recuperação de imagens similares a uma dada imagem de referência, empreendidas apenas no processo que auxilia o médico em seus diagnósticos. 


\subsection{Avaliação da interface}

A avaliação da interface constituiu em aplicar técnicas de interação humano-computador no protótipo MRI Browser. As avaliações foram conduzidas segundo um plano de avaliação que constituiu na escolha dos usuários, criação de um cronograma, preparação das tarefas e a decisão do local a ser realizada a avaliação. A seguir serão apresentadas a preparação e condução das avaliações empreendidas nesse estudo de caso.

\subsubsection{Inspeção heurística}

\subsubsection{Escolhendo as heurísticas}

A primeira tarefa ao planejar uma inspeção heurística foi decidir a série de guidelines ou heurísticas a serem usadas. Se a organização tivesse estabelecido um guia de estilo próprio, então esse deveria ter sido usado e aplicado consistentemente na avaliação.

No entanto, a série escolhida para o estudo em questão foram as heurísticas de usabilidade para design de interface propostas por Nielsen que apresentam bons resultados e permitem uma avaliação global do sistema. As "10 Heurísticas de Nielsen" focam problemas de usabilidade de alto nível e constituem dos seguintes itens:

1. Visibilidade do status do sistema.

2. Compatibilidade do sistema com o mundo real.

3. Controle e liberdade para o usuário.

4. Consistência e padrões.

5. Prevenção de erros.

6. Reconhecimento ao invés de lembrança.

7. Flexibilidade e eficiência de uso.

8. Estética e design minimalista.

9. Ajuda aos usuários a reconhecer, diagnosticar e recuperar os erros.

10. Ajuda e documentação.

Os defeitos de usabilidade devem ser avaliados em relação ao grau de severidade correspondentes à gravidade de cada problema em relação à freqüência com que os erros ocorrem, ao impacto do problema ocorrido e a persistência do problema, conforme ilustrado na Tabela 5.1. 
Tabela 5.1: Graus de severidade.

\begin{tabular}{|c|c|}
\hline $\begin{array}{l}\text { Graus de } \\
\text { severidade }\end{array}$ & Descrição \\
\hline 0 & Não concordo que este seja um problema de usabilidade. \\
\hline 1 & $\begin{array}{l}\text { Problema cosmético somente: não precisa ser consertado a menos que haja tempo extra } \\
\text { no desenvolvimento do projeto. }\end{array}$ \\
\hline 2 & Problema de usabilidade de pequeno impacto: a prioridade deste conserto deve ser baixa. \\
\hline 3 & $\begin{array}{l}\text { Problema de usabilidade de grande impacto: importante consertar, deve ser dada alta } \\
\text { prioridade a este conserto. }\end{array}$ \\
\hline 4 & $\begin{array}{l}\text { Catástrofe de usabilidade: este problema deve ser consertado antes que o produto seja } \\
\text { lançado. }\end{array}$ \\
\hline
\end{tabular}

\subsubsection{Escolhendo os inspetores}

Idealmente, um inspetor deve ser um especialista em usabilidade e sobre o domínio do sistema. Porém, essas habilidades dificilmente são encontradas em uma única pessoa. Na tentativa de se enquadrar dentro desse perfil, foram escolhidos quatro inspetores para participar da avaliação, contendo o seguinte background:

- um especialista em usabilidade;

- um especialista do domínio da aplicação; e

- dois especialistas do domínio da aplicação e com algum conhecimento em usabilidade.

\subsubsection{A locação da sessão de avaliação}

As inspeções heurísticas foram empreendidas como estudos controlados em um cenário informal, no laboratório do GBdI, sem nenhuma semelhança com o ambiente de trabalho dos usuários reais. Tal opção permite controlar o experimento conforme o especialista necessita.

\subsubsection{Coletando dados da avaliação}

Ao contrário da observação de usuários onde os defeitos de usabilidade são identificados somente durante a análise dos dados, na inspeção heurística os defeitos de usabilidade são identificados enquanto os inspetores percorrem a interface durante a sessão de avaliação. 
Por esse motivo, foi disponibilizado um formulário no formato digital para coletar dados durante a inspeção heurística, podendo ser impresso se assim o desejar. A proposta foi elaborar um formulário simples apenas para poder registrar os defeitos de usabilidade, associá-los as heurísticas e graus de severidade correspondentes e sugerir recomendações.

\subsubsection{Conduzindo a inspeção heurística}

Como os inspetores recrutados são pessoas que possuem conhecimento em usabilidade e sobre o domínio da aplicação, não foi necessário qualquer treinamento antes da sessão de avaliação. Caso contrário, provavelmente seria preciso esclarecer como que as heurísticas deveriam ser interpretadas no sistema.

A condução da inspeção heurística foi realizada individualmente, onde cada inspetor recebeu um documento de apresentação, explicando o propósito da avaliação e as instruções de preenchimento do formulário, bem como a lista das heurísticas e os graus de severidade.

Os inspetores conduziram a avaliação explorando a interface e associando os defeitos de usabilidade encontrados às heurísticas correspondentes e ao grau de severidade. Para cada problema encontrado também foram sugeridas recomendações para mudanças.

\subsubsection{Técnica observacional}

\subsubsection{Escolhendo os participantes}

Normalmente, cada sessão de avaliação tem um único participante que usa o sistema a ser avaliado. Para obter várias visões do mesmo sistema, a sessão deve ser empreendida com mais participantes. Os participantes não foram escolhidos aleatoriamente, cada participante deveria ser representado por um usuário real baseado no seu perfil.

Usuários reais são considerados como a melhor opção para obter um feedback apropriado, pois além de possuir conhecimento sobre o domínio da aplicação, pode representar vários níveis de experiência, desde usuários novatos a experientes e até mesmo eventuais.

O objetivo foi recrutar usuários que refletissem diferentes habilidades, conhecimento do domínio da aplicação e experiência dos usuários. Desse modo, a 
escolha dos participantes requereu usuários dentro de um grupo diversificado de médicos da área de radiologia com diferentes níveis de experiência profissional e computacional.

Em geral, não são necessários muitos participantes para empreender uma avaliação. Na prática, os primeiros participantes já conseguem prover as informações requeridas pelos avaliadores e estima-se que cerca de cinco participantes são freqüentemente suficientes [Stone-2005]. Se um participante identifica um problema, não precisa de mais participantes para reconhecer o mesmo problema. Às vezes, o primeiro usuário mostra tantos problemas que o avaliador tende a achar que o teste já foi suficiente. Porém, vale a pena persistir com um pouco mais de participantes, pois sempre tem uma informação extra a adicionar.

Idealmente, o número de participantes requerido deve-se iniciar com cinco e se os dados obtidos forem insuficientes ou se o tempo e orçamento permitir, é recomendado recrutar participantes extras que substituirão os que não compareceram. Normalmente, cerca de uma pessoa em cinco não comparece por problemas diversos: ou por algum imprevisto no trabalho ou na família, ou por esquecimento ou simplesmente mudam de idéia e desistem de participar. Em adição, uma pessoa em cinco geralmente não possui o perfil do usuário requerido devido a algum mal entendido no processo de recrutamento: alguém falha ao responder certas questões ou o participante não entendeu a questão. Como resultado, a cada cinco pessoas recrutadas, pode-se contar com cerca de apenas três participantes confirmados e isso pode não ser suficiente.

Levando em conta essas considerações, inicialmente, foram recrutados seis participantes, sendo cinco médicos radiologistas e um técnico em informática biomédica. Porém, por urgências médicas, dois não puderam comparecer e foram substituídos por participantes extras, um médico radiologista e dois radiologistas residentes, totalizando em sete participantes que empreenderam a avaliação. Todos os participantes recrutados são pesquisadores do CCIFM do Hospital das Clínicas da USP de Ribeirão Preto.

\subsubsection{Criando um cronograma de avaliação}

O tempo gasto na avaliação foi planejado antecipadamente a fim de criar um cronograma completo das sessões, levando em consideração:

- a duração necessária para cada sessão de avaliação; 
- um tempo extra entre os participantes; e

- o tempo total do processo de avaliação.

Usualmente, não é aconselhável ter sessões demoradas, pois podem cansar tanto os participantes como os avaliadores, assim avaliações curtas são mais efetivas. É recomendado que as sessões de avaliação devem ter a duração de 30 a 90 minutos [Stone-2005]. Assim, foi estabelecido que cada sessão de avaliação levaria cerca de 60 minutos, incluindo um tempo inicial para apresentação e explicação das tarefas e a finalização com algumas questões adicionais. Foi considerado um tempo extra entre os participantes para algumas anotações necessárias e para tolerar algum atraso na sessão sem ter que ultrapassar a próxima.

O tempo total do processo de avaliação foi estimado em dois dias, estabelecendo um horário de cada sessão bastante flexível em razão dos imprevistos e urgências médicas dos participantes.

\subsubsection{Preparando a descrição das tarefas}

As descrições das tarefas devem ser elaboradas de acordo com o quanto se quer avaliar. Desse modo, as tarefas deveriam representar o desempenho dos participantes nas interações com o protótipo durante a avaliação. A funcionalidade provida pelo sistema também influenciou na escolha das tarefas. Para a avaliação, não foram considerados todos os caminhos da interação oferecidos pelo sistema. As tarefas foram elaboradas para empreender apenas o processo que auxilia o médico em seus diagnósticos, ou seja, apenas o processo de busca de imagens semelhantes. Recursos mais avançados apresentados no protótipo MRI Browser como, por exemplo, geração de histogramas, geração de gráficos de precisão e revocação e classificação das imagens com características visuais relevantes, não fizeram parte desta avaliação.

As tarefas foram definidas para atender as seguintes características:

- tarefas freqüentemente desempenhadas pelos usuários;

- tarefas relevantes para o propósito em questão; e

- tarefas que precisam ser validadas com usuários para obter um maior esclarecimento ou entendimento pela equipe de desenvolvimento.

A quantidade de tarefas foi estabelecida levando em consideração a complexidade das tarefas e o tempo alocado para cada sessão de avaliação. Dessa maneira, foram formuladas cinco tarefas para empreender a sessão de avaliação dentro do tempo proposto. Os cenários das tarefas foram descritos em linguagem apropriada 
para que os participantes entendessem com clareza e se limitassem a realizar apenas o solicitado. As duas primeiras tarefas foram elaboradas com o objetivo de explorar a interface por tentativa e erro, visando conhecer e aprender a usar o sistema, a fim de identificar as opções disponíveis, realizar consultas textuais de imagens, selecionar imagens específicas e visualizar as mensagens exibidas na tela (Figura 5.9). A terceira tarefa introduziu a aprendizagem da busca por imagens similares a uma dada imagem de referência. As duas últimas tarefas focaram a usabilidade do sistema através do reconhecimento de objetos e ações ao invés da lembrança (Figura 5.10).

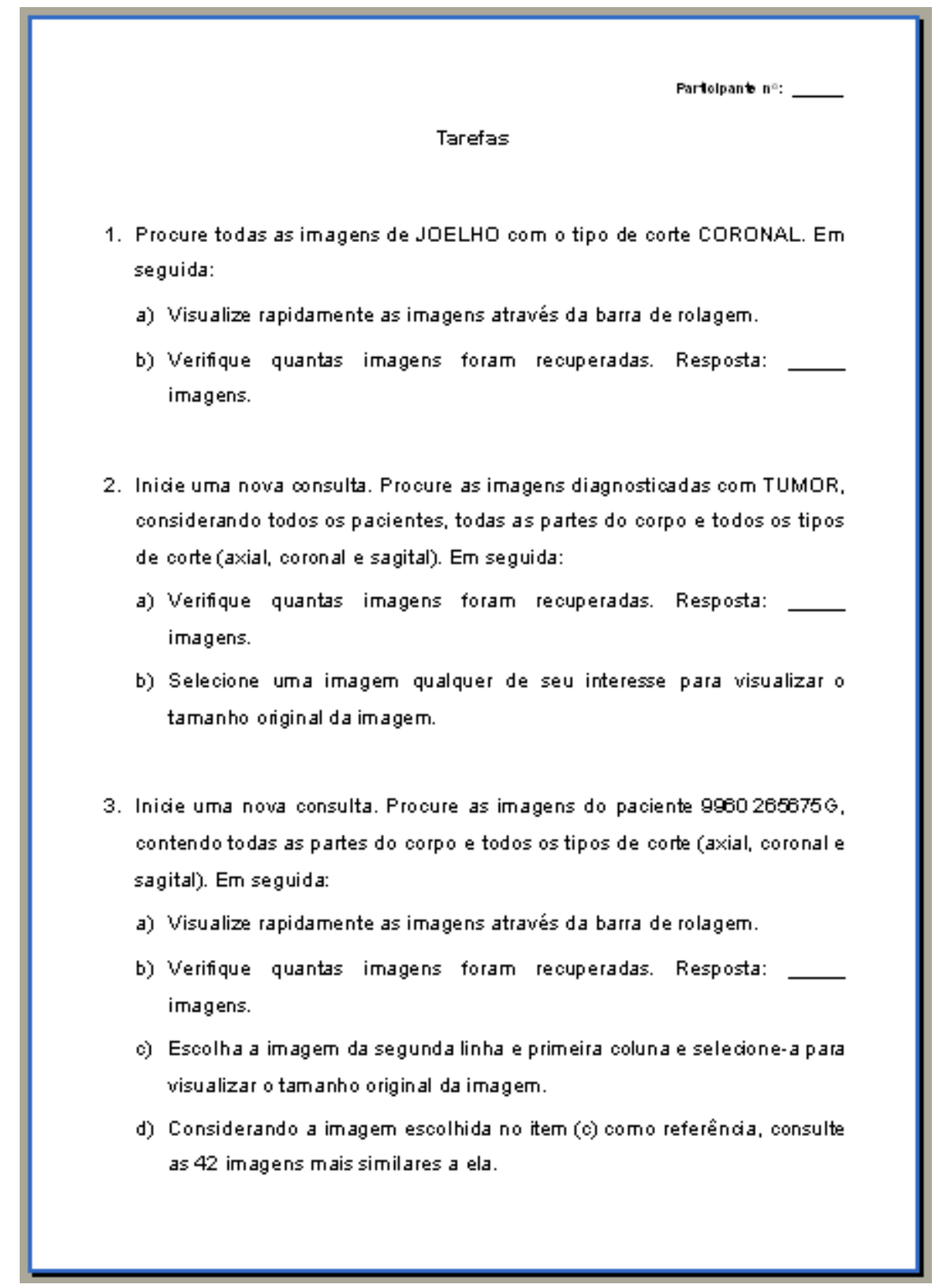

Figura 5.9: Descrição das tarefas 1, 2 e 3. 


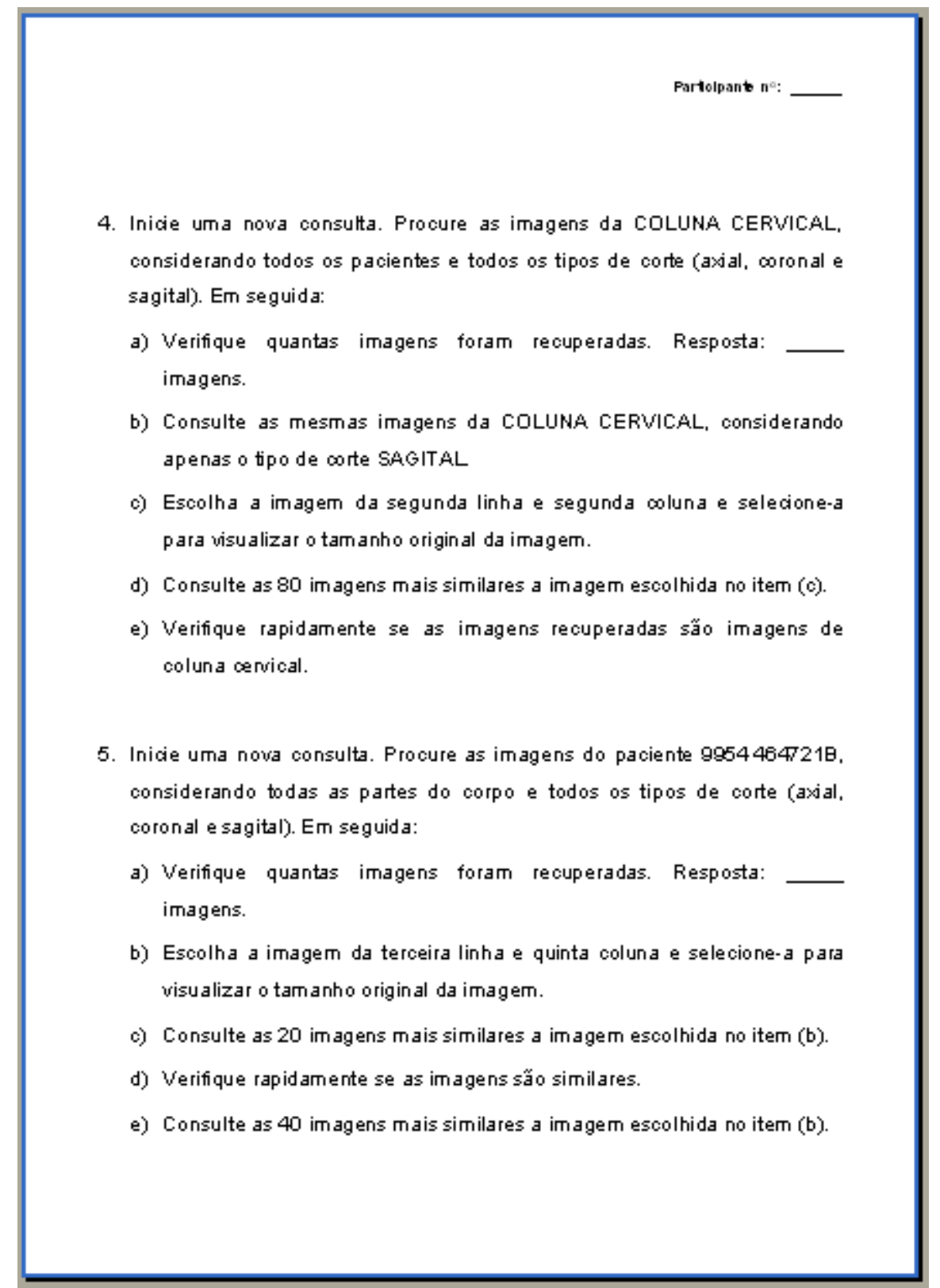

Figura 5.10: Descrição das tarefas 4 e 5.

\subsubsection{A locação da sessão de avaliação}

A avaliação foi empreendida como um estudo de campo no CCIFM do Hospital das Clínicas da USP de Ribeirão Preto, para poder extrair dados sobre o ambiente em que os usuários trabalham em seu sistema. Nem sempre é possível realizar avaliação no próprio local de trabalho do usuário e, nesse caso, pôde-se observar que o participante é constantemente interrompido por telefonemas e emergências médicas. Nessa situação foi impraticável realizar uma avaliação no local real do trabalho do usuário e as avaliações foram conduzidas em uma sala de reunião no próprio CCIFM. Os estudos tiveram uma simulação aproximada do ambiente de trabalho verdadeiro, contendo o 
mesmo equipamento do ambiente de trabalho, como móveis, iluminação, local limpo e arrumado, porém sem distrações possíveis.

\subsubsection{Organizando as sessões de avaliação}

Para conduzir a avaliação foi importante organizar, planejar e preparar com antecedência todos os detalhes para informar aos participantes. Um checklist foi uma boa opção para anotar todos os itens necessários para não serem esquecidos durante as sessões de avaliação.

\subsubsection{Coletando dados da avaliação}

Para coletar os dados foram utilizados questionários, relógio com cronômetro e anotações.

\section{Questionários}

A utilização de questionários durante as sessões de avaliação possui as seguintes vantagens:

- todas as questões que precisam ser perguntadas podem ser descritas no questionário, diminuindo a chance de esquecer alguma pergunta importante;

- todos os participantes recebem as mesmas questões, possibilitando comparar as respostas entre os participantes diferentes; e

- pode coletar tanto dados quantitativos como qualitativos.

A avaliação constitui da aplicação de dois questionários, um questionário antes do teste, denominado pré-sessão, para obter um feedback do perfil e formação do usuário e um questionário pós-sessão para obter um background dos sentimentos do usuário em relação ao uso do sistema (ver em Apêndice B).

O questionário pré-sessão, referente ao perfil do participante, constituiu de dois tipos de questões:

- Questões fechadas: onde o participante pode selecionar uma resposta dentre uma escolha de alternativas. Foram abordadas questões sobre o sexo, faixa de idade, grau de instrução, especialidade médica, tempo de atuação, experiência em informática e conhecimento da língua inglesa.

- Questões abertas: onde o participante é livre para prover sua própria resposta. São úteis para obter informação subjetiva geral, mas são difíceis de 
analisar ou comparar e podem ser consideradas apenas como um suplemento. No entanto, podem identificar erros ou fazer sugestões que não foram consideradas pelo designer. Foi elaborada apenas uma questão complementar referente à expectativa do participante sobre o uso de um sistema para recuperar imagens de exames médicos similares. Essa questão teve o propósito de obter uma perspectiva do usuário antes e depois do seu desempenho.

O questionário pós-sessão objetivou mensurar a satisfação do usuário em relação ao uso do sistema, a fim de se obter uma avaliação subjetiva. Esse tipo de avaliação é um componente importante nas avaliações de usabilidade. Essa preocupação levou ao desenvolvimento e padronização de alguns instrumentos gerais para avaliação de usuários em sistemas de computadores interativos. Esses instrumentos são compostos de questionários que possuem uma abordagem hierárquica de fatores de usabilidades, onde os dados são armazenados e analisados. Métodos de testes psicológicos também foram aplicados para assegurar uma validação empírica dos itens e estimar sua confiabilidade.

Como parte da avaliação de usabilidade encontram-se disponíveis vários questionários para uso acadêmico ou pessoal. Os questionários de avaliação de usabilidade mais conhecidos e que mais se destacam como produtos comerciais são:

- QUIS $^{12}$ (Questionnaire for User Interaction Satisfaction);

- SUMI $^{13}$ (Software Usability Measurement Inventory);

- WAMMI ${ }^{14}$ (Website Analysis and MeasurMent Inventory); e

- $\operatorname{SUS}^{15}$ (System Usability Scale).

Todos esses tipos de questionários são úteis para propósitos diferentes.

O QUIS foi desenvolvido pela University of Maryland e foi projetado para medir a satisfação global do sistema em uma organização hierárquica de medidas, abordando 11 fatores específicos de interface: fatores da tela, terminologia e feedback do sistema, fatores de aprendizagem, capacidade do sistema, manuais técnicos, tutoriais on-line, multimídia, reconhecimento de voz, ambiente virtual, acesso a Internet e instalação do software.

\footnotetext{
${ }^{12} \mathrm{http} / / /$ lap.umd.edu/QUIS/

${ }^{13} \mathrm{http}: / /$ sumi.ucc.ie

${ }^{14} \mathrm{http}: / /$ www.wammi.com

${ }^{15} \mathrm{http}: / / \mathrm{www} . \mathrm{mind}$.com
} 
O questionário QUIS original foi aplicado no teste piloto e demonstrou ser muito longo, cansativo e tedioso. Os participantes tiveram dúvidas durante o preenchimento em relação a algumas questões que pareciam ser bastante similares ou por falta de compreensão das afirmações.

Visando reduzir a carga de esforço dos participantes e também a encorajá-los a responder um segundo questionário depois de empreender o teste de avaliação da interface e não deixar que a sessão ultrapassasse o tempo determinado, a melhor opção para registrar a satisfação da interação do usuário no estudo em questão foi elaborar um outro questionário baseado no QUIS.

A proposta foi obter uma versão resumida do QUIS, constituindo de afirmações incorporadas a uma escala de classificação de diferencial semântico, que utiliza termos opostos colocados na mesma dimensão, onde os participantes selecionam o valor mais apropriado. Esses termos são adjetivos bi-polares colocados nos pontos extremos da escala como, por exemplo, de fácil a difícil ou de claro a confuso. Esse tipo de escala é bastante utilizada em pesquisas de HCI e é útil para indicar a preferência dos usuários, tendo a vantagem de ser fácil de analisar.

A fim de não confundir muito o participante, o grau de concordância da escala original foi reduzido de dez para cinco itens, variando de 1 (grau mais baixo) a 5 (grau mais alto) ou N/A (não se aplica).

A nova versão do QUIS foi projetada para focar seis fatores específicos de interface:

1. Reação do sistema.

2. Tela.

3. Terminologia e informação do sistema.

4. Aprendizado.

5. Capacidade do sistema.

6. Imagens.

Das 50 questões propostas no QUIS original foram consideradas as 25 questões que mais se aproximavam do estudo em questão. Baseadas no fator multimídia, foram adicionadas mais cinco questões específicas sobre os fatores relacionados a imagens, totalizando 30 questões.

$\mathrm{Na}$ última parte do formulário foi incluída uma questão aberta para que os respondentes pudessem registrar seus comentários e sugestões. 


\section{Relógio com cronômetro}

Um relógio com cronômetro foi usado para registrar o tempo durante a sessão a fim de validar métricas de usabilidade como, por exemplo, o tempo gasto para completar uma tarefa, o tempo gasto na correção de erros, entre outras.

\section{Anotações}

Foram feitas anotações em papel das informações obtidas durante a observação do usuário para registrar o desempenho, comportamento e atitudes em relação ao sistema.

\subsubsection{Preparando o equipamento}

Todas as sessões de avaliação utilizaram o mesmo equipamento para poder ter o mesmo padrão de resposta do sistema. O protótipo MRI Browser empreendido na avaliação foi instalado em um notebook com a seguinte configuração: processador Intel Celeron, com velocidade $1.5 \mathrm{GHz}, 256 \mathrm{MB}$ de RAM, $40 \mathrm{~GB}$ de HDD e tela LCD de 15,4" WXGA wide. Também foi conectado um mouse óptico para auxiliar a manipulação do equipamento.

\subsubsection{Designando papéis dos avaliadores}

Muitas vezes, uma sessão de avaliação pode envolver uma equipe com vários membros, podendo ser designados papéis diferentes para cada pessoa:

- Facilitador: é a pessoa que gerencia a avaliação, explica os objetivos da avaliação para os participantes, descreve como a avaliação será conduzida e também pode responder algumas dúvidas que o participante pode ter durante a avaliação;

- Observador: é a pessoa que observa o participante e toma nota das suas atitudes, seus comentários e qualquer problema de usabilidade;

- Avaliador: é a pessoa que planeja a avaliação, analisa os dados e reporta os resultados. Freqüentemente, o avaliador atua sozinho, desempenhando o papel de facilitador e observador;

- Recrutador: é a pessoa que seleciona os participantes para a avaliação; e 
- Operador de equipamento: é a pessoa responsável por preparar o equipamento de gravação de vídeo e gravar as sessões de avaliação.

Na prática, é difícil obter uma equipe com funções distintas e nesse estudo a sessão de avaliação contou com a participação de um recrutador e um avaliador, que além de desempenhar o papel de facilitador e observador, também representou o operador de equipamento.

\subsubsection{O teste piloto}

Antes de qualquer sessão de avaliação ser conduzida é necessário realizar um teste piloto a fim de avaliar a sessão e ajudar a garantir seu funcionamento. Esse processo teve como objetivo testar o funcionamento dos equipamentos, o material de avaliação, o cronograma de horas planejado, a adequação das descrições das tarefas e a execução da sessão. O foco no teste piloto foi ter certeza que todos os detalhes da avaliação estavam de acordo com o planejado.

\section{Participantes do teste piloto}

Para o teste piloto foram escolhidos dois participantes que não representavam o grupo de usuários reais. O perfil requerido foi recrutar pessoas iniciantes e experientes em informática, bem como pessoas com pouco e bastante conhecimento da língua inglesa.

\section{Ambiente de teste}

Foi montado um ambiente de teste semelhante à sessão de avaliação, contendo os seguintes itens necessários:

- equipamento de computador com o protótipo instalado;

- os materiais de avaliação: checklist, descrição das tarefas e questionários pré e pós-sessão;

- outros artefatos necessários, como papel e caneta para os participantes e para o avaliador; e

- equipamento de gravação, bem como uma lista de todos os itens integrantes ao equipamento para não ter como agravante o esquecimento de alguma parte vital do equipamento. 


\section{Executando o teste piloto}

A sessão do teste piloto foi conduzida da mesma maneira que as sessões reais de avaliação, onde o avaliador desempenhou o papel de observar e tomar notas. O teste piloto foi executado baseado nos procedimentos de avaliação e todo material de apoio para checar se:

- o protótipo funciona como requerido;

- o material introdutório esclarece qualquer dúvida tanto para o participante como para o avaliador;

- os procedimentos adotados para observação a fim de coletar dados funcionam;

- o avaliador consegue cumprir seu papel e responsabilidade; e

- a tarefa pode ser consumada no tempo planejado.

O teste piloto foi importante para observar e anotar o que precisou ser melhorado nos materiais e procedimentos de avaliação antes de conduzir a verdadeira sessão de avaliação. Alguns problemas foram revelados: algumas questões tiveram que ser reformuladas, a quantidade de tarefas foram diminuídas para se adequarem ao tempo planejado e o questionário de satisfação do usuário foi reduzido, pois além de ser muito longo e cansativo, continha questões similares que confundiram os usuários.

Pelo fato do avaliador também ser o responsável por operar o equipamento de gravação de vídeo, percebeu-se que houve uma falha ao gerenciar a avaliação, observar o usuário e tomar notas durante a sessão. Esse processo deveria ser executado exclusivamente por uma outra pessoa. Ao analisar e interpretar os dados obtidos no teste piloto por meio da gravação em vídeo, foi possível verificar que seria muito mais interessante ter as anotações do avaliador para completar e salientar alguns aspectos importantes.

\subsubsection{Conduzindo a sessão da avaliação}

A preparação final foi conciliar todo o plano de avaliação e estabelecer o que acontece em cada etapa do teste a fim de conduzir a avaliação [Rocha-2003].

- Preparação inicial: a etapa inicial teve o propósito de garantir que o equipamento de computador estivesse pronto e os materiais de apoio disponíveis antes de iniciar a avaliação. 
- Introdução: nessa etapa foi apresentado e explicado aos participantes como o teste seria conduzido. Antes de iniciar os testes, alguns pontos foram falados e esclarecidos, tais como: dar boas-vindas, explicar que o propósito do teste é avaliar o sistema e não o participante, explicar o papel do avaliador, estipular o tempo de duração da sessão, garantir o anonimato do participante, entre outros. Essa etapa finaliza com a solicitação ao participante para preencher o questionário pré-sessão.

- Teste: foi fornecido um formulário em papel com a descrição das tarefas e solicitado aos participantes para executarem as tarefas usando o protótipo MRI Browser. Durante essa etapa o facilitador conduziu a sessão, observando o usuário e registrando os acontecimentos.

- Sessão final: depois do tempo estipulado para completar as tarefas, os participantes foram convidados a preencherem o questionário de satisfação do usuário QUIS e a sessão terminou com um agradecimento final pela ajuda.

É usual oferecer algum tipo de agradecimento para os participantes pelo seu tempo e trabalho. Informalmente, quando o participante é um colega, apenas um obrigado pode ser suficiente. No entanto, como a avaliação foi ligeiramente mais formal, foi enviado um e-mail registrando o agradecimento para a pessoa responsável pelo recrutamento e cooperação.

\subsection{Considerações finais}

Neste capítulo é apresentado o estudo de caso aplicado à medicina, que foi o objeto de estudo e pesquisa dessa dissertação. Primeiramente, é abordado como as técnicas CBIR podem ser integradas aos PACS e SIH, visando centralizar em um sistema único e completo as informações dos pacientes e as imagens de exames gerados dentro do ambiente hospitalar. Em seguida é descrito o protótipo MRI Browser utilizado no processo de avaliação, que consiste em um sistema de navegação que utiliza técnicas CBIR para propiciar a recuperação de imagens de modalidade médica. O capítulo finaliza com a condução da avaliação da interface, descrevendo a inspeção heurística seguida pela observação do usuário. 



\subsection{Medidas de usabilidade}

As medidas de usabilidade refletem os resultados da interação dos usuários com o sistema proposto. Os dados relacionados a cada componente de usabilidade podem ser obtidos a partir de medidas objetivas ou subjetivas:

- Medidas objetivas: são medidas de observação direta, tipicamente em relação ao desempenho do usuário na execução de testes enquanto usa a interface. As medidas objetivas podem prover dados como medidas de tempo, velocidade ou ocorrência de eventos particulares.

- Medidas subjetivas: representam opiniões, usualmente dos usuários, no que diz respeito à usabilidade da interface. Respostas subjetivas provêm dados que expressam sentimentos, crenças, atitudes e preferências dos usuários.

Enquanto que as medidas objetivas fornecem indicações diretas de eficácia e eficiência do comportamento do usuário, as medidas subjetivas estão relacionadas diretamente com a satisfação do usuário, derivadas das opiniões que os usuários expressam sobre seus trabalhos e seus resultados. Entretanto, a satisfação também pode ser inferida por medidas objetivas do comportamento do usuário, assim como as estimativas de eficácia e eficiência podem ser derivadas de opiniões subjetivas expressadas pelos usuários.

\subsubsection{Escolha das medidas}

A escolha das medidas depende dos objetivos e do contexto em que a avaliação está inserida, pois freqüentemente possuem diferenças significativas dos tipos de usuários, tarefas ou ambientes [ISO-9241-11-1998]. Normalmente, é necessário fornecer pelo menos uma medida para estimar a eficácia, eficiência e satisfação. 


\section{Eficácia}

As medidas de eficácia estão relacionadas a acurácia e completude com que os usuários atingem objetivos específicos. A acurácia pode ser especificada ou medida pela quantidade de erros, enquanto que a completude pelo cumprimento da tarefa a ser realizada, ou seja, pela proporção que a tarefa foi alcançada.

\section{Eficiência}

As medidas de eficiência relacionam o nível de eficácia alcançada no dispêndio de recursos, como esforço mental ou físico, tempo, custos materiais ou financeiros. Ou seja, a eficiência é medida atribuindo o nível de eficácia alcançada com os recursos usados. Por exemplo, a eficiência temporal pode ser definida como a proporção entre a medida de eficiência em alcançar um objetivo específico e o tempo para alcançar tal objetivo.

\section{Satisfação}

A satisfação é uma resposta do usuário na interação com o produto. Permite medir a extensão pela qual os usuários estão livres de desconforto e as atitudes em relação ao uso do produto. A satisfação pode ser especificada e medida pela avaliação subjetiva em escalas de desconforto experimentado, gosto pelo produto, satisfação com o uso do produto, aceitação da carga de trabalho quando realizam diferentes tarefas ou a extensão com os quais objetivos particulares de usabilidade foram alcançados. Outras medidas de satisfação podem incluir o número de comentários positivos e negativos registrados durante o uso do produto.

A satisfação pode ser avaliada ou estimada através de medidas subjetivas ou objetivas. Medidas objetivas podem ser baseadas na observação do comportamento do usuário como, por exemplo, a postura corporal, movimento do corpo, freqüência de distração ou através do monitoramento de respostas psicológicas do usuário. As medidas subjetivas de satisfação são adquiridas quantificando subjetivamente a intensidade das reações, atitudes ou opiniões expressadas pelo usuário. Esse processo de quantificação pode ser correspondente à intensidade de seus sentimentos ou classificando produtos na ordem de preferência ou atribuindo uma escala de atitudes baseada em questionário. 


\subsubsection{Critérios de medidas}

A Tabela 6.1 resume alguns critérios que foram considerados nesse estudo para medir a eficácia, eficiência e satisfação, de acordo com os objetivos de usabilidade baseados na ISO 9241 .

Tabela 6.1: Medidas de usabilidade.

\begin{tabular}{|c|c|c|c|}
\hline $\begin{array}{l}\text { Objetivos de } \\
\text { usabilidade }\end{array}$ & Medidas de eficácia & Medidas de eficiência & Medidas de satisfação \\
\hline Usabilidade global & $\begin{array}{l}\text { Porcentagem de } \\
\text { objetivos alcançados } \\
\text { Porcentagem de } \\
\text { usuários completando a } \\
\text { tarefa com sucesso } \\
\text { Média da acurácia de } \\
\text { tarefas completadas }\end{array}$ & $\begin{array}{l}\text { Tempo para completar } \\
\text { uma tarefa } \\
\text { Tarefas completadas por } \\
\text { unidade de tempo }\end{array}$ & $\begin{array}{l}\text { Escala de satisfação } \\
\text { Freqüência de uso }\end{array}$ \\
\hline $\begin{array}{l}\text { Adequado às } \\
\text { necessidades de } \\
\text { usuários treinados }\end{array}$ & $\begin{array}{l}\text { Número de tarefas } \\
\text { importantes realizadas } \\
\text { Porcentagem de funções } \\
\text { relevantes usadas }\end{array}$ & $\begin{array}{l}\text { Eficiência relativa } \\
\text { comparada com um } \\
\text { usuário experiente }\end{array}$ & $\begin{array}{l}\text { Escala para satisfação } \\
\text { com características } \\
\text { importantes }\end{array}$ \\
\hline $\begin{array}{l}\text { Adequado às } \\
\text { necessidades para usar } \\
\text { facilmente }\end{array}$ & $\begin{array}{l}\text { Porcentagem de tarefas } \\
\text { completadas com } \\
\text { sucesso na primeira } \\
\text { tentativa }\end{array}$ & $\begin{array}{l}\text { Tempo gasto na primeira } \\
\text { tentativa } \\
\text { Eficiência relativa na } \\
\text { primeira tentativa }\end{array}$ & Taxa de uso voluntário \\
\hline $\begin{array}{l}\text { Adequado às } \\
\text { necessidades para uso } \\
\text { não freqüente ou } \\
\text { intermitente }\end{array}$ & $\begin{array}{l}\text { Porcentagem de tarefas } \\
\text { completadas com } \\
\text { sucesso depois de um } \\
\text { período específico sem } \\
\text { uso }\end{array}$ & $\begin{array}{l}\text { Tempo gasto } \\
\text { reaprendendo funções } \\
\text { Número de erros } \\
\text { persistentes }\end{array}$ & Freqüência de reuso \\
\hline Facilidade de aprender & $\begin{array}{l}\text { Número de funções } \\
\text { aprendidas } \\
\text { Porcentagem de } \\
\text { usuários que conseguem } \\
\text { aprender por critério }\end{array}$ & $\begin{array}{l}\text { Tempo para aprender } \\
\text { por critério } \\
\text { Eficiência relativa } \\
\text { durante o aprendizado }\end{array}$ & $\begin{array}{l}\text { Escala para facilidade de } \\
\text { aprendizado }\end{array}$ \\
\hline Tolerância a erros & $\begin{array}{l}\text { Porcentagem de erros } \\
\text { corrigidos } \\
\text { Número tolerado de } \\
\text { erros do usuário }\end{array}$ & $\begin{array}{l}\text { Tempo gasto na } \\
\text { correção de erros }\end{array}$ & $\begin{array}{l}\text { Escala para tratamento } \\
\text { de erros }\end{array}$ \\
\hline $\begin{array}{l}\text { Legibilidade e } \\
\text { visibilidade }\end{array}$ & & & $\begin{array}{l}\text { Escala para desconforto } \\
\text { visual }\end{array}$ \\
\hline
\end{tabular}




\subsection{Análise e interpretação dos dados}

O processo de análise e interpretação concentrou-se em transformar os dados coletados da avaliação em informações para auxiliar a tomada de decisões sobre o re-design da interface do usuário. A análise da avaliação seguiu os seguintes passos:

- Coletar dados: envolveu registrar os dados quantitativos e qualitativos produzidos nas sessões de avaliação por meio de anotações em formulários de papel, planilhas eletrônicas e processadores de texto.

- Resumir os dados: envolveu extrair as informações importantes dos dados coletados. Isso implicou em trabalhar com dados quantitativos e qualitativos. Os dados quantitativos foram resumidos em tabelas e gráficos para prover uma representação visual dos dados e por meio de descritores estatísticos para descrever os dados obtidos por meio de medidas estatísticas simples. Os dados qualitativos identificaram os defeitos existentes e a intensidade do impacto.

- Examinar os dados: envolveu um exame minucioso dos dados resumidos a fim de identificar os problemas de usabilidade.

Uma vez analisados os dados, o passo final foi interpretar os dados com o objetivo de decidir o que causou os defeitos identificados e recomendar o que fazer sobre isso. Primeiramente, foram analisados e interpretados os dados da observação do usuário e em seguida os dados da inspeção heurística. O resultado da avaliação será apresentado a seguir.

\subsubsection{Observação dos usuários}

A partir do questionário pré-sessão foi possível obter um feedback do perfil e formação dos usuários. Visto que a proposta de testar o sistema deveria representar o cenário que mais se aproximava da vida real, a observação dos usuários contou com a colaboração de sete participantes da área médica, que reuniu 57\% de médicos radiologistas, $29 \%$ de radiologistas residentes e $14 \%$ de técnicos em informática biomédica, conforme mostra a Figura 6.1. 


\section{ESPECIALIDADE DOS PARTICIPANTES}

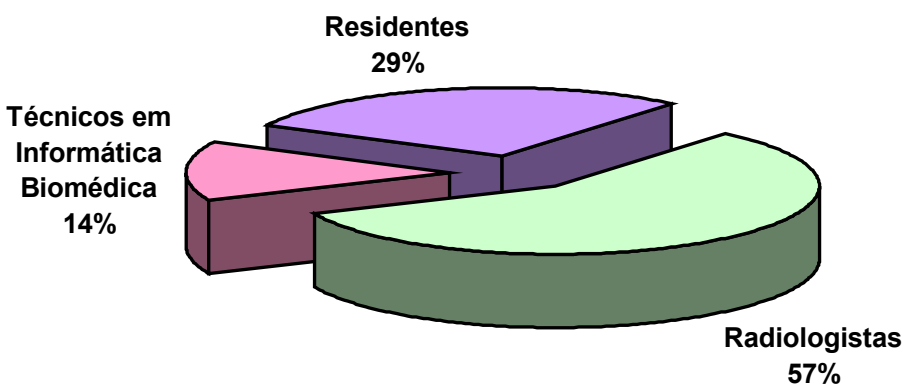

Figura 6.1: Participação dos usuários por área de especialidade médica.

Os participantes recrutados constituíram, na sua maioria, de $71 \%$ do sexo masculino, enquanto que apenas $29 \%$ pertenciam ao sexo feminino. A Figura 6.2 ilustra o percentual dos participantes por sexo.

\section{SEXO DOS PARTICIPANTES}

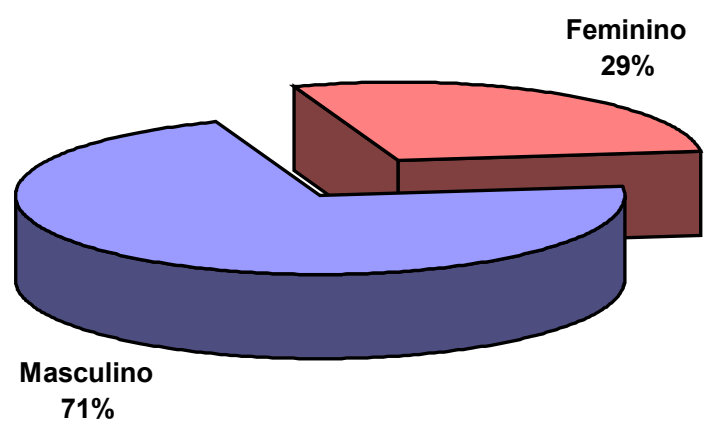

Figura 6.2: Participação dos usuários por sexo.

Muitas vezes, o perfil do usuário é descrito como um conjunto geral da população do usuário em termos dos atributos ou características relevantes para o design. No entanto, é desejável dividir essa população de usuários em pequenos grupos de usuários para focar mais objetivamente quem são os usuários do sistema e seus diferentes padrões de uso. 
Primeiro, os participantes foram divididos por faixa etária, sendo que $43 \%$ corresponderam a faixa de 18 a 30 anos, 14\% entre 31 a 44 anos e $43 \%$ entre 45 a 64 anos. A partir dessa divisão foi possível classificar os participantes nos seguintes grupos de usuários:

- Adultos jovens: de 18 a 30 anos.

- Adultos de meia idade: de 31 a 44 anos.

- Adultos mais velhos: de 45 a 64 anos.

A Figura 6.3 apresenta a distribuição dos participantes por grupos de acordo com a faixa etária.

\section{FAIXA ETÁRIA DOS PARTICIPANTES}

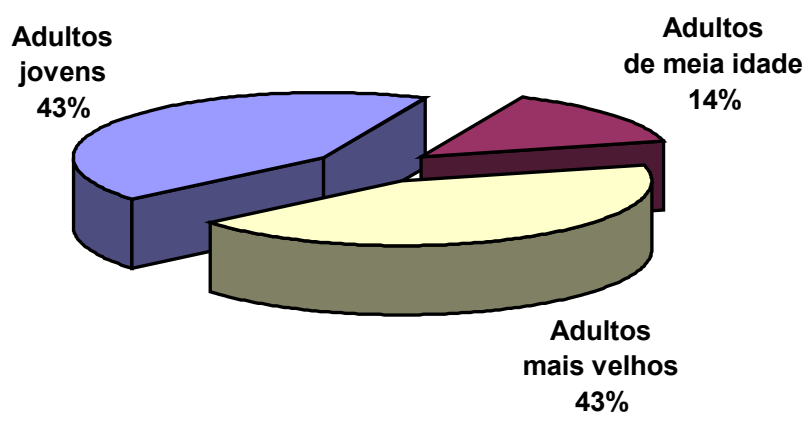

Figura 6.3: Participação dos usuários por faixa etária.

Os participantes foram requeridos com o propósito de ter alguma habilidade computacional, um pouco de conhecimento na língua inglesa e nenhuma experiência em sistemas CBIR.

A Figura 6.4 apresenta a experiência dos participantes em informática de acordo com a freqüência de uso de sistemas computacionais. Por meio da freqüência de uso, nota-se que todos os participantes têm alguma familiaridade com sistemas computacionais. Sistemas médicos informatizados são utilizados diariamente por $71 \%$ dos participantes, enquanto que 29\% usam semanalmente. Quanto ao uso de correio eletrônico e Internet, todos possuem o hábito diário e semanal. Apenas em relação ao uso de editores de texto e/ou planilhas eletrônicas indicou um percentual de $29 \%$ que utilizam eventualmente, sendo que os demais usam diariamente e semanalmente. 


\section{EXPERIÊNCIA EM INFORMÁTICA \\ Freqüencia de Uso}

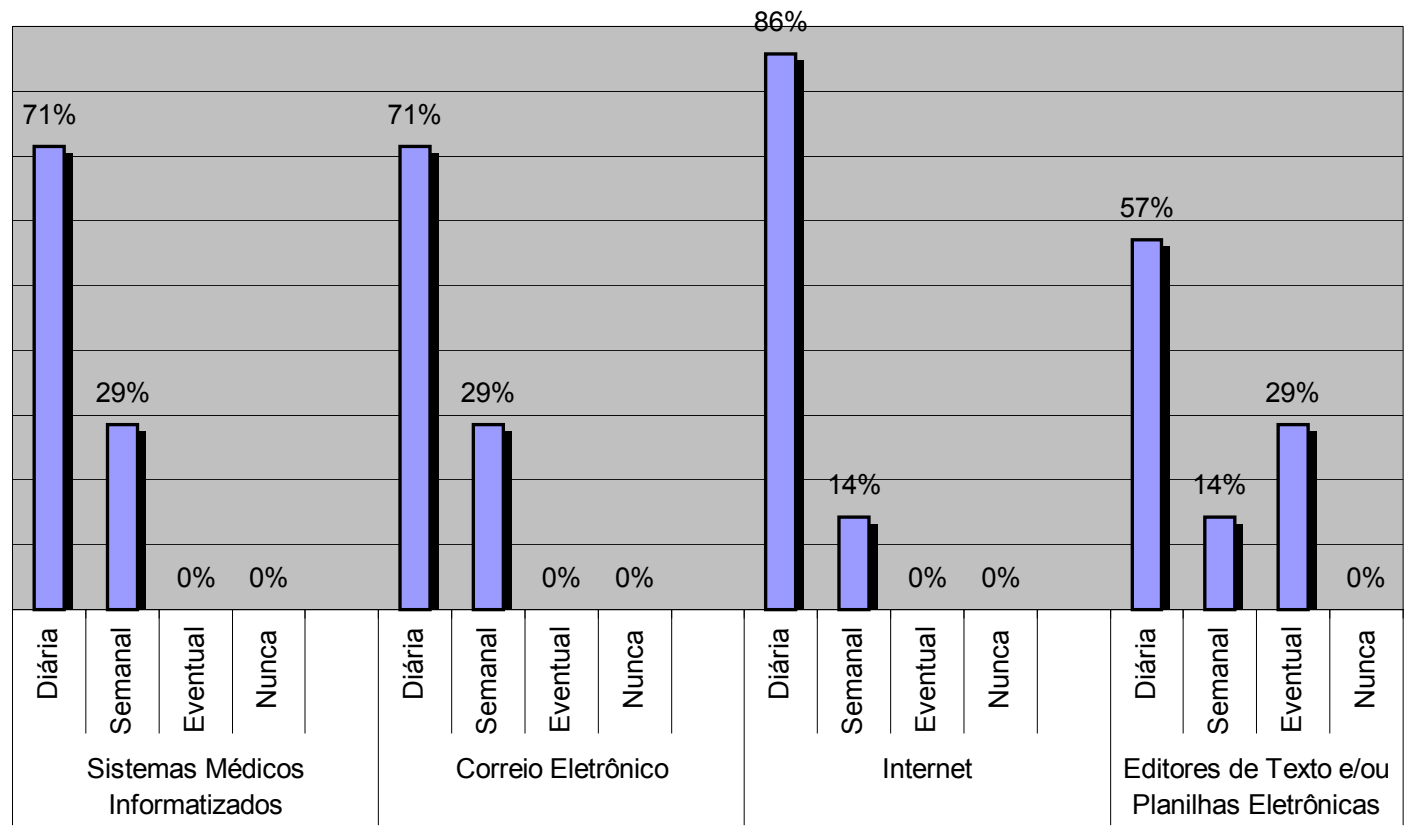

Figura 6.4: Experiência dos participantes em informática.

Além desses dados, anotações adicionais também foram feitas durante as sessões. Visto que participantes mais jovens demonstraram uma maior habilidade e agilidade computacional, foi possível classificar os participantes em vários níveis de experiência em informática, constituindo de usuários principiantes, médios e experientes. A Figura 6.5 indica os níveis de experiência em informática, sendo que $14 \%$ representam participantes principiantes, $43 \%$ médios e $43 \%$ experientes.

\section{NÍVEIS DE EXPERIÊNCIA EM INFORMÁTICA}

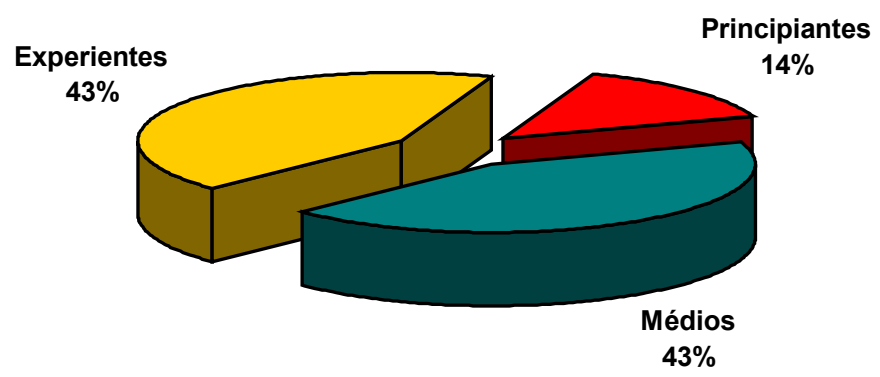

Figura 6.5: Participantes por níveis de experiência em informática. 
O idioma inglês adotado como padrão da interface não influenciou no desempenho dos participantes. A Figura 6.6 aponta que, no geral, os participantes possuíam um bom conhecimento na língua inglesa. Percebe-se que os maiores índices atingiram $66 \%$ dos participantes com boa compreensão, $57 \%$ fala razoavelmente, $71 \%$ lê bem e $43 \%$ escreve bem. Já os menores índices corresponderam a $17 \%$ na compreensão, $14 \%$ fala pouco, $29 \%$ lê razoavelmente e $14 \%$ escreve pouco.

CONHECIMENTO DA LÍNGUA INGLESA

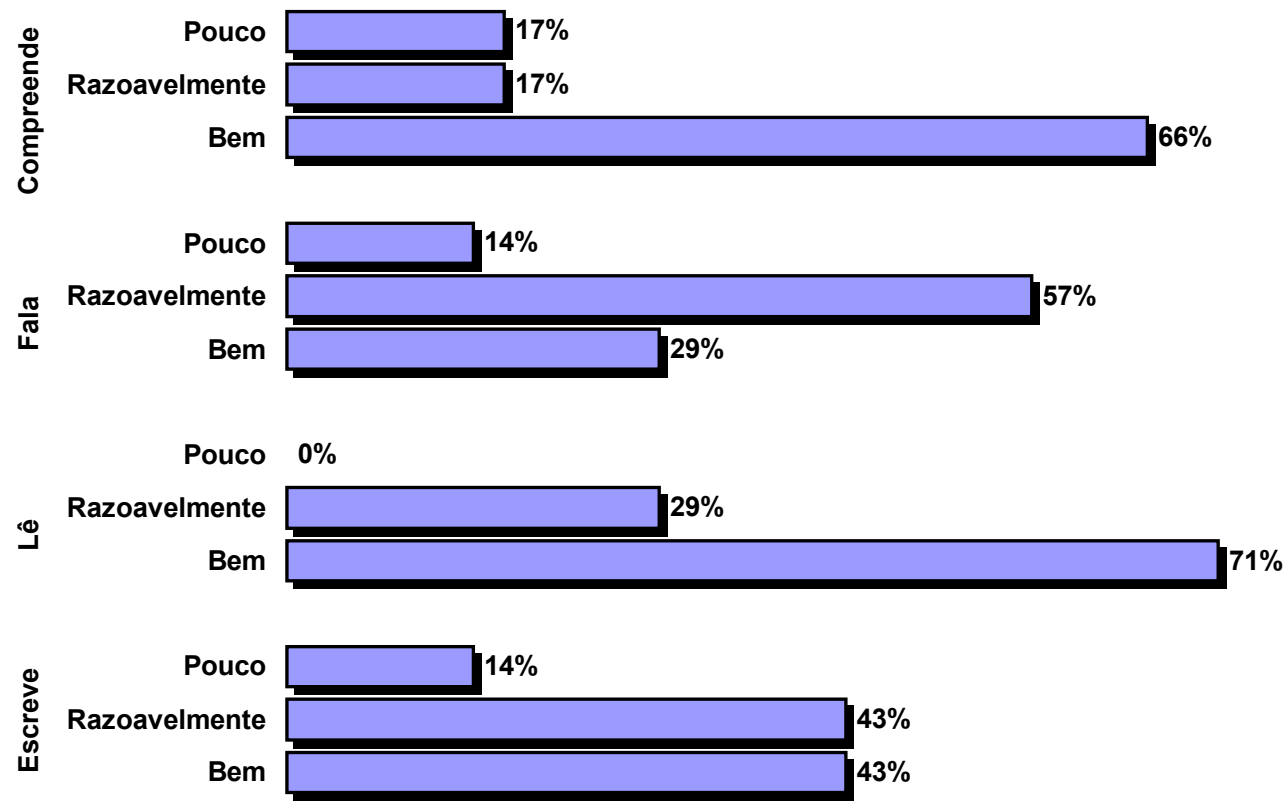

Figura 6.6: Conhecimento dos participantes na língua inglesa.

O tempo de atuação profissional dos participantes é apresentado na Figura 6.7, correspondendo $42 \%$ aos participantes que possuem menos de 5 anos de atuação profissional e 58\% acima de 11 anos. 


\section{TEMPO DE ATUAÇÃO PROFISSIONAL}

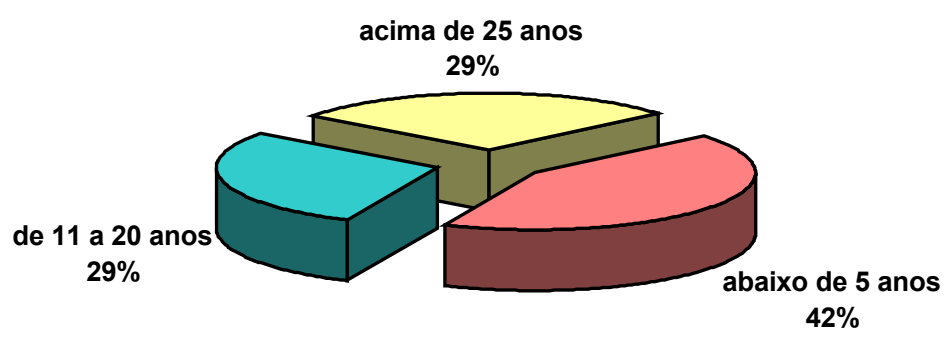

Figura 6.7: Tempo de atuação profissional dos participantes.

A partir desses dados, os participantes foram classificados em novatos e experientes de acordo com o conhecimento do domínio clínico. Verificou-se que alguns termos e funções avançadas utilizadas no sistema apresentaram ser mais familiares para os participantes experientes. Assim, pode-se dizer que o tempo de atuação profissional dos participantes reflete diretamente nas necessidades de uso de funções relevantes disponíveis no sistema.

Na Tabela 6.2 é apresentado o tempo que cada participante levou para completar as tarefas, bem como seu perfil em relação ao nível de experiência em informática e sua faixa etária. É notado que:

- Adultos mais jovens e com boa experiência em informática, atingiram um desempenho melhor no uso do sistema, levando menos de 10 minutos para completar todas as tarefas.

- Adultos de meia idade e com experiência média em informática levaram quase que 17 minutos para realizar as tarefas.

- Adultos mais velhos e com experiência média em informática levaram aproximadamente 40 minutos para completar as tarefas.

- Adultos mais velhos e com pouca experiência em informática levaram mais de 40 minutos para realizar as tarefas. 
Percebeu-se que quando o participante é mais jovem e com maior habilidade computacional ele utiliza o sistema mais fácil e rapidamente.

Observa-se, também, que o tempo médio para completar cada tarefa foi diminuindo ao decorrer da sessão, devido ao aprendizado introduzido.

Tabela 6.2: Tempo de execução de tarefas por participante.

\begin{tabular}{|c|c|c|c|c|c|c|c|c|}
\hline \multirow{2}{*}{$\begin{array}{l}\text { Partici- } \\
\text { pante }\end{array}$} & \multirow{2}{*}{$\begin{array}{l}\text { Experiência } \\
\text { em } \\
\text { informática }\end{array}$} & \multirow{2}{*}{$\begin{array}{l}\text { Faixa } \\
\text { etária }\end{array}$} & \multicolumn{5}{|c|}{$\begin{array}{c}\text { Tempo de tarefa } \\
\text { (Hora : Minuto : Segundo) }\end{array}$} & \multirow{2}{*}{$\begin{array}{c}\text { Tempo } \\
\text { Total }\end{array}$} \\
\hline & & & Tarefa 1 & Tarefa 2 & Tarefa 3 & Tarefa 4 & Tarefa 5 & \\
\hline P1 & Principiante & $\begin{array}{l}\text { Adulto mais } \\
\text { velho }\end{array}$ & 0:12:08 & $0: 11: 44$ & $0: 12: 03$ & 0:04:49 & $0: 02: 57$ & $0: 43: 41$ \\
\hline P2 & Médio & $\begin{array}{l}\text { Adulto mais } \\
\text { velho }\end{array}$ & 0:08:15 & 0:07:16 & 0:09:23 & 0:08:05 & 0:05:10 & 0:38:09 \\
\hline P3 & Experiente & Adulto jovem & $0: 00: 51$ & 0:01:00 & 0:03:03 & 0:02:05 & $0: 02: 12$ & 0:09:11 \\
\hline P4 & Médio & $\begin{array}{l}\text { Adulto mais } \\
\text { velho }\end{array}$ & $0: 14: 43$ & 0:05:12 & 0:05:55 & 0:05:04 & 0:05:12 & $0: 36: 06$ \\
\hline P5 & Médio & $\begin{array}{l}\text { Adulto de } \\
\text { meia idade }\end{array}$ & 0:03:35 & $0: 02: 15$ & 0:04:10 & 0:03:44 & 0:03:08 & $0: 16: 52$ \\
\hline P6 & Experiente & Adulto jovem & 0:01:23 & $0: 00: 45$ & 0:01:31 & 0:02:03 & 0:01:15 & 0:06:57 \\
\hline P7 & Experiente & Adulto jovem & $0: 01: 13$ & $0: 01: 21$ & $0: 01: 43$ & 0:01:59 & 0:03:36 & 0:09:52 \\
\hline $\begin{array}{l}\text { Tempo } \\
\text { Médio }\end{array}$ & & & 0:06:01 & 0:04:13 & 0:05:24 & 0:03:58 & 0:03:21 & \\
\hline
\end{tabular}

As tarefas foram elaboradas para conceber os processos de aprendizagem de uso do sistema, consistindo em três etapas:

- processo de exploração do sistema por tentativa e erro;

- processo de busca por imagens similares; e

- processo de reconhecimento de objetos e ações ao invés de lembrança.

A Tabela 6.3 apresenta o tempo de aprendizagem do uso do sistema em cada etapa da execução das tarefas por participantes. 
Tabela 6.3: Tempo de aprendizagem de uso do sistema.

\begin{tabular}{|c|c|c|c|c|}
\hline \multirow[b]{2}{*}{ Participante } & \multicolumn{3}{|c|}{$\begin{array}{l}\text { Tempo de aprendizagem } \\
\text { (Hora : Minuto : Segundo) }\end{array}$} & \multirow{2}{*}{$\begin{array}{c}\text { Tempo } \\
\text { Total }\end{array}$} \\
\hline & $\begin{array}{c}\text { Processo de } \\
\text { exploração do sistema } \\
\text { por tentativa e erro }\end{array}$ & $\begin{array}{l}\text { Processo de busca } \\
\text { por imagens similares }\end{array}$ & $\begin{array}{c}\text { Processo de } \\
\text { reconhecimento de } \\
\text { objetos e ações ao } \\
\text { invés de lembrança }\end{array}$ & \\
\hline P1 & $0: 23: 52$ & $0: 12: 03$ & $0: 07: 46$ & $0: 43: 41$ \\
\hline P2 & $0: 15: 31$ & $0: 09: 23$ & $0: 13: 15$ & 0:38:09 \\
\hline P3 & $0: 01: 51$ & 0:03:03 & $0: 04: 17$ & 0:09:11 \\
\hline P4 & 0:19:55 & 0:05:55 & $0: 10: 16$ & $0: 36: 06$ \\
\hline P5 & 0:05:50 & 0:04:10 & $0: 06: 52$ & $0: 16: 52$ \\
\hline P6 & $0: 02: 08$ & 0:01:31 & 0:03:18 & 0:06:57 \\
\hline P7 & $0: 02: 34$ & $0: 01: 43$ & $0: 05: 35$ & 0:09:52 \\
\hline $\begin{array}{l}\text { Tempo } \\
\text { Médio }\end{array}$ & $0: 10: 14$ & $0: 05: 24$ & 0:07:20 & \\
\hline
\end{tabular}

A primeira etapa teve o objetivo de conhecer e aprender a usar o sistema por meio da exploração da interface por tentativa e erro. O tempo gasto de cada participante para explorar o sistema variou, aproximadamente, cerca de 2 a 24 minutos, obtendo uma média aproximada de 10 minutos. Essa etapa correspondeu à execução das duas primeiras tarefas. Nota-se que os participantes mais jovens obtiveram um desempenho melhor nessa etapa.

A segunda etapa correspondeu à introdução da aprendizagem da busca por imagens similares a uma dada imagem de referência. Essa etapa correspondeu à execução de uma tarefa e levou um tempo médio de aproximadamente 5 minutos e meio.

A terceira etapa focou o uso do sistema por meio do reconhecimento de objetos e ações ao invés de lembrança e durou um tempo médio de aproximadamente 7 minutos e meio. Essa etapa correspondeu à execução das duas últimas tarefas referentes a todo o processo de busca textual e por similaridade, bem como a execução de algumas ações relevantes.

Cada tarefa foi formulada visando alcançar mais de um objetivo. Conforme ilustrado na Figura 6.8, as duas primeiras tarefas constituíram de 3 objetivos, a terceira tarefa reuniu 5 objetivos e as duas últimas incorporaram 6 objetivos. 


\section{QUANTIDADE DE OBJETIVOS DAS TAREFAS}

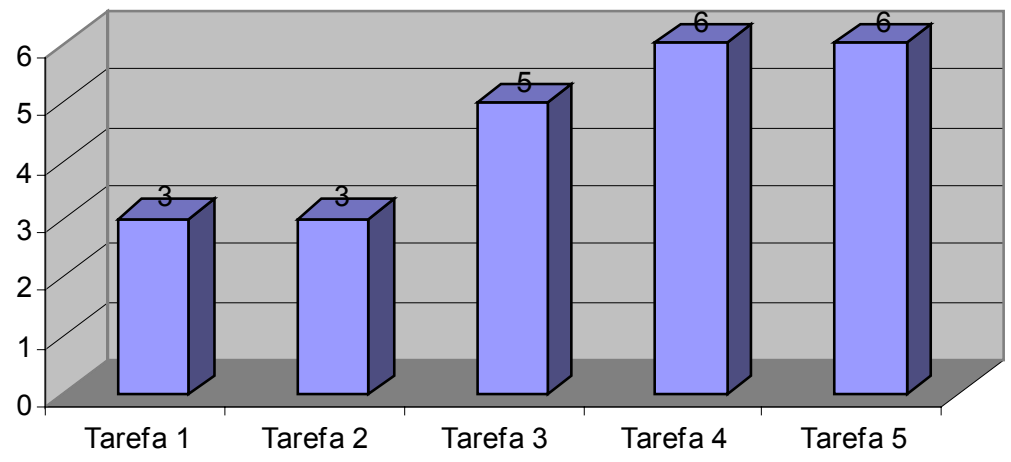

Figura 6.8: Quantidade de objetivos por tarefa.

Considerando que cada tarefa possuiu vários objetivos a serem alcançados, foi possível calcular a completude de cada tarefa. A Figura 6.9 apresenta o percentual de completude das tarefas por participante. Nota-se que a maioria das tarefas foram completadas em $100 \%$.

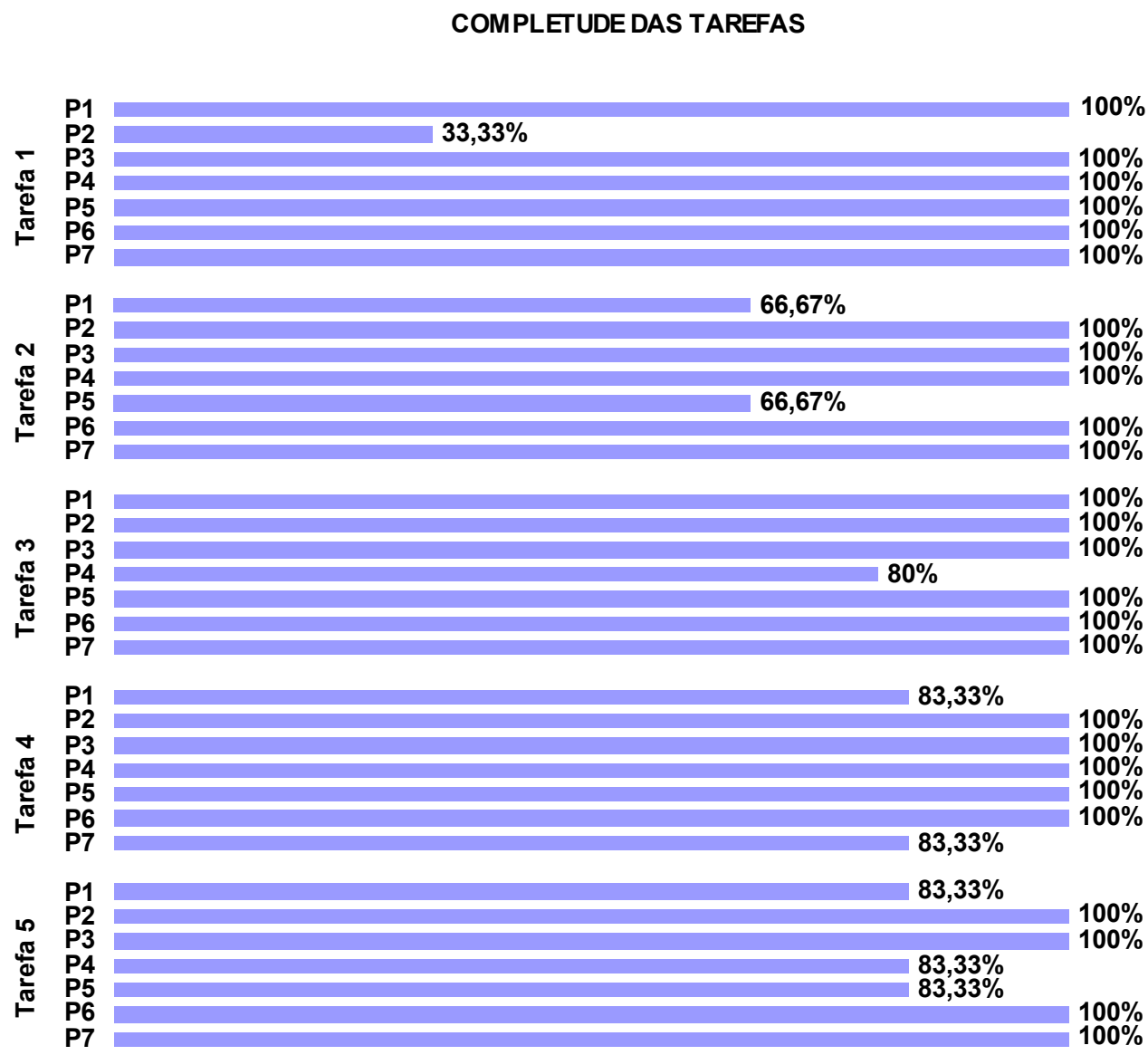

Figura 6.9: Completude das tarefas por participante. 
Na Tabela 6.4 é apresentada a acurácia de tarefas completadas, ou seja, a quantidade de erros cometidos durante as tarefas e o tempo gasto para corrigi-los. Observa-se que, na maioria, o tempo gasto para recuperar um erro é muito pequeno, alguns desses erros foram realizados por engano e percebidos rapidamente pelos participantes. No geral, os erros de uma determinada tarefa foram cometidos sucessivamente, assim foi possível medir o tempo gasto na correção de cada erro. A representação do sinal “---" significa que o participante não percebeu o erro e por isso não foi corrigido. A maioria desses erros não corrigidos decorreu da falta de visibilidade da mensagem exibida na tela informando a quantidade de imagens recuperadas.

Apesar da facilidade que os jovens e experientes em informática demonstraram no desempenho da tarefa, não teve nenhuma relação quanto aos erros cometidos pelos participantes. Independente da idade e habilidade computacional, percebeu-se que participantes mais cautelosos e que tiveram mais atenção na formulação das tarefas obtiveram menos erros.

Tabela 6.4: Quantidade de erros cometidos e o tempo gasto para corrigi-los.

\begin{tabular}{|c|c|c|c|c|c|c|c|c|c|c|c|}
\hline & \multicolumn{10}{|c|}{ Quantidade de erros cometidos e o tempo gasto para corrigi-los } & \multirow{3}{*}{ Total } \\
\hline & \multicolumn{2}{|c|}{ Tarefa 1} & \multicolumn{2}{|c|}{ Tarefa 2} & \multicolumn{2}{|c|}{ Tarefa 3} & \multicolumn{2}{|c|}{ Tarefa 4} & \multicolumn{2}{|c|}{ Tarefa 5} & \\
\hline & Qtd. & Tempo & Qtd. & Tempo & Qtd. & Tempo & Qtd. & Tempo & Qtd. & Tempo & \\
\hline P1 & 3 & 0:09:03 & 4 & 0:09:56 & 3 & $0: 04: 36$ & 1 & --- & 1 & -- & 12 \\
\hline P2 & 1 & --- & & & 1 & $0: 02: 30$ & & & 1 & $0: 00: 53$ & 3 \\
\hline P3 & & & & & 1 & 0:01:59 & & & 1 & $0: 00: 45$ & 2 \\
\hline P4 & 7 & $0: 10: 52$ & 3 & $0: 02: 20$ & 3 & $0: 02: 24$ & & & 4 & $0: 03: 53$ & 17 \\
\hline P5 & 1 & $0: 01: 47$ & 3 & 0:01:03 & 2 & $0: 02: 48$ & & & 1 & --- & 7 \\
\hline P6 & 2 & 0:01:15 & & & & & 1 & $0: 00: 44$ & & & 3 \\
\hline P7 & & & & & & & 1 & --- & 2 & $0: 01: 45$ & 3 \\
\hline Total & 14 & & 10 & & 10 & & 3 & & 10 & & 47 \\
\hline
\end{tabular}

A satisfação pôde ser medida por meio do questionário pós-sessão QUIS, que foi organizado de maneira modular, focando seis fatores de interesse particular da interface: reação do sistema, tela, terminologia e informação do sistema, aprendizado, capacidade do sistema e imagens. As respostas obtidas nos questionários foram convertidas em valores numéricos e realizadas análises estatísticas simples. 
Com relação à avaliação da satisfação da interface, os participantes se mostraram bastante familiarizados com a interface. A grande maioria das tarefas foram cumpridas tanto na acurácia e completude. Os resultados obtidos no QUIS apresentados na Figura 6.10 foram os seguintes:

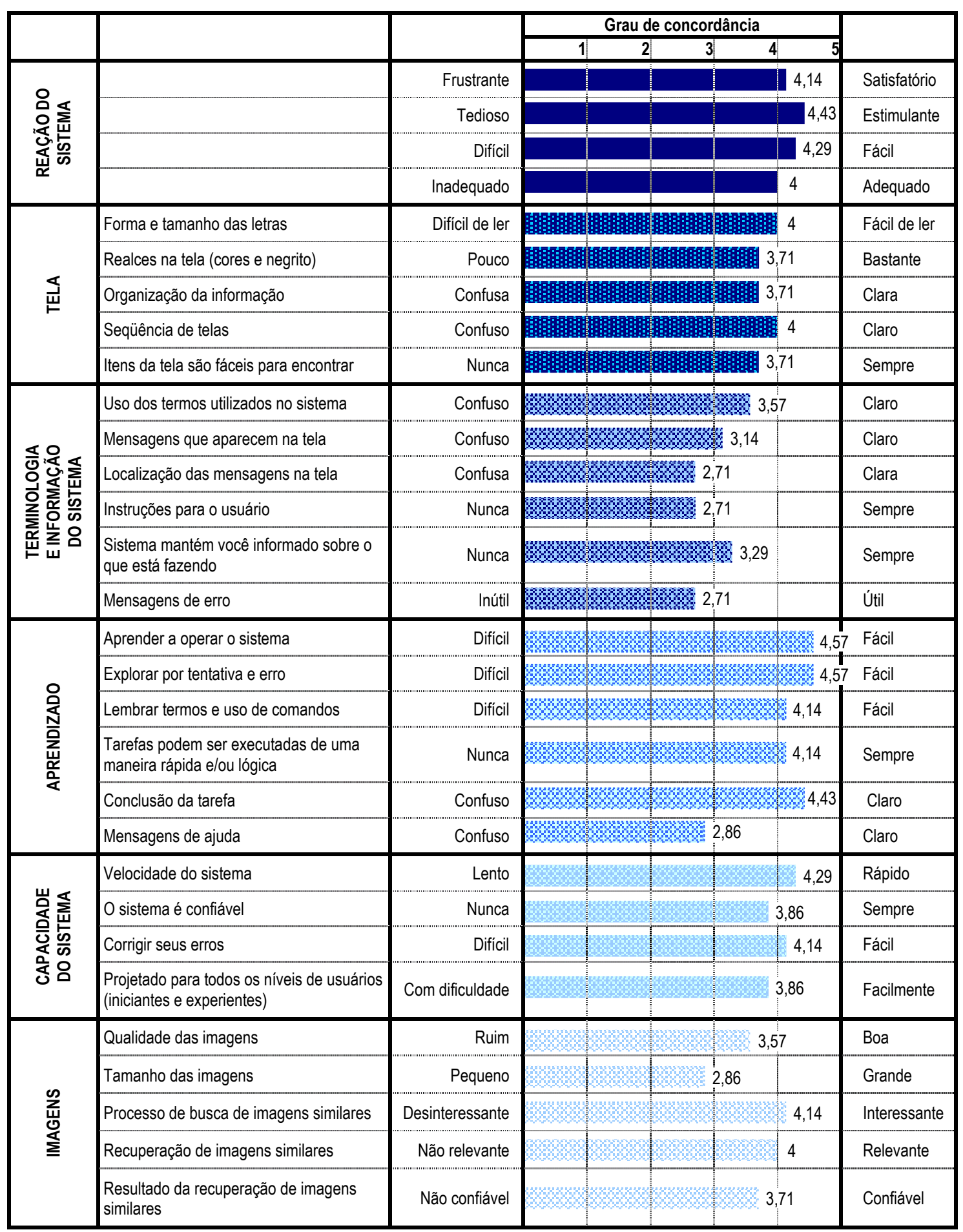

Figura 6.10: Resultado das medidas de satisfação do QUIS. 


\section{Reação do sistema}

A impressão geral que os participantes apontaram foi um sistema muito satisfatório, bem estimulante, muito fácil de usar e adequado.

\section{Tela}

Os participantes consideraram a forma e tamanho da letra fácil de ler. Contudo, apontaram que nem sempre os itens da tela são fáceis de encontrar. Embora a seqüência de telas esteja apresentada de maneira clara, a organização da informação não está disposta tão claramente e o sistema não dispõe de muitos realces na tela em relação a cores e negrito para ressaltar as informações relevantes.

\section{Terminologia e informação do sistema}

O uso de termos utilizados no sistema não demonstrou ser tão claro. Percebeu-se que profissionais iniciantes não têm conhecimento mais aprofundado sobre o assunto e o sistema não possui instruções para auxiliá-los. No entanto, às vezes, o sistema mantém o usuário informado sobre o que está fazendo. Além disso, as poucas mensagens que apareceram na tela não são claras e sua localização um pouco confusa e muitas vezes despercebida. Constatou-se que as mensagens de erro não se mostraram úteis.

\section{Aprendizado}

O sistema foi considerado muito fácil de aprender a operar e explorar por tentativa e erro. As tarefas quase sempre puderam ser executadas de uma maneira rápida e/ou lógica e demonstrou facilidade ao lembrar de termos e uso de comandos. A conclusão das tarefas mostrou-se bem clara. O sistema não provê mensagens de ajuda, o que poderia ser muito útil para esclarecer dúvidas durante o aprendizado.

\section{Capacidade do sistema}

Os participantes apontaram que o sistema possui uma velocidade rápida e quase sempre apresentaram respostas confiáveis. Demonstrou facilidade na correção dos erros. O sistema foi projetado facilmente para atender todos os níveis de usuários, tanto para iniciantes como experientes. 


\section{Imagens}

Embora a qualidade das imagens ser considerada boa, o tamanho não agradou muitos participantes, sendo um pouco pequeno para requerer uma visualização mais minuciosa dos detalhes da imagem. O processo de busca de imagens similares foi considerado muito interessante e relevante, embora o resultado demonstrou nem sempre ser confiável.

\subsubsection{Inspeção heurística}

A análise e interpretação dos dados seguem o mesmo processo da observação de usuários. Os dados da avaliação heurística foram coletados a partir do formulário padrão usado durante a inspeção, em que cada avaliador individualmente reportou os defeitos encontrados, associados às heurísticas e aos graus de severidade, bem como as sugestões para corrigi-los.

Para uma melhor visualização e entendimento das tabelas e gráficos apresentados a seguir, cada heurística será representada pela letra " $H$ " seguida pelo número da heurística correspondente, como H1, H2, H3 e assim por diante (ver Seção 5.3.1.1). Os graus de severidade também adotarão esse mesmo padrão, usando a letra “G” seguida dos níveis de severidade, variando de G0 a G4 (ver Seção 5.3.1.1).

A avaliação heurística envolveu a participação de quatro inspetores, compondo de $25 \%$ de especialistas em usabilidade, $25 \%$ de especialistas do domínio da aplicação e $50 \%$ de especialistas do domínio da aplicação com algum conhecimento em usabilidade, conforme ilustra a Figura 6.11.

INSPETORES DA AVALIAÇÃO HEURÍSTICA

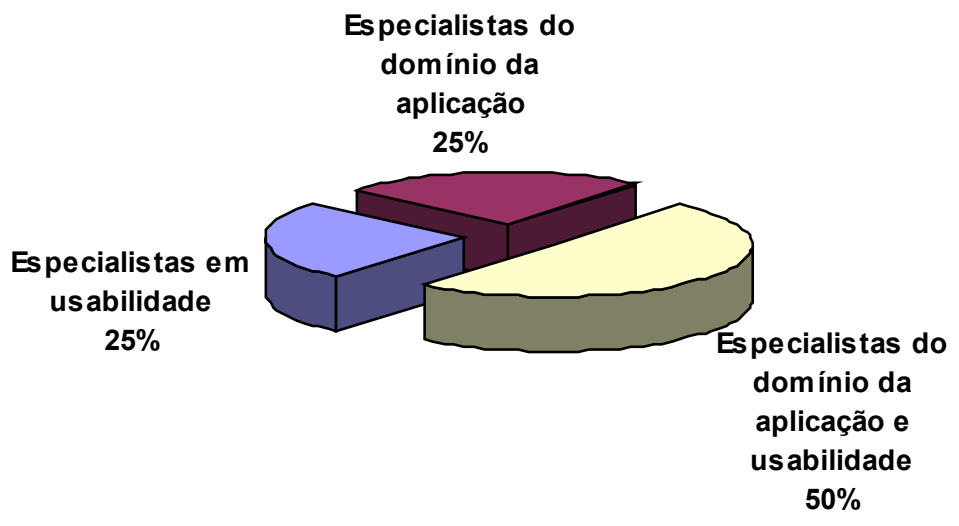

Figura 6.11: Especialidade dos inspetores. 
Os dados foram tabulados e resumidos, conforme mostra a Tabela 6.5, onde apresenta a quantidade de defeitos de usabilidade encontrados em cada heurística e distribuídos pelos graus de severidade. Dos 63 defeitos encontrados, mais da metade dos defeitos são referentes ao grau de severidade 3 , correspondentes a problemas de usabilidade de grande impacto, enquanto que as heurísticas que apresentaram mais defeitos foram a $\mathrm{H} 2$ e $\mathrm{H} 5$, referentes respectivamente à compatibilidade do sistema com o mundo real e a prevenção de erros.

Tabela 6.5: Quantidade de defeitos de usabilidade encontrados em cada heurística e distribuídos pelos graus de severidade.

\begin{tabular}{|c|c|c|c|c|c|c|c|c|c|c|c|}
\hline & H1 & $\mathrm{H} 2$ & H3 & H4 & H5 & H6 & H7 & H8 & H9 & H10 & Total \\
\hline G0 & & 1 & & 1 & 1 & & & 2 & & & 5 \\
\hline G1 & & & & & & 1 & & & 1 & & 2 \\
\hline G2 & 1 & 2 & & 3 & 2 & 2 & 1 & & & & 11 \\
\hline G3 & 3 & 7 & 1 & 3 & 5 & 4 & 3 & 1 & 5 & 1 & 33 \\
\hline G4 & 1 & & 2 & & 2 & 1 & 1 & & 3 & 2 & 12 \\
\hline Total & 5 & 10 & 3 & 7 & 10 & 8 & 5 & 3 & 9 & 3 & 63 \\
\hline
\end{tabular}

Uma outra visão da quantidade de defeitos de usabilidade relacionados a cada heurística e seus graus de severidade é apresentada na Figura 6.12. 


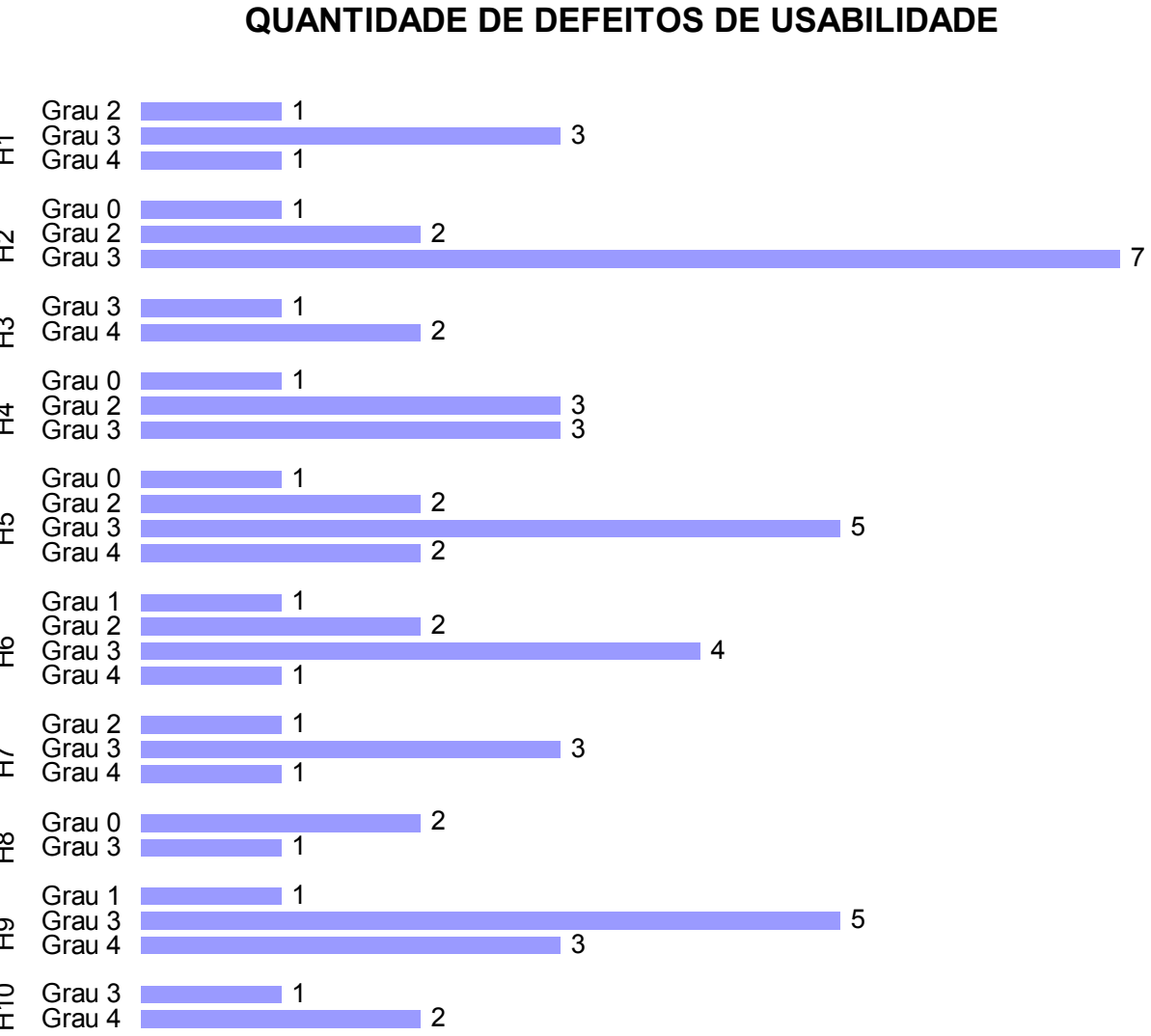

Figura 6.12: Quantidade de defeitos de usabilidade pelos graus de severidade.

A Figura 6.13 ilustra que cerca de $53 \%$ dos defeitos de usabilidade referem-se ao grau de severidade 3, que correspondem aos problemas de usabilidade de grande impacto, sendo importante consertar, requerendo alta prioridade de correção. Pode-se observar, também, que 19\% dos defeitos estão relacionados ao grau de severidade 4 e são considerados como catástrofe de usabilidade e devem ser consertados antes que o produto seja lançado. Para os defeitos de usabilidade de pequeno impacto, de grau 2, foram registrados $17 \%$, sendo que a prioridade deste conserto deve ser baixa. Apenas $3 \%$ dos defeitos classificados com grau 1 foram considerados como sendo somente problemas cosméticos, não precisando ser consertado a menos que haja tempo disponível. Finalmente, $8 \%$ foram determinados com grau 0 , isto é, não foram considerados como um problema de usabilidade.

Percebe-se que $89 \%$ dos defeitos encontrados devem ser consertados independentemente da intensidade do impacto. 


\section{DEFEITOS DE USABILIDADE POR GRAU DE SEVERIDADE}

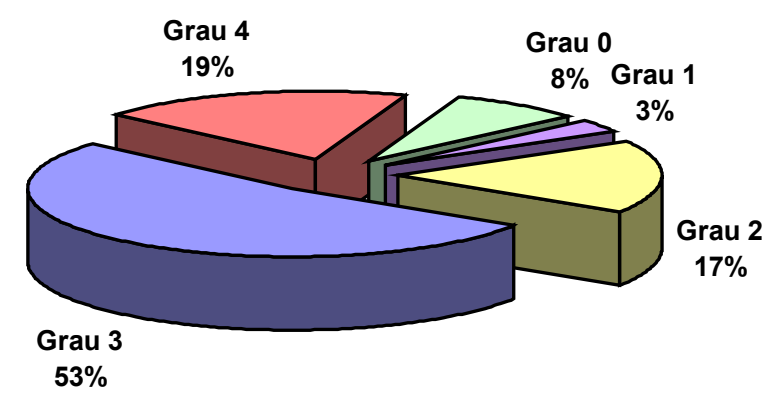

Figura 6.13: Defeitos encontrados por grau de severidade.

As Figuras 6.14 e 6.15 mostram que os maiores defeitos de usabilidade, correspondendo ao mesmo valor de $15,9 \%$, são atribuídos a duas heurísticas:

- referente à compatibilidade do sistema com o mundo real, não expressando uma linguagem familiar para os usuários. O sistema deve falar a linguagem do usuário, com palavras, frases e conceitos familiares ao usuário, ao invés de termos técnicos orientados ao sistema e deve seguir as convenções do mundo real, fazendo com que a informação apareça em uma ordem natural e lógica $(\mathrm{H} 2)$; e

- atribuída à prevenção de erros, onde o sistema não previne que o erro ocorra antes de acontecer. O sistema deve possuir um design cuidadoso, eliminando as condições favoráveis a erro e apresentar ao usuário uma opção de confirmação antes de executar uma ação (H5).

A falta de ajuda aos usuários a reconhecer, diagnosticar e recuperar seus erros representou $14,3 \%$ dos defeitos de usabilidade. As mensagens de erro devem ser expressas em linguagem clara, sem utilização de códigos, indicando precisamente o problema e sugerindo uma solução (H9).

O reconhecimento ao invés de lembrança, não possuindo instruções de uso do sistema e sobrecarregando a memória do usuário, indicou $12,7 \%$ dos problemas encontrados. O sistema deve permitir que o usuário possa lembrar da informação de uma parte do diálogo para outra. Instruções de uso do sistema devem estar visíveis e facilmente acessíveis quando necessário (H6). 
A consistência e padrões representaram $11,1 \%$ dos defeitos de usabilidade. $\mathrm{O}$ sistema deve sempre seguir as convenções de plataforma computacional, permitindo que os usuários não tenham que adivinhar que diferentes palavras, situações ou ações significam a mesma coisa (H4).

Para as duas heurísticas $\mathrm{H} 1$ e $\mathrm{H} 7$ obteve-se o mesmo valor de 7,9\% de defeitos referentes:

- à visibilidade do status do sistema. O sistema deve manter o usuário informado sobre o que está acontecendo, fornecendo um feedback apropriado dentro de um tempo razoável (H1); e

- à flexibilidade e eficiência de uso, sendo um ambiente intuitivo para interação tanto dos usuários iniciantes como experientes. Deve prover aceleradores de modo a aumentar a velocidade da interação para que os usuários novatos se tornem peritos com o uso (H7).

Os menores defeitos foram encontrados em três heurísticas com 4,8\% cada, a saber:

- referente ao controle e liberdade para o usuário quando os usuários, freqüentemente, escolhem funções por engano e precisam de uma "saída de emergência" claramente definida para sair do estado indesejado sem ter que percorrer um extenso diálogo. O sistema deve prover suporte a funções de desfazer (undo) e refazer (redo) (H3);

- correspondem a estética e design minimalista. O sistema deve apresentar um design simples e prático, sem informações irrelevantes ou desnecessárias. Qualquer unidade de informação extra no diálogo compete com as unidades relevantes de informação e diminui sua visibilidade relativa (H8); e

- embora possa-se pensar que um sistema que não necessita de documentação seja melhor do que outro que a demande, é sempre necessário prover ajuda ao usuário e a documentação completa do sistema. As informações devem ser fáceis de encontrar e focadas na tarefa do usuário (H10). 


\section{DEFEITOS DE USABILIDADE POR HEURÍSTICAS}

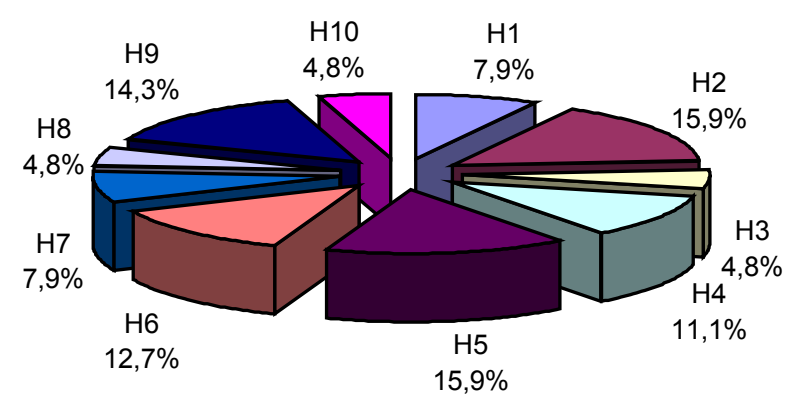

Figura 6.14: Defeitos encontrados por heurística.

\section{HEURÍSTICAS}

บิ Compatibilidade do sistema com o mundo real

Ajuda aos usuários a reconhecer, diagnosticar e recuperar os erros
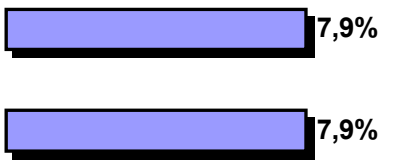

Controle e liberdade para o usuário
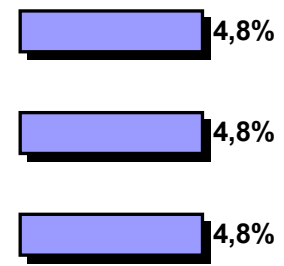

Figura 6.15: Defeitos de usabilidade encontrados. 
Constatou-se que cada avaliador identificou problemas de usabilidade diferentes. A Figura 6.16 mostra a quantidade de defeitos encontrados pelos inspetores. Neste estudo, foi possível perceber que avaliadores com conhecimento do domínio da aplicação (inspetores 2, 3 e 4) tiveram uma visão mais geral do sistema, comparando com outros sistemas semelhantes, enquanto que o especialista em usabilidade (inspetor 1) teve uma interpretação mais crítica e detalhista de cada ponto da interface. Pode-se concluir que existe uma relação entre o perfil dos avaliadores e os problemas encontrados. Assim sendo, é importante recrutar inspetores com áreas de conhecimento diferentes, pois o perfil do avaliador tem uma influência direta na descoberta de problemas.

\section{QUANTIDADE DE DEFEITOS ENCONTRADOS POR INSPETOR}

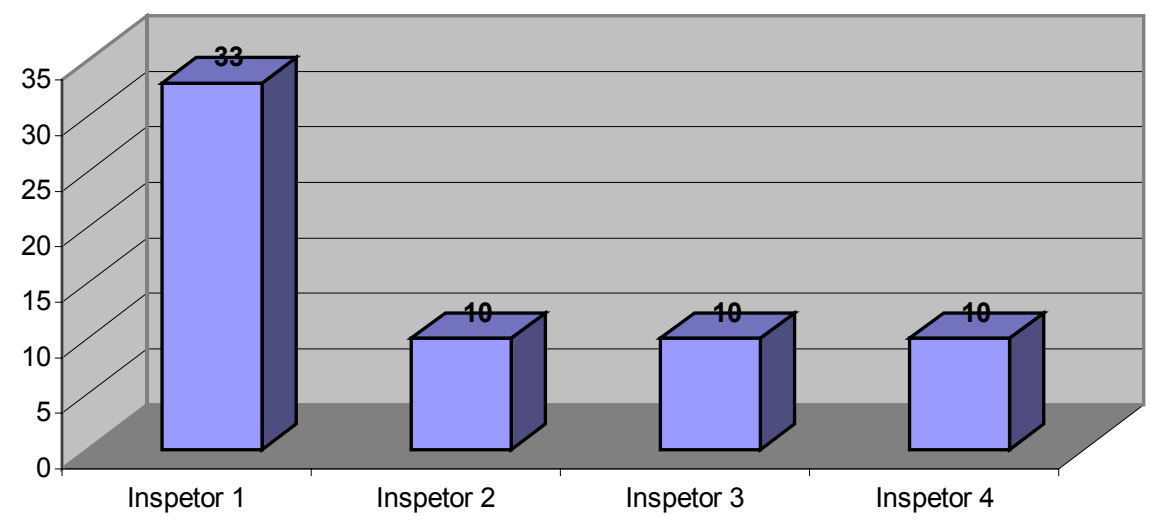

Figura 6.16: Quantidade de defeitos encontrados por cada inspetor.

\subsection{Recomendações finais}

Mesmo que muitos problemas possuam soluções óbvias, nem sempre é fácil interpretar os resultados e uma avaliação pode apresentar muitas surpresas. É possível descobrir defeitos em pontos da interface que podem ser melhorados e, ao contrário, usuários podem estar completamente confortáveis com detalhes que o avaliador apontou como um problema relevante. Também é possível descobrir que durante a análise dos resultados simplesmente não tem dados para prover uma resposta. Se os participantes não encontram nenhum problema, não se pode concluir que a interface é satisfatória. É importante perceber que um fracasso ao encontrar problemas na avaliação não implica que a interface é usável. Nesse caso, deve ser considerado apenas que a interface funciona com algumas tarefas determinadas. 
As recomendações para prevenir defeitos de usabilidade e projetar boas interfaces de usuários devem conter uma mistura de vários pontos relacionados aos seus objetivos e necessidades que estão resumidos na Tabela 6.6.

Tabela 6.6: Recomendações para abordagens de design.

\begin{tabular}{|c|c|c|}
\hline Objetivo & Necessidade & Recomendação \\
\hline Eficaz & Acurácia & $\begin{array}{l}\text { - } \quad \text { Prever pontos da interface que induz a erros. } \\
\text { - } \quad \text { Prover feedback e confirmações. } \\
\text { - } \quad \text { Prover confiança e credibilidade. }\end{array}$ \\
\hline Eficiente & $\begin{array}{l}\text { Velocidade } \\
\text { operacional }\end{array}$ & $\begin{array}{l}\text { - } \quad \text { Facilitar a navegação para a execução das tarefas. } \\
\text { - } \quad \text { Minimizar as ações requeridas através do estilo da interação. } \\
\text { - } \quad \text { Prover aceleradores para que usuários novatos se tornem } \\
\text { - } \quad \text { Proverientes. } \\
\text { - } \quad \text { Considerar somentrole e liberdade para o usuário. } \\
\text { - Seguir padrões de design. }\end{array}$ \\
\hline Atraente & Atrair usuários & $\begin{array}{l}\text { - Considerar e incorporar no design os aspectos que são mais } \\
\text { atrativos. } \\
\text { - } \quad \text { Ressaltar informações relevantes. } \\
\text { - Usar forma e tamanho de letras legível. } \\
\text { - Prover imagens de boa qualidade e tamanho. }\end{array}$ \\
\hline $\begin{array}{l}\text { Fácil de } \\
\text { aprender }\end{array}$ & Instrução & $\begin{array}{l}\text { - Criar interfaces passo a passo para ajudar os usuários a } \\
\text { navegar através de tarefas complexas. } \\
\text { - } \quad \text { Fornecer instruções de uso. } \\
\text { - Prover ajuda e documentação. }\end{array}$ \\
\hline $\begin{array}{l}\text { Tolerante ao } \\
\text { erro }\end{array}$ & Validação & $\begin{array}{l}\text { - Usar seleção para substituir entrada de dados. } \\
\text { - } \quad \text { Realizar cálculos para auxiliar dados de entrada. } \\
\text { - Prover mensagens de ajuda para reconhecer e corrigir erros. }\end{array}$ \\
\hline
\end{tabular}




\section{Recomendações para mudanças}

Visto que o objetivo deste estudo foi verificar se o sistema MRI Browser está de acordo com os requisitos a fim de melhorar sua interface, então foi incluída uma sessão de recomendação para determinar quais as mudanças que devem ser realizadas na interface. Essas recomendações estão disponíveis no Apêndice $\mathbf{C}$. 


\section{Conclusões}

\subsection{Considerações e discussão}

O design de uma interface intuitiva e atraente para o usuário é essencial para o sucesso de qualquer sistema computacional. Dentro do escopo de sistemas CBIR, que são sistemas inerentemente interativos, a interface do usuário ainda é um elemento constituído de pouca pesquisa e desenvolvimento. Um dos maiores obstáculos para a eficácia de design desses sistemas consiste da necessidade em prover aos usuários uma interface de alta qualidade na formulação de perguntas e exibição dos resultados.

Esse estudo introduziu um esforço para testar o desempenho de um sistema CBIR típico em relação à funcionalidade e usabilidade por meio da interação de usuários reais dentro do domínio da aplicação. Por esse motivo, o desempenho de tais sistemas pôde ser avaliado por critérios reais, fundamentando uma base sólida para julgar a percepção humana e prover meios para melhorar o desenvolvimento de sistemas que apóiam usuários reais em suas tarefas.

Para alcançar esse desafio, foram adotadas técnicas de avaliação da interação humano-computador, a fim de identificar abordagens promissoras no desempenho e satisfação dos usuários. Primeiramente, foi empreendida a técnica de observação de usuário, com o envolvimento efetivo de usuários reais, completando a seguir com a inspeção heurística, conduzida por meio da participação de especialistas.

A observação de usuários atingiu o objetivo proposto, pois pôde prover uma grande percepção de como os usuários pensam sobre a interface. Independente do perfil do usuário, a interface demonstrou facilidade de uso, assegurando que, no geral, os participantes cumprissem as tarefas tanto na acurácia como na completude. Percebeu-se que os usuários mais jovens demonstraram uma maior habilidade e agilidade computacional, conseguindo desempenhar as tarefas com mais eficiência. No entanto, 
os usuários que possuem mais conhecimento profissional desempenharam as tarefas com mais eficácia. Com relação à satisfação da interface, os usuários superaram suas expectativas que foram observadas antes e depois da interação.

Além disso, a introdução de sistemas CBIR dentro do domínio clínico determinou um fator importante para conhecimento e aceitação dos especialistas em sistemas de apoio a diagnósticos, uma vez que percebe-se muita restrição no uso de sistemas que efetuam diagnósticos médicos automáticos. Esta aceitação decorreu da facilidade de utilização do sistema por meio de interfaces intuitivas e também da confiabilidade e credibilidade da resposta provida pelo sistema. Apesar do tempo de resposta do sistema ser um fator primordial que influencia a expectativa do usuário, a qualidade da resposta, referente à quão similar as imagens são perante a uma dada imagem de referência, é tão ou mais importante que o tempo.

Nessa primeira avaliação pôde-se concluir que a experiência de trabalhar com usuários reais pode mudar totalmente a percepção de análise das tarefas dentro do domínio da aplicação. Não importa quão bom ou eficiente seja a aplicação, a aceitação ou não da aplicação depende, principalmente, das atitudes dos usuários em relação ao uso do computador no trabalho. Nesse contexto é necessário dar continuidade a pesquisas contando sempre com o envolvimento do usuário real.

Contudo, o sistema submetido à avaliação heurística sugere um escopo considerável de melhorias. Observou-se que os problemas encontrados pelos avaliadores com conhecimento em usabilidade foram identificados em função de conhecimentos prévios desses avaliadores. Enquanto que os problemas encontrados pelos avaliadores com conhecimento sobre o domínio da aplicação foram limitados em função de conhecimentos associados às heurísticas. Esses problemas poderiam não ser identificados se os avaliadores inexperientes em usabilidade não tivessem uma apresentação prévia das heurísticas.

Com essa segunda avaliação pôde-se perceber que é desejável que os avaliadores possuam uma certa experiência em usabilidade para abstrair todo o conhecimento requerido. Também é necessária a realização de novas experiências no sentido de identificar novas funcionalidades e melhorias para serem incorporadas em sistemas CBIR. Para uma próxima versão ou re-design pode-se considerar a inclusão das recomendações apresentadas no Apêndice $\mathbf{C}$.

A sinergia da combinação de técnicas de avaliação proporcionou a sugestão de melhorias significativas, provendo uma estimativa da utilidade potencial do sistema por 
meio da participação de especialistas e revelando as reações e percepções dos usuários reais. Conseqüentemente, o emprego de várias técnicas deve ser visto como um complemento efetivo para avaliação.

Uma outra contribuição deste trabalho foi direcionar um estudo detalhado de atividades para preparar, executar e analisar experimentos de avaliação de usabilidade. Em particular, esse estudo se estendeu desde a definição do domínio da aplicação, dos usuários, suas tarefas e do ambiente dentro do contexto em que o sistema está inserido, até a seleção das técnicas de avaliação mais apropriadas para compor a avaliação em questão.

De maneira geral, conclui-se que o uso de técnicas de interação humano-computador para avaliar a funcionalidade e a usabilidade de sistemas CBIR aplicados à medicina são primordiais para torná-los mais usáveis, eficientes e com elevado grau de satisfação para o usuário médico. Assim, os sistemas CBIR poderão ser melhor empregados pela comunidade médica, contribuindo para aprimorar os diagnósticos e tratamentos médicos.

Ainda há muito trabalho a ser realizado nessa área. Por um lado, deve-se dar continuidade ao desenvolvimento de algoritmos e técnicas automáticas para detectar e recuperar informações baseadas em conteúdo. E, por outro lado, deve-se enfatizar mais os aspectos da interação humano-computador e ter um bom conhecimento dos fatores humanos que afetam as estratégias de busca dentro do contexto de uso, levando em consideração as necessidades particulares dos usuários.

\subsection{Sugestões de trabalhos futuros}

Assim como a medicina, quase todas as áreas da ciência que possuem imagens diversificadas também podem se beneficiar com a pesquisa sobre recuperação de imagens por conteúdo e consultas por similaridade. Na agricultura e meio ambiente é comum o uso de imagens de satélite para monitorar o uso e cobertura da terra, visando caracterizar a dinâmica espaço-temporal do uso da terra e o impacto ambiental decorrente. O desenvolvimento das tecnologias de geoprocessamento e de informação permite a consolidação de métodos para tratamento e consulta de conjuntos de dados orbitais, porém a interpretação das imagens de satélite requer o auxílio de especialistas desse domínio. 
O Centro Nacional de Pesquisa de Monitoramento por Satélite da Empresa Brasileira de Pesquisa Agropecuária (Embrapa), mais conhecido como Embrapa Monitoramento por Satélite, localizado em Campinas-SP, vem atuando na busca de soluções tecnológicas, competitivas e sustentáveis voltadas à pesquisa na área agrícola e ambiental. Para efetivar a sua missão, são adotados procedimentos baseados em geotecnologias, fundamentando os conceitos básicos de tecnologias de localização, incluindo imagens de satélites, sistemas de informação geográfica, cartografia digital, posicionamento por satélites e como essas tecnologias se interagem para serem usadas como ferramentas de tomada de decisão.

Um dos desafios colocados à Embrapa Monitoramento por Satélite foi organizar um grande acervo de dados geográficos e imagens de satélites de todos os estados da federação brasileira em uma base digital de fácil consulta e disponibilizar informações sobre o uso das terras e as características ambientais do território nacional, a partir de imagens geradas pelo sistema de monitoramento espacial Landsat.

Como sugestão para um futuro trabalho, as imagens de satélite podem ser incorporadas em um sistema de busca por conteúdo a fim de detectar as características comuns predominantes nas imagens de todo o território brasileiro para auxiliar o técnico especialista a conhecer melhor os diferentes aspectos da agricultura e do meio ambiente. Desse modo, os estados brasileiros disporiam de um instrumento para apoiar suas ações de preservação ambiental e desenvolvimento sustentável.

Contudo, um novo estudo de avaliação da interação humano-computador deve ser efetuado dentro desse contexto para prover informações de qualidade, cuja aplicação e utilização pode ser a mais variada possível e como conseqüência, produzir e fornecer produtos e serviços mais específicos, que atendam às necessidades dos usuários com eficiência e eficácia. 


\section{Referências}

[Alferez-2005] R. Alferez, Y.-F. Wang, L. Jiao, "An Affine-Invariant Tool for Retrieving Images from Homogeneous Databases", Multimedia Tools and Applications, Vol. 25, No. 1, January, pp. 133-159.

[Amsaleg-2004] L. Amsaleg, P. Gros, S.-A. Berrani, "Robust Object Recognition in Images and the Related Database Problems", Multimedia Tools and Applications, Vol. 23, No. 3, August, pp. 221-235.

[Andrade-2003] R. Andrade, A.v. Wangenheim, M.K. Bortoluzzi, "Wireless and PDA: a novel strategy to access DICOM-compliant medical data on mobile devices", International Journal of Medical Informatics, Vol. 71, No. 2-3, September, pp. 157-163.

[Araujo-2001] M.R.B. Araujo, J.M. Bueno, H.L. Razente, C. Traina Jr., A.J.M. Traina, "Sistema de Recuperação de Imagens por Conteúdo em Arquitetura Aberta", Workshop de Informática Médica (WIM'2001), Rio de Janeiro, RJ, Brasil, 4 out., pp. 2 in CD-ROM.

[Araujo-2002] M.R.B. Araujo, C. Traina Jr., A.J.M. Traina, J.M. Bueno, H.L. Razente, "Extending Relational Databases to Support Content-based Retrieval of Medical Images", Proceedings of the 15th IEEE Symposium on Computer-Based Medical Systems (CBMS'02), Maribor, Slovenia, June 4-7, pp. 303-308.

[Baeg-2000] S. Baeg and N. Kehtarnavaz, "Texture Based Classification of Mass Abnormalities in Mammograms", Proceedings of the 13th IEEE Symposium on Computer-Based Medical Systems (CBMS'00), Houston, Texas, USA, June 2324, pp. 163-168.

[Baeza-Yates-1999] R.A. Baeza-Yates and B.A. Ribeiro-Neto, Modern Information Retrieval. Wokingham, UK: Addison-Wesley, 1999.

[Beier-2003] B. Beier and M.W. Vaughan, "The Bull's-Eye: A Framework for Web Application User Interface Design Guidelines", Proceedings of the SIGCHI Conference on Human Factors in Computing Systems (CHI'03), Ft. Lauderdale, Florida, USA, April 5-10, pp. 489-496.

[Blackmon-2003] M.H. Blackmon, M. Kitajima, P.G. Polson, "Repairing Usability Problems Identified by the Cognitive Walkthrough for the Web", Proceedings of the SIGCHI Conference on Human Factors in Computing Systems (CHI'03), Ft. Lauderdale, Florida, USA, April 5-10, pp. 497-504.

[Blackmon-2005] M.H. Blackmon, M. Kitajima, P.G. Polson, "Tool for Accurately Predicting Website Navigation Problems, Non-Problems, Problem Severity, and Effectiveness of Repairs", Proceedings of the SIGCHI Conference on Human Factors in Computing Systems (CHI'05), Portland, Oregon, USA, April 2-7, pp. 31-40. 
[Bortoluzzi-2003] M.K. Bortoluzzi, A.v. Wangenheim, K. Maximini, "A Clinical Report Management System based upon the DICOM Structured Report Standard", Proceedings of the 16th IEEE Symposium on Computer-Based Medical Systems (CBMS'03), New York, NY, USA, June 26-27, pp. 183-188.

[Bueno-2002a] J.M. Bueno, Suporte à recuperação de imagens médicas baseada em conteúdo através de histogramas métricos, Tese (Doutorado em Ciências de Computação e Matemática Computacional), Universidade de São Paulo, São Carlos, 2002a.

[Bueno-2002b] J.M. Bueno, F.J.T. Chino, A.J.M. Traina, C. Traina Jr., P.M.d.A. Marques, "How to Add Content-based Image Retrieval Capability in a PACS", Proceedings of the 15th IEEE Symposium on Computer-Based Medical Systems (CBMS'02), Maribor, Slovenia, June 4-7, pp. 321-326.

[Bueno-2002c] J.M. Bueno, A.J.M. Traina, C. Traina Jr., P.M.d.A. Marques, "cbPACS: PACS com Suporte à Recuperação de Imagens Médicas Baseada em Conteúdo", VIII Congresso Brasileiro de Informática em Saúde (CBIS'2002), Natal, RN, Brasil, 29 de setembro a 2 de outubro, pp. 6 in CD-ROM.

[Bueno-2003] J.M. Bueno and A.J.M. Traina, "Suporte à Recuperação de Imagens Médicas Baseada em Conteúdo através de Histogramas Métricos", VIII Simpósio de Teses e Dissertações Defendidas, São Carlos, SP, Brasil, 29 e 30 de outubro, pp. 13.

[Cai-2001] T.W. Cai, D.D. Feng, R. Fulton, "Web-Based Digital Medical Images", IEEE Computer Graphics and Applications, Vol. 21, No. 1, January/February, pp. 44-47.

[Campo-2003] C.Y. Campo and A.J.M. Traina, "Uma Abordagem Eficiente para Recuperação de Imagens Médicas", $3^{\circ}$ Workshop de Informática Médica (WIM'2003), Fortaleza, CE, Brasil, 1 de setembro, pp. 8 in CD-ROM.

[Cao-2003] P. Cao, M. Hashiba, K. Akazawa, T. Yamakawa, T. Matsutoc, "An integrated medical image database and retrieval system using a web application server", International Journal of Medical Informatics, Vol. 71, No. 1, August, pp. 51-55.

[Card-1983] S.K. Card, T.P. Moran, A. Newell, The Psychology of Human-Computer Interaction. Hillsdale: Lawrence Erlbaum Associates, 1983.

[Çarkacioglu-2003] A. Çarkacioglu and F. Yarman-Vural, "SASI: a generic texture descriptor for image retrieval", Pattern Recognition, Vol. 36, No. 11, November, pp. 2615-2633.

[Carro-2003] S.A. Carro, J. Scharcanski, J.V.d. Lima, "MedISeek: A Web Based Diffusion System for Medical Visual Information", Proceedings of the 5th ACM International Workshop on Web Information and Data Management (WIDM'03), New Orleans, Louisiana, USA, November 7-8, pp. 54-57. 
[Castañón-2003a] C.A.B. Castañón, Recuperação de imagens por conteúdo através de análise multiresolucao por Wavelets, Dissertação (Mestrado em Ciências de Computação e Matemática Computacional), Universidade de São Paulo, São Carlos, 2003a.

[Castañón-2003b] C.A.B. Castañón and A.J.M. Traina, "Caracterização de Imagens através de Análise Multiresolução por Wavelets para Sistemas CBIR", XXIX Conferência Latino-Americana de Informática (CLEI'2003), La Paz, Bolivia, 29 de setembro a 2 de outubro, pp. 12 in CD-ROM.

[Chávez-2001] E. Chávez, G. Navarro, R.A. Baeza-Yates, J.L. Marroquín, "Searching in Metric Spaces", ACM Computing Surveys, September, pp. 273-321.

[Chen-2000] Z. Chen, X. Yu, D.D. Feng, "A Telemedicine System over the Internet", Selected Papers From the Pan-Sydney Workshop on Visualisation, Sydney, Australia, December, pp. 113-115.

[Cheng-2003] S.-C. Cheng, "Content-based image retrieval using moment-preserving edge detection", Image and Vision Computing, Vol. 21, No. 9, September, pp. 809-826.

[Dix-2004] A. Dix, J. Finlay, G.D. Abowd, R. Beale, Human-Computer Interaction, 3 ed. Essex: Prentice Hall, 2004.

[Ereback-1994] A.-L. Ereback and K. Hook, "Using Cognitive Walkthrough for Evaluating a CSCW Application", Conference Companion on Human Factors in Computing Systems (CHI'94), Boston, Massachusetts, USA, April 24-28, pp. 9192.

[Felipe-2002] J.C. Felipe and A.J.M. Traina, "Utilizando Características de Textura para Identificação de Tecidos em Imagens Médicas", $2^{\circ}$ Workshop de Informática Médica (WIM'2002), Gramado, RS, Brasil, 17 de outubro, pp. 4 in CD-ROM.

[Feng-2001] D.D. Feng, T.W. Cai, J. Kim, Y.S. Lim, "Medical Image Data Retrieval and Manipulation through the WWW", Proceedings of 2001 International Symposium on Intelligent Multimedia, Video and Speech Processing, Kowloon Shangri-La, Hong Kong, May 2-4, pp. 381-384.

[Gagaudakis-2001] G. Gagaudakis and P.L. Rosin, "Shape measures for image retrieval", Proceedings of the 2001 International Conference on Image Processing (ICIP'01), Thessaloniki, Greece, October 7-10, pp. 757-760.

[Ginneken-2001] B.v. Ginneken, "Towards a clinical chest workstation", Proceedings of VISIM, Utrecht, Netherland, October 18, pp. 4.

[Glatard-2004] T. Glatard, Johan Montagnat, I.E. Magnin, "Texture Based Medical Image Indexing and Retrieval: Application to Cardiac Imaging", Proceedings of the 6th ACM SIGMM International Workshop on Multimedia Information Retrieval (MIR'04), New York, NY, USA, October 15-16, pp. 135-142.

[Huang-2003] P.-W. Huang and S.K. Dai, "Image retrieval by texture similarity", Pattern Recognition, Vol. 36, No. 3, March, pp. 665-679. 
[Huang-2004] P.-W. Huang and C.-H. Lee, "Image Database Design Based on 9D-SPA Representation for Spatial Relations", IEEE Transactions on Knowledge and Data Engineering, Vol. 16, No. 12, December, pp. 1486-1496.

[ISO-9241-11-1998] ISO-9241-11, Ergonomic requirements for office work with Visual Display Terminals (VDTs): guidance on usability. Genebra, 1998.

[Jones-2005] P.H. Jones and C. Chisalita, "Cognition and Collaboration - Analyzing Distributed Community Practices for Design", CHI'05 Extended Abstracts on Human Factors in Computing Systems, Portland, Oregon, USA, April 2-7, pp. 2120

[Khludov-2000] S. Khludov, L. Vorwerk, C. Meinel, "Internet-orientated medical information system for Dicom-data transfer, visualization and revision", Proceedings of the 13th IEEE Symposium on Computer-Based Medical Systems (CBMS'00), Houston, Texas, USA, June 23-24, pp. 293-296.

[Kim-2000] J. Kim, D.D. Feng, T.W. Cai, "A Web Based Medical Image Data processing and Management System", Selected Papers From the Pan-Sydney Workshop on Visualisation, Sydney, Australia, December, pp. 89-91.

[Kim-2002] J. Kim, D.D. Feng, T.W. Cai, S. Eberl, "Content access and distribution of multimedia medical data in e-health", IEEE International Conference on Multimedia and Expo (ICME'2002), Lausanne, Switzerland, August 26-29, pp. 341-344.

[Kosara-2002] R. Kosara and S. Miksch, "Visualization methods for data analysis and planning in medical applications", International Journal of Medical Informatics, Vol. 68, No. 1-3, December, pp. 141-153.

[Lecce-1999] V.D. Lecce and A. Guerriero, "An Evaluation of the Effectiveness of Image Features for Image Retrieval", Journal of Visual Communication and Image Representation, Vol. 10, No. 4, December, pp. 351-362.

[Lewis-1990] C. Lewis, P.G. Polson, C. Wharton, J. Rieman, "Testing a Walkthrough Methodology for Theory-Based Design of Walk-Up-and-Use Interfaces", Proceedings of the SIGCHI Conference on Human Factors in Computing Systems: Empowering People (CHI'90), Seattle, Washington, USA, April 1-5, pp. $235-242$.

[Li-2000] J. Li, J.Z. Wang, G. Wiederhold, "IRM: Integrated Region Matching for Image Retrieval", Proceedings of the Eighth ACM International Conference on Multimedia (MULTIMEDIA'00), Marina del Rey, California, USA, October, pp. 147-156.

[Lin-2003] H.-C. Lin, C.-Y. Chiu, S.-N. Yang, "Finding textures by textual descriptions, visual examples, and relevance feedbacks", Pattern Recognition Letters, Vol. 24, No. 14, October, pp. 2255-2267. 
[Long-2003] L.R. Long, S.K. Antani, G.R. Thoma, "A Prototype Content-based Image Retrieval System for Spine X-rays", Proceedings of the 16th IEEE Symposium on Computer-Based Medical Systems (CBMS'03), New York, NY, USA, June 26-27, pp. 156-162.

[Lopes-2005] O.C. Lopes, iRIS Servidor: Sistema servidor para recuperação de imagens por conteúdo, Dissertação (Mestrado em Ciências de Computação e Matemática Computacional), Universidade de São Paulo, São Carlos, 2005.

[Mankoff-2003] J. Mankoff, A.K. Dey, G. Hsieh, J. Kientz, S. Lederer, M. Ames, "Heuristic Evaluation of Ambient Displays", Proceedings of the SIGCHI Conference on Human Factors in Computing Systems (CHI'03), Ft. Lauderdale, Florida, USA, April 5-10, pp. 169-176.

[McQuaid-2001] H.L. McQuaid and D. Bishop, "An integrated method for evaluating interfaces", CHI'01 Extended Abstracts on Human Factors in Computing Systems, Seattle, Washington, USA, March 31-April 5, pp. 287-288.

[Mirmehdi-2002] M. Mirmehdi and R. Perissamy, "Perceptual Image Indexing and Retrieval", Journal of Visual Communication and Image Representation, Vol. 13, No. 4, December, pp. 460-475.

[Moghaddam-2000] B. Moghaddam, H. Biermann, D. Margaritis, "Image retrieval with local and spatial queries", International Conference on Image Processing (ICIP'00), Vancouver, Canada, September, pp. 542-545.

[Moghaddam-2001] B. Moghaddam, H. Biermann, D. Margaritis, "Regions-of-Interest and Spatial Layout for Content-Based Image Retrieval", Multimedia Tools and Applications, Vol. 14, No. 2, June, pp. 201-210.

[Müller-2004] H. Müller, N. Michoux, D. Bandon, A. Geissbuhler, "A review of content-based image retrieval systems in medical applications-clinical benefits and future directions", International Journal of Medical Informatics, Vol. 73, No. 1, February, pp. 1-23.

[Nema-2005] Nema, "DICOM - Digital Imaging and COmmunications in Medicine", Disponível em: $<$ http://medical.nema.org/> . Acesso em: 27 dez. 2005.

[Nielsen-1990] J. Nielsen and R. Molich, "Heuristic evaluation of user interfaces", Proceedings of the SIGCHI Conference on Human Factors in Computing Systems: Empowering People (CHI'90), Seattle, Washington, USA, April 1-5, pp. 249-256.

[Nielsen-1993] J. Nielsen, Usability Engineering. Boston: Academic Press, 1993.

[Nielsen-2005] J. Nielsen, "Heuristic evaluation", Disponível em:

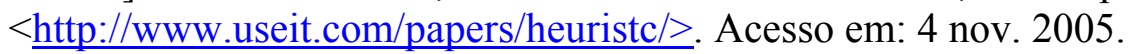

[Oeiras-2001] J.Y.Y. Oeiras, L.A.S. Romani, S.M.F.S. Massruhá, M.C.C. Baranuskas, "Abordagem etnográfica-aplicada e a avaliação de interfaces: um estudo de caso", Universidade Estadual de Campinas, Campinas, Technical Report, IC-01002, março. 
[Park-2002] M. Park, J.S. Jin, L.S. Wilson, "Fast Content-Based Image Retrieval Using Quasi-Gabor Filter and Reduction of Image Feature Dimension", Proceedings of the Fifth IEEE Southwest Symposium on Image Analysis and Interpretation (SSIAI'02), Santa Fe, NM, USA, April 7-9, pp. 178-182.

[Pereira-2001] J. Pereira, A. Lamelo, J.M. Vázquez-Naya, M. Fernández, J.M. LópezGestal, J. Teijero, A. Pazos, "Design and implementation of a DICOM PACS with secure access via internet", 23rd Annual International Conference of the IEEE Engineering in Medicine and Biology Society (EMBC 2001), Istanbul, Turkey, October 25-28, pp. 3724-3727.

[Pereira-2002] J. Pereira, A. Castro, D. Ronda, B. Arcay, A. Pazos, "Development of a System for Access to and Exploitation of Medical Images", Proceedings of the 15th IEEE Symposium on Computer-Based Medical Systems (CBMS'02), Maribor, Slovenia, June 4-7, pp. 309-314.

[Pereira-2003] J. Pereira, A. Castro, B. Arcay, A. Pazos, A. Gomez, "Framework of a system for the management and assistance in analysis of medical images", Proeddings of the 4th Annual IEEE Conference on Information Technology Applications in Biomedicine, Birmingham, UK, April 24-26, pp. 86-89.

[Pinelle-2002] D. Pinelle and C. Gutwin, "Groupware Walkthrough: Adding Context to Groupware Usability Evaluation", Proceedings of the SIGCHI Conference on Human Factors in Computing Systems: Changing Our World, Changing Ourselves (CHI'02), Minneapolis, Minnesota, USA, April 20-25, pp. 455-462.

[Polson-1992] P.G. Polson, C. Lewis, J. Rieman, C. Wharton, "Cognitive Walkthroughs: A Method for Theory-Based Evaluation of User Interfaces", Univesity of Colorado, Boulder, Technical Report \#91-01.

[Preece-1994] J. Preece, Y. Rogers, H. Sharp, B. D., H. S., C. T., Human-Computer Interaction. Wokingham: Addison-Wesley, 1994.

[Preece-1995] J. Preece, A Guide to Usability: human factors in computing. Wokingham: Addison-Wesley Publishing Company, 1995.

[Preece-2005] J. Preece, Y. Rogers, H. Sharp, Design de Interação: além da interação homem-computador. Porto Alegre: Bookman, 2005.

[Rocha-2003] H.V. Rocha and M.C.C. Baranauskas, Design e Avaliação de Interfaces Humano-Computador. Campinas: NIED/UNICAMP, 2003.

[Rosa-2002a] N.A. Rosa, Uma abordagem prática e eficiente de consultas por similaridade para suporte a diagnóstico por imagens, Dissertação (Mestrado em Ciências de Computação e Matemática Computacional), Universidade de São Paulo, São Carlos, 2002a.

[Rosa-2002b] N.A. Rosa, R.F. Santos Filho, J.M. Bueno, A.J.M. Traina, C. Traina Jr., "Sistema de Recuperação de Imagens Similares em um Hospital Universitário", VIII Congresso Brasileiro de Informática em Saúde (CBIS'2002), Natal, RN, Brasil, 29 de setembro a 2 de outubro, pp. 6 in CD-ROM. 
[Rosa-2002c] N.A. Rosa, A.J.M. Traina, C. Traina Jr., "Recuperação de Imagens Médicas por Similaridade em um Hospital Universitário", $2^{\circ}$ Workshop de Informática Médica (WIM'2002), Gramado, RS, Brasil, 17 de outubro, pp. 4 in CD-ROM.

[Rosa-2003] N.A. Rosa and A.J.M. Traina, "Uma abordagem prática e eficiente de consultas por similaridade para suporte a diagnóstico por imagens", VIII Simpósio de Teses e Dissertações Defendidas, São Carlos, SP, Brasil, 29 e 30 de outubro, pp. 10.

[Rui-1999] Y. Rui, T.S. Huang, S.-F. Chang, "Image Retrieval: Current Techniques, Promising Directions, and Open Issues", Journal of Visual Communication and Image Representation, Vol. 10, No. 4, April, pp. 39-62.

[Smith-1986] S.L. Smith and J.N. Mosier, "Guidelines for designing user interface software", Disponível em: <http://www.hcibib.com>. Acesso em: 4 nov. 2005.

[Stehling-2002] R.O. Stehling, M.A. Nascimento, A.X. Falcão, "A Compact and Efficient Image Retrieval Approach Based on Border/Interior Pixel Classification", Proceedings of the Eleventh International Conference on Information and Knowledge Management (CIKM'02), McLean, Virginia, USA, November 4-9, pp. 102-109.

[Stone-2005] D. Stone, C. Jarret, M. Woodroffe, S. Minocha, User Interface Design and Evaluation. San Francisco: Morgan Kaufmann, 2005.

[Sung-2000] M.Y. Sung, M.S. Kim, M.-W. Sung, E.J. Kim, J.H. Yoo, "CoMed: A Realtime Collaborative Medicine System", Proceedings of the 13th IEEE Symposium on Computer-Based Medical Systems (CBMS'00), Houston, Texas, USA, June 23-24, pp. 215-220.

[Torres-2003] R.S. Torres, E.M. Picado, A.X. Falcão, L.F.d. Costa, "Effective Image Retrieval by Shape Saliences", 16th Brazilian Symposium on Computer Graphics and Image Processing (SIBGRAPI'03), São Carlos, SP, Brazil, October 12-15, pp. 167-174.

[Tory-2004] M. Tory and T. Möller, "Human Factors in Visualization Research", IEEE Transactions on Visualization and Computer Graphics, Vol. 10, No. 1, January/February, pp. 72-84.

[Traina-2003a] A.J.M. Traina, C.A.B. Castañón, C. Traina Jr., "MultiWaveMed: A System for Medical Image Retrieval through Wavelets Transformations", Proceedings of the 16th IEEE Symposium on Computer-Based Medical Systems (CBMS'03), New York, NY, USA, June 26-27, pp. 150-155.

[Traina-2003b] A.J.M. Traina, N.A. Rosa, C. Traina Jr., "Integrating Images to Patient Electronic Medical Records through Content-based Retrieval Techniques", Proceedings of the 16th IEEE Symposium on Computer-Based Medical Systems (CBMS'03), New York, NY, USA, June 26-27, pp. 163-168. 
[Traina-2004] A.J.M. Traina, A.G.R. Balan, L.M. Bortolotti, C. Traina Jr., "Contentbased Image Retrieval Using Approximate Shape of Objects", Proceedings of the 17th IEEE Symposium on Computer-Based Medical Systems (CBMS'04), Bethesda, Maryland, USA, June 24-25, pp. 91-96.

[Traina Jr.-2003] C. Traina Jr., A.J.M. Traina, M.R.B. Araujo, J.M. Bueno, F.J.T. Chino, H.L. Razente, P.M.d.A. Marques, "Using an Image-Extended Relational Database to Support Content-based Image Retrieval in a PACS", Computer Methods and Programs in Biomedicine, Vol. 80, No. 1, December, pp. 71-83.

[Traina Jr.-2004] C. Traina Jr., A.J.M. Traina, J.M.d. Figueiredo, "Including Conditional Operators in Content-Based Image Retrieval in Large Sets of Medical Exams", Proceedings of the 17th IEEE Symposium on Computer-Based Medical Systems (CBMS'04), Bethesda, Maryland, USA, June 24-25, pp. 85-90.

[Traina Jr.-2005] C. Traina Jr., A.J.M. Traina, M.C.N. Barioni, H.L. Razente, "SIREN SImilarity Retrieval ENgine", Disponível em: $<$ http://www.gbdi.icmc.usp.br/siren>. Acesso em: 9 dez. 2005.

[Vu-2003] K. Vu, K.A. Hua, W. Tavanapong, "Image Retrieval Based on Regions of Interest", IEEE Transactions on Knowledge and Data Engineering, Vol. 15, No. 4, July/August, pp. 1045-1049.

[Wolf-2000] C. Wolf, J.-M. Jolion, W.G. Kropatsch, H. Bischof, "Content based Image Retrieval using Interest Points and Texture Features", Proceedings of the International Conference on Pattern Recognition (ICPR'00), Barcelona, Spain, September 3-7, pp. 234-237.

[Xu-2003] X. Xu, D.J. Lee, S. Antani, L.R. Long, "Localizing Contour Points for Indexing an X-ray Image Retrieval System", Proceedings of the 16th IEEE Symposium on Computer-Based Medical Systems (CBMS'03), New York, NY, USA, June 26-27, pp. 169-174.

[Zhang-2003] H.-j. Zhang, Z. Chen, M. Li, Z. Su, "Relevance Feedback and Learning in Content-Based Image Search", World Wide Web Journal, Vol. 6, No. 2, June, pp. 131-155.

[Zhang-2001] Z.M. Zhang, G. Pu, A. Krol, "IBMAS: An Internet Based Medical Archive System", Proceedings of the 14th IEEE Symposium on Computer-Based Medical Systems (CMBS'01), March 26-27, pp. 541-546.

[Zhou-2003] X.S. Zhou and T.S. Huang, "Relevance feedback in image retrieval: A comprehensive review", Multimedia Systems, Vol. 8, No. 6, April, pp. 536-544.

[Zhuang-2001] Y. Zhuang, Q. Li, R.W.H. Lau, "Web-Based Image Retrieval: a Hybrid approach", Proceedings of the International Conference on Computer Graphics, Hong Kong, China, July 3-6, pp. 62-69. 


\section{Sistemas CBIR on-line}

\section{Accio (A Localized CBIR System)}

Washington University in Saint Louis, USA

http://www.cs.wustl.edu/accio/index.html

ADL (Alexandria Digital Library)

University of California, Santa Barbara, USA

http://www.alexandria.ucsb.edu

ALIPR (Automatic Linguistic Indexing of Pictures)

http://www.alipr.com

BDLP (Berkeley Digital Library Project)

University of California, Berkeley, USA

http://elib.cs.berkeley.edu

\section{Betaface (Face Detection and Face Recognition)}

http://www.betaface.com

\section{Blobworld}

Digital Library Project - University of California, Berkeley, USA

http://elib.cs.berkeley.edu/blobworld/

BSIm (Color-Based Image Retrieval Using Compact Binary Signatures)

Department of Computing Science, University of Alberta, Canada

http://db.cs.ualberta.ca/BSIm/bsim.cgi

\section{C-bird (Content-Based Image Retrieval from Digital Libraries)}

School of Computing Science, Simon Fraser University, Burnaby, B.C., Canada

http://www.cs.sfu.ca/cbird/ 


\title{
CalPhotos
}

Biodiversity Sciences Technology (BSCIT) - University of California, Berkeley, USA

http://calphotos.berkeley.edu

\section{CANDID (Comparison Algorithm for Navigating Digital Image Databases)}

Computer Research and Applications Group, Los Alamos National Laboratory, USA

http://public.lanl.gov/kelly/CANDID/index.shtml

\section{CBIR: Content Based Image Retrieval (Aysegul Cuhadar)}

Carleton University, Canada

http://www.sce.carleton.ca/faculty/cuhadar/CBIR/

\section{CBsIR (Content-Based Sub-Image Retrieval)}

Department of Computing Science, University of Alberta, Canada

http://www.cs.ualberta.ca/ iieluo/CBsIR.html

\section{CIRES (Content Based Image REtrieval System)}

University of Texas, Austin, USA

http://amazon.ece.utexas.edu/ qasim/research.htm

\section{Code Project (Finding Similiar Images)}

The Code Project

http://www.codeproject.com

\section{COMPASS (COMPuter Aided Search System)}

ITC-IRST Centre for Scientific and Technological Research

http://compass.itc.it

\author{
Cortina (Large-Scale, Content-based Image Retrieval on the WWW) \\ Vision Research Lab, UCSB, USA \\ http://vision.ece.ucsb.edu/multimedia/cortina.html
}

\section{FIR (Formula Image Retrieval)}

Fraunhofer Institute for Computer Graphics, Darmstadt, Germany, in association with Txt Ingegneria Informatica S.P.A. (Italy), Giunti Multimedia Srl (Italy), Epsilon Software (Greece), and Kino TV \& Movie Productions S.A. (Greece)

http://www.igd.fhg.de/igd-a7/projects/formula/formula e.html

\section{FIRE (Flexible Image Retrieval Engine)}

Open Source - development by Daniel Keysers and Thomas Deselaers

http://www-i6.informatik.rwth-aachen.de/ deselaers/fire.html 


\section{ImageFinder}

Attrasoft Inc.

http://www.imagequery.net

\section{ImageGrouper}

University of Illinois, USA

http://www.ifp.uiuc.edu/ nakazato/grouper/

\section{ImageRETRO (Image RETrieval by Reduction and Overview)}

Department of Computer Science, University of Amsterdam, The Netherlands http://carol.wins.uva.nl/ vendrig/imageretro/

\section{ImageRover}

Department of Computer Science, Boston University, MA, USA

http://www.cs.bu.edu/groups/ivc/lmageRover/Home.html

\section{ImageScape}

LIACS MEDIA LAB \& Leiden University, The Netherlands

http://skynet.liacs.nl/imagescape/

IMEDIA (Image and Multimedia Indexing, Browsing and Retrieval)

INRIA, Rocquencourt, France

http://www-rocq.inria.fr/imedia/

\section{ImgSeek}

Licensed under the GPL

http://www.imgseek.net

\section{Informedia Digital Video Library}

Carnegie Mellon, USA

http://www.informedia.cs.cmu.edu

\section{IQUEST}

Laboratoire de Bases de Données, Ecole Polytechnique Fédérale de Lausanne http://lbdwww.epfl.ch/e/research/iquest/

IRMA (Image Retrieval in Medical Applications)

Universitätsklinikum der RWTH Aachen

http://phobos.imib.rwth-aachen.de/irma/index en.php 
ISLA (Intelligent Systems Lab Amsterdam)

Departmentof Computer Science, University of Amsterdam

http://lbdwww.epfl.ch/e/research/iquest/

\section{LCPD (Leiden 19th Century Portrait Database)}

Department of Computer Science, Leiden University, The Netherlands

http://nies.liacs.nl:1860/

\section{MARS (Multimedia Analysis and Retrieval System)}

Department of Computer Science, University of Illinois at Urbana-Champaign, further developed at Department of Information and Computer Science, University of California at Irvine, CA, USA http://www-db.ics.uci.edu/pages/research/mars.shtml

\section{MetaSEEk}

Image and Advanced Television Lab, Columbia University, NY, USA

http://www.ctr.columbia.edu/metaseek/

\section{MIR (Multimodal Information Retrieval System)}

Center of Excellence for Document Analysis and Recognition, University at Buffalo, NY, USA http://www.cedar.buffalo.edu/mmir/mmir.html

\section{MIRROR (Multimedia Information Retrieval Reducing information OveRload)}

University of Twente, The Netherlands

http://wwwhome.cs.utwente.nl/ arjen/mmdb.html

MRML (Perl MRML CGI Client)

http://viper.csse.monash.edu.au/ davids/cgi-bin/PerlMRMLClient/PerIMRMLClient.pl

\section{Multi-Channel (Image Retrieval System)}

Information Retrieval Group, Univ. Of Virginia, USA

http://www.cs.virginia.edu/ xj3a/research/CBIR/

MUVIS (A System For Content-Based Indexing And Retrieval In Multimedia Databases)

Tampere University of Technology, Finland

http://muvis.cs.tut.fi

\section{Object and Concept Recognition for Content-Based Image Retrieval}

Department of Computer Science and Engineering, University of Washington, Seattle, WA, USA

http://www.cs.washington.edu/research/imagedatabase/ 


\section{Octagon (Content Based Image Retrieval Software)}

University of Turku, Finland

http://users.utu.fi/jukvii/octagon/

\section{Photobook}

Vision and Modeling Group, MIT Media Laboratory, Cambridge, MA, USA

http://vismod.media.mit.edu/vismod/demos/photobook/index.html

\section{PhotoFinder}

University of Maryland, USA

http://www.cs.umd.edu/hcil/photolib/

\section{PicSOM (Picture Self-Organising Maps)}

Laboratory of Computer and Information Science, Helsinki University of Technology, Finland http://www.cis.hut.fi/picsom/

\section{PicToSeek}

Department of Computer Science, University of Amsterdam, The Netherlands http://zomax.science.uva.nl:5345/ret user/index.html

\section{QBIC (Query By Image Content)}

IBM Almaden Research Center, San Jose, CA, USA

http://wwwqbic.almaden.ibm.com

\section{SaFe (Spatial and Feature Query System)}

Department of Electrical Engineering, Columbia University, USA

http://www.ee.columbia.edu/ irsmith/html/pubs/mmsp98/mmspfin/WWW/safe.html

\section{SIMBA (Search Images By Appearance)}

Institute for Pattern Recognition and Image Processing, Freiburg University, Germany http://simba.informatik.uni-freiburg.de

\section{SIMPLYcity (Semantics-sensitive Integrated Matching for Picture Libraries)}

Stanford and Pennsylvania State Universities, USA

http://wang14.ist.psu.edu/cgi-bin/zwang/regionsearch show.cgi

\section{SQUID (Shape Queries Using Image Databases)}

Centre for Vision, Speech, and Signal Processing, University of Surrey, UK http://www.ee.surrey.ac.uk/Research/VSSP/imagedb/demo.html 
Apêndice A

\section{Tiltomo}

http://www.tiltomo.com

\section{Viper (Visual Information Processing for Enhanced Retrieval)}

Computer Vision Group, University of Geneva, Switzerland

http://viper.unige.ch

Virage

http://www.virage.com/home/index.en.html

\section{VISOO}

Cobion $\mathrm{GmbH}$, Germany

http://www.visoo.de

\section{VisualSEEk}

Image and Advanced Television Lab, Columbia University, NY, USA

http://www.ee.columbia.edu/ln/dvmm/researchProjects/Multimedialndexing/VisualSEEk/VisualSEEk.htm

\section{WebSEEK}

Image and Advanced Television Lab, Columbia University, NY, USA

http://www.ctr.columbia.edu/WebSEEk/ 


\section{Questionários}

\section{Questionário pré-sessão}

Partolpant $n^{\circ}$

Questionário

1. Sexo:

2. Faixa de idsde: [ ] a sté 17 anos

] 18 a 30 mos

] 31 \& 44 mos

[ ] 45 a 64 mos

[ ] acima de 65 mos

3. Grau de instrufão:

[ ] Superior completo. Especialidade:

Tempo de stuarão:

[ ] Syerior incompleto.

Especifique:

\begin{tabular}{|c|c|c|c|c|}
\hline \multirow[b]{2}{*}{ 4. Experiêndia en infounática: } & \multicolumn{4}{|c|}{ Frequiêrncia de uso } \\
\hline & Diária & Semanal & Evrentral & Firuca \\
\hline Uso de sistemas médicos informatizados & & & & \\
\hline Uso de correio eletrônico (e-mails) & & & & \\
\hline Uso de intemet (por ex. pesquisa e diversão) & & & & \\
\hline $\begin{array}{l}\text { Uso de editores de texto (por ex. Word) e/ou } \\
\text { plarimas eletrônic as (por ex. Excel) }\end{array}$ & & & & \\
\hline
\end{tabular}

\begin{tabular}{|l|l|l|l|}
\hline \multicolumn{1}{|c|}{ 5. Conhecinento da líguaingles: } & Pouco & Razoswehnerte & Bem \\
\hline Compreende & & & \\
\hline Fala & & & \\
\hline Lề & & & \\
\hline Escreve & & & \\
\hline
\end{tabular}

6. O que você epera de um sistema para auxiliar o diagnóstico méciico, que ten o objelivo de recuperar imagens de exames méticos similares?

Figura B.1: Questionário pré-sessão. 
Questionário pós-sessão

Partolpante $n^{\circ}$ :

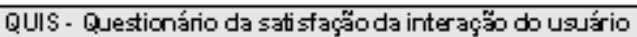

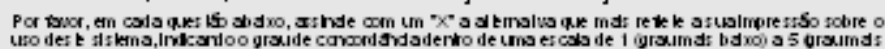
abi culA (HS se anka).

PARTE A - REACAO DO IIS TEMA

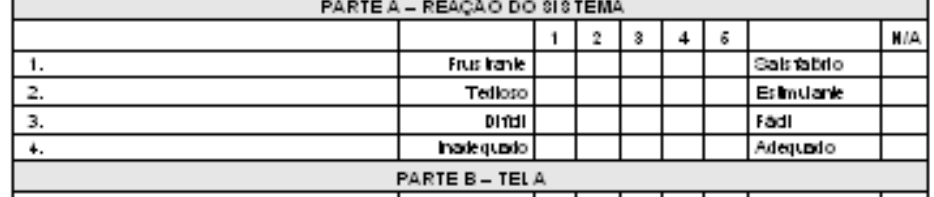

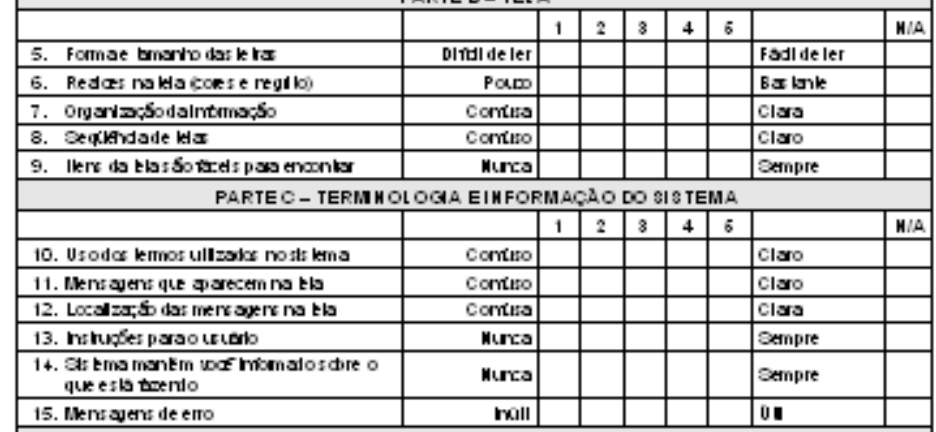

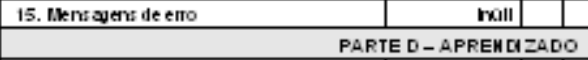

\begin{tabular}{|c|c|c|c|c|c|c|c|c|}
\hline & & 1 & 2 & 3 & 4 & 6 & & H/A \\
\hline 16. Aprewdera qerar oste ems & Diñal & & & & & & FadI & \\
\hline 17. Exporar por kntalwae efro & Diñal & & & & & & FadI & \\
\hline 18. Lembrar tma e to ode $a$ mand $\alpha$ & Diñal & & & & & & FOAI & \\
\hline 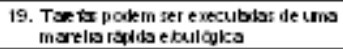 & Murca & & & & & & Sempre & \\
\hline 20. Conckr Soda bret & Comiro & & & & & & Claro & \\
\hline 21. I.kentanes de alds & Comaro & & & & & & claro & \\
\hline
\end{tabular}

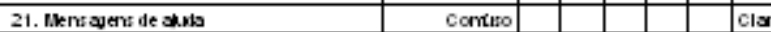

\begin{tabular}{|c|c|c|c|c|c|c|c|c|}
\hline & & 1 & 2 & 3 & 4 & 6 & & H/A \\
\hline 22. Vetochask dosts tmo & Lenb & & & & & & Rapldo & \\
\hline 23. 0 sts tma e anfor:t & Murca & & & & & & Sempre & \\
\hline 24. comidrsece enas & Diñal & & & & & & Fadl & \\
\hline 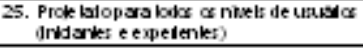 & Com dikcudsie & & & & & & Fodmenk & \\
\hline
\end{tabular}

\begin{tabular}{|c|c|c|c|c|c|c|c|c|}
\hline \multicolumn{9}{|c|}{ PARTE F-IMAGEMO } \\
\hline & & 1 & 2 & 3 & 4 & 6 & & H/A \\
\hline 25. Qusldste da Imsyerx & Putn & & & & & & $B 00$ & \\
\hline 27. Tanavoda mayery & Pequeno & & & & & & Gravile & \\
\hline 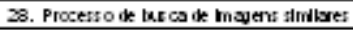 & Destrikeresrank & & & & & & inkressank & \\
\hline 29. Reapera, Sode mayerr stmilas: & MSo retevant & & & & & & Rekwont & \\
\hline 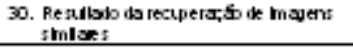 & MSocanfart & & & & & & comfrat & \\
\hline
\end{tabular}

Figura B.2: Questionário pós-sessão (frente). 


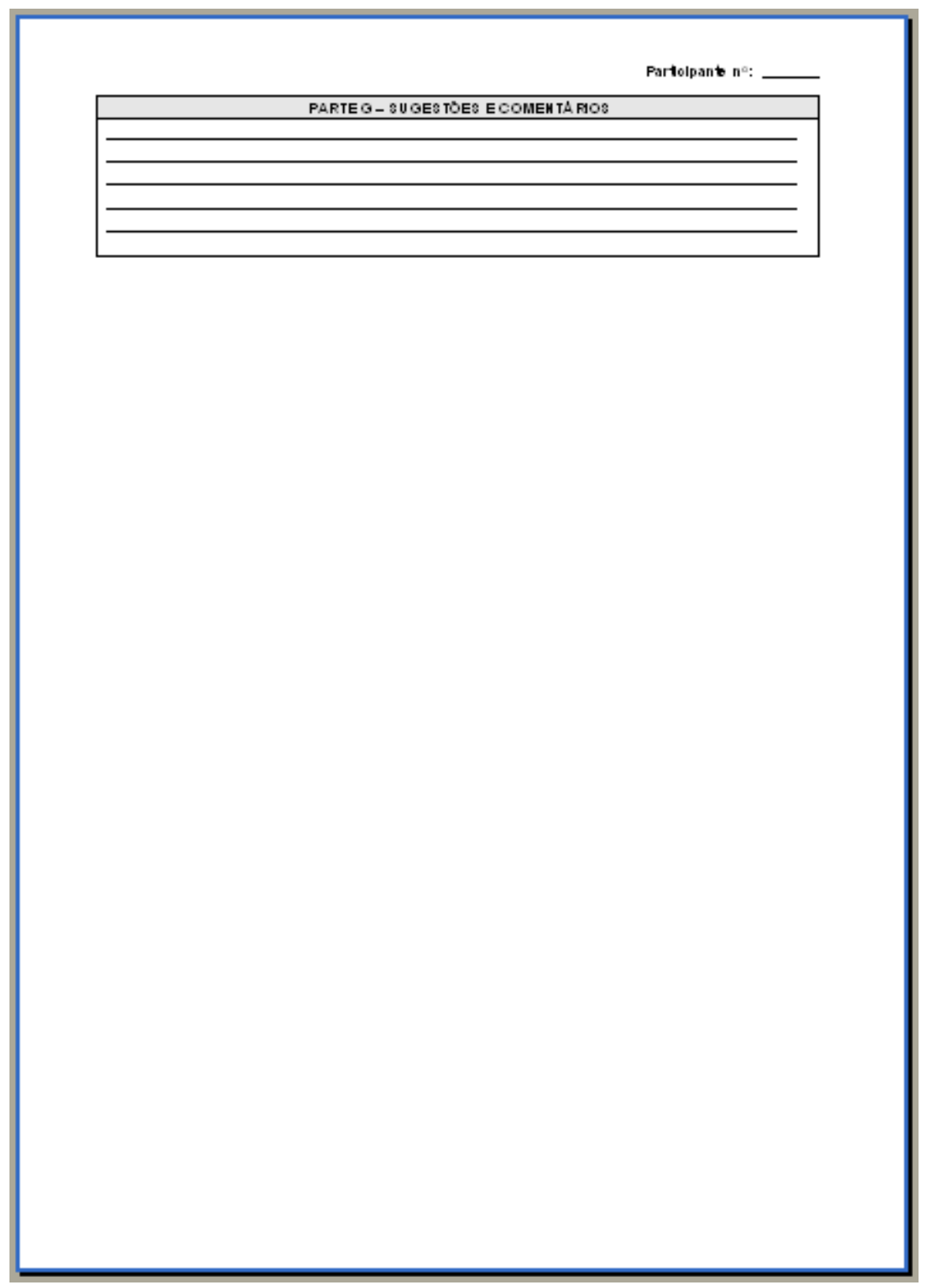

Figura B.3: Questionário pós-sessão (verso). 



\section{Recomendações para mudanças}

\section{H1: Visibilidade do status do sistema}

- Fornecer feedback ao usuário, informando o que está acontecendo e reportando os erros ou ações incompatíveis.

Alta

- Corrigir a informação exibida na barra de status referente a quantidade de imagens selecionadas.

- Fornecer feedback ao usuário ao modificar os valores das opções "CBIR option", localizada na janela que exibem informações sobre a imagem selecionada.

- Utilizar janelas “pop-up” para exibir informações do sistema, fornecendo feedback ao usuário.

- Utilizar uma janela de status como, por exemplo, uma "Progress Bar" para informar qual operação está sendo executada, pois o sistema não informa as características que estão sendo usadas na consulta e nem o que é possível fazer com as imagens retornadas. 


\section{H2: Compatibilidade do sistema com o mundo real}

\section{Recomendações}

\section{Prioridade}

- Incluir mais opções na janela principal, pois não fornece uma visão do que o sistema faz. A janela "Query by Text" é exibida sem que o usuário tenha selecionado, sendo que não precisaria ficar aberta $\mathrm{e}$

Alta não tem equivalente no menu da janela principal.

- Usar termos mais claros e esclarecedores. As opções "Echo Time" e "Repetition Time" não são muito claras. O intervalo de 10 em 10

Alta também deve ser esclarecido.

- Usar termos do vocabulário dos usuários na opção "Method". As siglas usadas podem não ser do conhecimento do usuário.

Alta

- Usar termos mais claros para o usuário na opção "BodyPart". Deve esclarecer melhor alguns itens como, por exemplo "SpArray".

Alta

- Usar termos mais significativos na opção "Type", pois não diz ao usuário que o seu conteúdo refere-se ao "tipo de corte ou

Alta orientação".

- Usar termos do vocabulário dos usuários nas opções "Cluster" e "Class", pois podem não ser familiares ao público alvo.

Alta

- Prover um "help" para ajudar o usuário a entender o que as opções significam e como seria a melhor maneira de usá-las.

Alta

- Prover um "help" para explicar os termos utilizados na janela "Query by Text", pois não é fácil entender o significados das opções "Height" e "Range" e dos valores pré-definidos que mudam ao pressionar a setinha para cima ou para baixo.

\section{H3: Controle e liberdade para o usuário}

\section{Recomendações}

Prioridade

- Prover funções de "undo" e "redo".

Alta

- Colocar opção de desfazer as ações do menu “Action”.

Alta 


\section{H4: Consistência e padrões}

\section{Recomendações}

\section{Prioridade}

- Deve manter uma consistência do que é o default para o sistema. Ao selecionar o botão de "Reset" na janela "Query by Text", todas opções voltam para o default que é diferente das opções que estão previamente selecionadas quando o sistema é iniciado.

- Deve manter uma padronização na opção "BodyPart". Os itens disponíveis devem ser padronizados em um único idioma e as palavras devem estar ou em maiúsculas ou minúsculas.

- Deve ter uma tecla "ESC" para deselecionar as imagens.

Alta

- Deve manter um padrão na opção “Type”, pois o conteúdo está em Português, fora do padrão da interface que é Inglês.

- Deve incluir uma opção de iniciar a pesquisa ou padronizar o default.

- Deve seguir as convenções de consistência e padronização. 


\section{H5: Prevenção de erros}

\section{Recomendações}

\section{Prioridade}

- Incluir uma opção de acesso no menu da janela principal, pois ao fechar a janela "Query by Text" não há como acessá-la novamente.

Alta Para isso, é preciso fechar o aplicativo e abrir novamente.

- Prevenir que o sistema pare de responder e precise ser fechado ao executar uma consulta.

Alta

- Habilitar e desabilitar algumas opções que parecem não ter utilidade. Na janela de "Result", a opção "Selection - Select all" não parece ter muita utilidade, pois quando todas as imagens estão

Alta selecionadas, as opções em "Action" ficam desabilitadas.

- Tomar cuidado no design, pois o item "Classify" da opção "Action" parece executar sempre a mesma coisa, independe da imagem que

Alta está selecionada.

- Prevenir que o cursor fique posicionado e piscando em campos que não é possível digitar nada. Na janela de informação sobre a imagem, há uma área intitulada "Dicom Info", o cursor fica Alta piscando no campo "Usercomment", mas não é possível digitar nada.

- Posicionar o curso nos campos de entrada de texto para digitação. Na janela de informação sobre a imagem é possível modificar o número de imagens similares que se procura (o default é 42), no Alta entanto, o cursor não fica posicionado sobre este campo.

- Deve prevenir erros na geração do gráfico "Precision vs Recall”, sendo esta uma opção muito difícil de utilizar.

Alta

- Prevenir que o erro ocorra antes de acontecer.

Baixa

- Apresentar ao usuário uma opção de confirmação que a tarefa foi executada com sucesso ou não. O item "List Dicom Filenames" salva o arquivo, mas não fecha a janela. Com isso, o usuário não sabe se a tarefa foi executada. 


\section{H6: Reconhecimento ao invés de lembrança}

\section{Recomendações}

- Prover documentação para mostrar todas as funcionalidades do programa. Algumas opções ficam escondidas no menu.

- Alterar o termo "Type" para um nome mais significativo, pois não diz ao usuário que o seu conteúdo refere-se ao "tipo de corte ou orientação".

- O item "Classify" da opção "Action" deve estar em outra opção ou categoria que seja mais claro para o usuário, pois parece executar sempre a mesma coisa, independe da imagem que está selecionada.

- Utilizar opções mais fáceis de usar na caixa de entrada da opção "Filename" como, por exemplo, um botão do tipo "Procurar...".

- O sistema deve ser mais auto-informativo, mostrar mais "labels", além de efeitos visuais que evidenciem as próximas opções disponíveis e recomendadas, pois o sistema não é muito parecido com softwares existentes que seguem padrões visuais.

- Alterar o texto do botão "Query" para "Execute", pois é um termo mais compatível com a operação de execução da query já formulada. O usuário pode confundir com "formular a query", que é a opção do "Edit SQL".

- Incluir uma opção de iniciar a pesquisa ou padronizar o default. Ao pressionar o botão de "Reset", todos os campos vão para as opções default, mas não voltam para as opções em que o sistema é iniciado.

- Deve prover instruções de uso do sistema visíveis e facilmente acessíveis para minimiza a sobrecarga da memória do usuário, permitindo que o usuário possa lembrar da informação quando necessário.

\section{Prioridade}

Alta

Alta

Alta

Alta

Alta

Baixa

Baixa

Baixa 


\section{H7: Flexibilidade e eficiência de uso}

\section{Recomendações}

\section{Prioridade}

- Tornar o programa mais intuitivo e fazer um manual.

Alta

- Incluir uma opção no menu ou dicas na barra de status para selecionar um conjunto de imagens. A seleção não é intuitiva para usuários iniciantes, pois é preciso usar a tecla "Ctrl + mouse" para selecionar uma a uma ou "Shift + mouse" para selecionar várias

Alta imagens. No caso do "Shift", o sistema não funciona de maneira correta, pois às vezes seleciona a imagem que se está clicando e outras vezes seleciona uma outra imagem ao lado.

- Alterar a opção "Filename" para um modo mais fácil de usar para recuperar o nome do arquivo da imagem.

Alta

- Prover um "help” para usuários iniciantes.

Alta

- Prover treinamento na ferramenta.

Baixa

\section{H8: Estética e design minimalista}

\section{Recomendações}

Prioridade

- O design deve ser simplificado e mais automático em alguns pontos. Não é minimalista e é difícil de usar.

- Deve apresentar design simples e prático, sem informações irrelevantes ou desnecessárias. 
H9: Ajuda aos usuários a reconhecer, diagnosticar e recuperar os erros

\section{Recomendações}

- Corrigir a opção "Database - Image Directory" da janela principal, pois que não funciona.

- Deve apresentar mensagens para ajudar o usuário.

- Deve apresentar mensagens de erro.

- Deve mostrar uma janela com mensagem mais significativa. Ao executar uma query cujo resultado é vazio, é aberta a janela de "Result" criando uma expectativa para o usuário e a mensagem é apresentada somente na barra de status.

- Retirar a mensagem do item "Comment" em "Action", pois apresenta uma mensagem informando que os comentários foram inseridos com sucesso mesmo não escrevendo nada na caixa de comentário.

- Fornecer feedback ao usuário ao modificar os valores das opções em "CBIR options".

- Retirar o cursor da mesma janela de informação sobre a imagem, em uma área intitulada "Dicom Info", para que o usuário não tenha a impressão de que ele pode alterar a informação. O cursor fica piscando no campo "Usercomment" e não é possível digitar nada.

- Colocar o cursor no campo da janela de informação, onde é possível modificar o número de imagens similares que se procura (o default é 42).

- Prover janelas para tratamento de erros.

\section{Prioridade}

Alta

Alta

Alta

Alta

Alta

Alta

Alta

Alta

Baixa

\section{H10: Ajuda e documentação}

\section{Recomendações}

Prioridade

- Prover ajuda e documentação.

Alta

- O ambiente deve possuir um "help" e um manual do usuário.

Alta 



\section{Sistemas de armazenamento e comunicação de imagens}

\section{DICOM}

O DICOM (Digital Imaging and COmmunications in Medicine) é um protocolo universal de comunicação e armazenamento de imagens médicas que foi desenvolvido por um comitê de trabalho formado por membros do American College of Radiology (ACR) e do National Electrical Manufactures Association (NEMA).

Foi criado para manter padrões internacionais no formato de geração e comunicação de diagnóstico médico em todas as áreas que utilizam imagens associadas a dados complementares. Trata-se de um padrão resultante da cooperação e participação dos fabricantes de equipamentos geradores de imagens médicas.

Primeiramente, os padrões são desenvolvidos por todas as empresas envolvidas e posteriormente reportados a um comitê que efetiva sua aprovação. Os trabalhos tiveram início em 1983, com a necessidade de definir padrões que permitissem a conexão de aparelhos de fabricantes diferentes. O primeiro padrão, denominado ACR-NEMA 300-1985, foi estabelecido em 1985 e uma segunda versão foi lançada em 1988 e denominada ACR-NEMA 300-1988. Finalmente, a terceira e atual versão, já com o nome de DICOM 3.0, foi lançada em 1993 apresentando um novo processo de protocolo de comunicação em rede com algumas alterações das versões anteriores [Bueno-2002a, Lopes-2005].

O padrão DICOM foi estruturado como um documento multi-parte para facilitar a extensão do padrão. Em 1994 foi incorporada a Parte 10 do protocolo, denominado "Media Storage \& File Format", que define, entre outras coisas, um formato de arquivo genérico, contendo um pequeno cabeçalho (header), o "Dicom File Meta Information 
Header", consistindo de 128 bytes de preâmbulo que permite inserir qualquer tipo de informação.

Em 2000, com a criação do relatório estruturado DICOM-SR (Digital Imaging and COmmunications in Medicine - Structured Reporting), o padrão começou a incluir estruturas normalizadas descrevendo dados médicos textuais, implementando uma parte importante do registro eletrônico do paciente, de modo estruturado e independente do fabricante [Bortoluzzi-2003]. O padrão DICOM-SR estabelece um método para construir e transferir Objetos de Informação que codificam documentos estruturados como laudos, resultados de laboratórios, relatórios clínicos, prescrições ou qualquer outro tipo de documento. Os relatórios estruturados facilitam a busca específica da informação, tradução de relatórios e comparação de laudos diferentes.

Os arquivos DICOM são compostos por uma imagem e informações textuais armazenadas em tags. As tags são pares representados no formato <atributo, valor> de seqüência textual ou numérica que possui informação dos dados do paciente e informação técnica sobre o exame das imagens [Traina-2003b]. Alguns exemplos de informações suportadas pelo padrão DICOM são nome do paciente, tipo de exame, número de imagens, data do procedimento, formato das imagens gravadas, tipo de compressão utilizada, impossibilidade de alteração da imagem gravada, etc. No padrão DICOM, as imagens podem ser arquivadas no formato bitmaps com compressão, podendo ou não ter um cabeçalho (header) contendo a tabela de cores e os dados da imagem.

Um dos maiores problemas é o acesso às imagens, onde, na maioria dos aparelhos, os dados são armazenados em formatos proprietários, o que dificulta a integração com imagens de outros aparelhos. O objetivo do padrão DICOM é obter a compatibilidade e melhorar a eficiência na comunicação de dados entre diversos sistemas de imagens e informação dentro do ambiente médico, para comportar uma grande variedade de aparelhos diferentes distribuídos geograficamente [Nema-2005].

Atualmente, o DICOM está completo e estável, sendo utilizado pelos mais diversos equipamentos de geração de imagens médicas e é adequado para o desenvolvimento e implementação de sistemas de radiologia sem filme (filmless).

O padrão DICOM tem sido cada vez mais usado como mecanismo de comunicação quando integrado a diferentes modalidades de equipamentos de imagens médicas como Tomografia Computadorizada (CT), Ressonância Magnética (MR), Radiografia Computadorizada (CR), raio-X, Ultrassonografia, Medicina Nuclear (NM), 
Radiografia Direta (DR), etc. Tem auxiliado diversas áreas da saúde, que inclui a cardiologia, odontologia, endoscopia, mamografia, oftalmologia, ortopedia, patologia, pediatria, radiologia, cirurgia, entre outras [Khludov-2000].

Com o aumento da necessidade de padronização, armazenagem, transmissão de dados clínicos e a interoperabilidade de sistemas de vários fabricantes, o padrão DICOM tem sido incorporado em sistemas diversificados utilizando, até mesmo, a tecnologia móvel para prover acesso rápido ao registro do paciente e melhorar o atendimento [Andrade-2003].

Com todas as melhorias feitas na versão 3.0 o padrão DICOM está pronto para, além de permitir a transferência de imagens médicas de diferentes fabricantes, facilitar o desenvolvimento e expansão para os Sistemas de Armazenamento e Comunicação de Imagens (PACS) e as interfaces para os Sistemas de Informações Hospitalares (SIH).

\section{PACS}

PACS (Picture Archiving and Communication Systems) são sistemas de armazenamento e comunicação de imagens desenvolvidos para manipular um grande volume de dados complexos gerados por sistemas diferentes, provendo aquisição, arquivamento, recuperação, processamento e distribuição de imagens digitais [Cai2001].

Apesar das funções básicas de um PACS serem consideradas apenas o armazenamento e a comunicação de imagens, vários fabricantes consideram também a aquisição, exibição e processamento de imagens como características complementares.

A infraestrutura de um PACS consiste de algumas modalidades de aquisição de imagem, uma rede de comunicação, um dispositivo de armazenamento e uma estação de trabalho para visualização e pós-processamento. A Figura I.1 mostra a infraestrutura de um PACS em um ambiente hospitalar. 


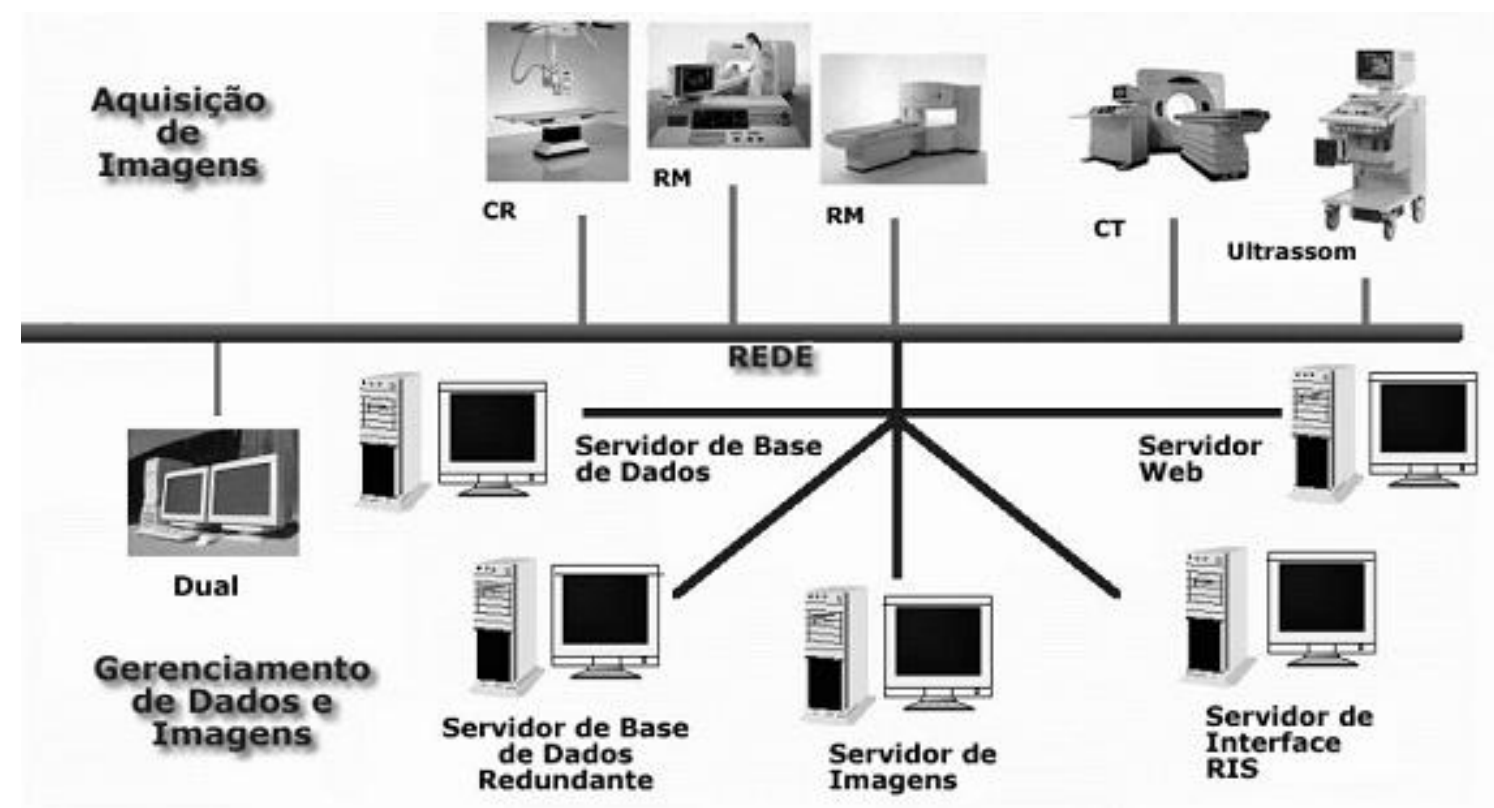

Figura I.1: Infraestrutura de um PACS em um ambiente hospitalar [Campo-2003, p.2].

Os sistemas PACS utilizam-se da análise de imagens para dar suporte à tomada de decisões e têm sido de grande importância em ambientes médicos para dar suporte ao diagnóstico baseado nas imagens de exames gerados [Bueno-2003]. Sistemas de arquivamento de imagens em ambiente hospitalar têm sido descritos como um fator clínico e economicamente importante [Müller-2004]. Assim, a tecnologia PACS vem sendo utilizada em ambientes hospitalares para possibilitar a radiologia sem filme (filmless), onde o filme tem sido substituído, quase por completo, por sistemas eletrônicos que adquirem, armazenam, comunicam e exibem imagens [Rosa-2002b]. A vantagem de utilizar a tecnologia sem filme é a diminuição do custo operacional dos exames de imagens, permitindo direcionar o investimento em outras áreas de interesse [Campo-2003].

Os PACS recebem imagens médicas de diversas modalidades e equipamentos que são arquivadas e podem ser recuperadas rapidamente. A maioria dos equipamentos para as modalidades digitais possui uma interface DICOM para comunicação de imagens médicas associadas às informações referentes aos pacientes e exames, preservando a fidelidade original das imagens geradas, como a resolução espacial e contraste. Na ausência de uma interface DICOM, placas de captura de vídeo podem ser utilizadas para capturar as imagens e digitalizar a saída de vídeo de um monitor ou câmera, porém esse tipo de procedimento pode inferir na qualidade da imagem tornando-a degradada. 
A recuperação das imagens nos sistemas PACS é obtida por meio de um processo de busca por informações textuais associadas à imagem armazenada. Esses sistemas ainda não suportam recursos de busca de imagens por conteúdo e similaridade, entretanto, com a rápida evolução das pesquisas nesse campo, em um futuro breve, esses sistemas também devem ser extensíveis em relação aos novos métodos de extração de características automáticas.

\section{PACS com técnicas de CBIR}

O sistema cbPACS (content-based Picture Archiving and Communication System) vêm sendo desenvolvido pelo Grupo de Bases de Dados e Imagens (GBdI) do ICMC-USP em conjunto com o CCIFM do Hospital das Clínicas da Faculdade de Medicina de Ribeirão Preto da USP, para dar suporte aos PACS tradicionais, incorporando recursos de recuperação de imagem baseada em conteúdo [Lopes-2005]. O termo cbPACS foi empregado para denotar um sistema PACS que utiliza técnicas de CBIR, visando satisfazer as necessidades de busca semântica sobre a imagem e alcançar uma nova funcionalidade para atender as consultas por similaridade [Rosa-2002b, Rosa2002c, Castañón-2003a].

O cbPACS responde consultas por similaridade onde as imagens são comparadas através da extração de características, bem como a indexação e recuperação realizada por métodos de acesso métrico embutidos nos gerenciadores de base de dados de imagens [Traina Jr.-2003]. O sistema cbPACS considera as características da imagem baseadas na distribuição de cor da imagem e permite construir histogramas métricos que são invariantes em relação à escala, translação e rotação das imagens e também na transformação de brilho [Bueno-2002c]. Além disso, características baseadas em textura e forma dos principais objetos na imagem vêm sendo estudadas e integradas aos novos cbPACS [Rosa-2002a, Castañón-2003b, Rosa-2003].

A arquitetura do cbPACS apresenta quatro módulos principais para operações de armazenamento e recuperação de imagens, que inclui os seguintes sistemas [Bueno2002b]:

- Sistema de aquisição de imagens: responsável por receber imagens no formato DICOM 3.0 e enviar informações textuais dos pacientes e imagens para a base de dados;

- Sistema de processamento de imagens: executa a manipulação da imagem e a extração das características das imagens; 
- Servidor de base de dados: consiste em um sistema gerenciador de base de dados relacional estendido para dar suporte às imagens por meio de uma extensão SQL; e

- Servidor Web: encarregado de gerenciar o fluxo de informação entre o servidor de base de dados e os clientes e também são implementadas nesse módulo as políticas de proteção e privacidade.

\section{PACS via Web}

Para aumentar tanto a utilização quanto a utilidade, os sistemas PACS foram disponibilizados na Internet com o objetivo de tornar esses sistemas acessíveis a qualquer lugar, independente da sua localização geográfica. Visando a eficiência e eficácia do uso de sistemas PACS através da Internet, esses sistemas provêm mecanismos de segurança para restringir acesso e permitir uma comunicação segura. Os dados a respeito dos pacientes devem ser sigilosos e para isso, entre outras medidas de segurança, é necessário fornecer um protocolo seguro, transmitir dados encriptados, permitir a identificação e autenticação de usuários e definir perfis de usuários no SGBD com privilégios distintos [Lopes-2005].

Alguns PACS de suporte a diagnóstico médico foram desenvolvidos e disponibilizados com acesso remoto através da Internet, como o CoMeb, um sistema médico colaborativo em tempo real, que permite especialistas comunicar e compartilhar registros de pacientes [Sung-2000] e o SINFIM que constitui de um PACS tradicional [Pereira-2001, Pereira-2002, Pereira-2003]. Outros sistemas incorporaram as consultas baseadas no conteúdo da imagem via Web [Chen-2000, Kim-2000, Feng-2001, Zhang2001, Zhuang-2001, Kim-2002, Cao-2003, Carro-2003, Long-2003].

Os PACS com plataforma baseada na Web têm algumas vantagens sobre os PACS tradicionais para acessar e manipular dados de imagens médicas [Cai-2001]:

- a Web provê uma interface universal com funcionalidades que facilitam o compartilhamento ao acesso de imagens médicas entre os sistemas hospitalares, independentes da sua localização;

- suportam operações para visualização de dados multimídia e a construção de relacionamentos através de hyperlinks;

- navegadores da Web estão disponíveis em todas as plataformas de computadores e sistemas operacionais; 
- o custo de manutenção dos sistemas pode ser bem reduzido, pois os navegadores podem ser adquiridos gratuitamente e possuem fácil atualização; e

- a familiaridade com os navegadores requer um treinamento mínimo para o pessoal técnico envolvido. 